SMOKESTACK PERCEPTIONS:

EXPLORING OPPORTUNITIES FOR INTENSIFICATION AND LIGHT-INDUSTRIAL MIXED USE ON GEARY AVENUE

\author{
by \\ Alexander Smiciklas \\ BA, Simon Fraser University, 2018 \\ A Major Research Paper \\ Presented to Ryerson University \\ in partial fulfillment of the requirements for the degree of \\ Master of Planning \\ in \\ Urban Development
}

Toronto, Ontario, Canada, 2020

(C) Alexander Smiciklas 2020 


\section{Author's Declaration}

I hereby declare that I am the sole author of this MRP. This is a true copy of the MRP, including any required final revisions.

I authorize Ryerson University to lend this paper to other institutions or individuals for the purpose of scholarly research.

I further authorize Ryerson University to reproduce this MRP by photocopying or by other means, in total or in part, at the request of other institutions or individuals for the purpose of scholarly research.

I understand that my MRP may be made electronically available to the public. 


\title{
SMOKESTACK PERCEPTIONS: EXPLORING OPPORTUNITIES FOR INTENSIFICATION AND LIGHT-INDUSTRIAL MIXED USE ON GEARY AVENUE
}

C) Alexander Smiciklas 2020

Master of Planning

in

Urban Development

Ryerson University

\begin{abstract}
The high value of land, strain from rising property taxes, and pressure to redevelop impacts low-rise industrial users in Toronto and is leading to a dwindling supply of industrial employment land. The push for 'highest and best use' often leads to mixeduse development, common in most urban areas. Currently, most mixed-use projects deliver Commercial Residential (CR), meaning industrial users, which provide competitive wages and have linkages to other industries that benefit the overall economy, have been largely left out of the conversation. This research explores how light industrial uses could be integrated into new mixed-use development to meet the demands of intensification, while adopting measures to incentivize its protection and vitality. Case study exploration from Vancouver and San Francisco, and in-depth subject area analysis prompt recommendations for a more diverse mix including compatible industrial use on Geary Avenue, one of Toronto's remaining urban industrial corridors.
\end{abstract}

Key words: production, distribution, repair (PDR); light industrial; mixed-use; intensification 


\section{Acknowledgements}

I would like to thank all the people whose assistance was a critical milestone in the completion of my MRP. My supervisor, Dr. Zhixi Zhuang, for her steadfast patience, support and insight -not only through the completion of this work -- but as a cheerleader for myself and so many other students during our entire time at Ryerson University. My second reader, Christine FangDenissov, for her expertise on the subject of mixed-use development and graciousness in dedicating time to provide comments that helped ground my research in reality. My roommates and partner, who were by my side during the long weeks and late nights, for their emotional support (which often came in the form of baked goods), and for putting up with me during a global pandemic. My family in Vancouver - your love and championing the last two years has been endless and something I will always be grateful for. I had a dream to move to Toronto and attend planning school, and you've been behind me every step of the way. Lastly, a special shout out to my Granny, Lillias Beale, who has always believed in the importance of education. Graduate school can be challenging, but you remind me of what a privilege it truly is.

\section{Dedication}

This research is dedicated to my Dida, Peter Smiciklas, who passed away in April 2020. A resident of the Roncesvalles community for over 50 years, he was always saying hello to both neighbours and strangers, and insisted on helping people whenever he could. I have many fond childhood memories of the activities we would do together during my visits in the humid Toronto summers: going to a local greasy spoon for breakfast, visiting Croatian friends that rain a nearby tailor shop, and feeding squirrels in High Park (one of his favourite hobbies). He was a true urbanite and a firm supporter of community, and was a seminal influence on my interest in placemaking and urban planning. Thank you, Dida. Volim te. 


\section{Table of Contents}

List of Tables vi vi

List of Figures vii

$\begin{array}{ll}\text { Introduction } & 1\end{array}$

$\begin{array}{ll}\text { Literature Review } & 4\end{array}$

$\begin{array}{lr}\text { Methods } & 19\end{array}$

Case Study 1: False Creek Flats and Strathcona Village, Vancouver 21

Case Study 2: 100/150 Hooper, San Francisco 40

$\begin{array}{ll}\text { Study Area: Geary Avenue } & 48\end{array}$

$\begin{array}{ll}\text { Recommendations } & 63\end{array}$

$\begin{array}{ll}\text { Bibliography } & 72\end{array}$ 


\section{List of Tables}

1. Geary Works Planning Study Stakeholder Feedback 60

2. Geary Works Planning Study Community Member Feedback 


\section{List of Figures}

1. Comparative urban growth models 5

2. A Typical Rural-Urban Transect, with Transect Zones 15

3. False Creek Flats industrial lands 22

4. Powell Street/Clark Drive industrial lands 22

5. Neighbourhood Context of the False Creek Flats 23

6. Ground/Second Floor Industrial with Retail at Grade and Office Above 25

7. False Creek Flats Zoning Intent 26

8. Atlantic/Malkin Transitional Edge 27

9. Illustrated Character of Innovation Hub 29

10. Map of Corridor 29

11. False Creek Flats Planning Area and Rezoning Policy Areas 30

12. Millennium Line Broadway Extension 31

13. GBL Architects - Strathcona Village - East Hastings, Vancouver BC 35

14. Cross Section of 955 East Hastings Street 36

15. Floor Plan of the The WorkSpaces and Current Tenants 37

16. Photo of $100 / 150$ Hooper 42

17. 100 Hooper Floor Plan 43

18. 100 Hooper Project Breakdown 44

19. The Breezeway 44

20. Toronto's Employment Areas and Employment Monitoring Areas 49

21. Character Area 3.0 / Geary Davenport Park, The Green Line 53

22. Toronto Development Tracking, 2014-2020 54

23. Rendering of 22 Geary 55

24. 22 Geary Avenue existing use $\quad 55$

25. Aerial View of 888 Dupont Street Looking Northeast 57

26. Illustrated Mix of Uses for 888 Dupont Street 57

27. Conceptualization of a future public parking lot and Green Line extension 64

28. Kensington Market Parking Lot with retail at-grade 65

29. Detroit parking lot with retail at-grade 65

30. Aerial of laneway 66

31. Photo of existing conditions in laneway 66

32. Photo of existing conditions in laneway 66 
33. Photo of existing conditions in laneway 


\section{Introduction}

High land value in Toronto has put a strain on single-use low-rise buildings due to rising property taxes or pressure to redevelop, leading to a dwindling supply of industrial employment land. The pressure for 'highest and best use' development often lends itself to a mixed-use building typology, a common form in most urban areas. To meet the demand for intensification, light industrial uses could be integrated into new mixed use development to ensure its protection and vitality. However, most mixed-use projects deliver Commercial Residential (CR), and industrial uses have been largely left out of the conversation. This research seeks to understand how a more diverse mix that includes compatible industrial use could be reconsidered for Geary Avenue, one of Toronto's remaining urban industrial corridors.

While the City of Toronto has requirements that ensures mixed-use development replaces the number of jobs lost to demolition, it does not dictate the size of the space allocated or the type of employment. It also fails to protect work in the production, distribution, repair (PDR) categories. PDR is a concept that originated in San Francisco and has since spread across the world. It is a term to describe a wide range of light-industrial activity that is different from the more intensive, larger "smokestack" industry that had largely moved to more affordable suburban locations by the 1980s (San Francisco Planning, 2002). While covering a diverse range of businesses and industries, PDR share the common need for relatively flexible building space and cheap rents (San Francisco Planning, 2002), and rising rents and policy driven intensification has displaced many of these original uses. PDR plays an important role in the stability and diversity of the economy, as most activities are closely linked to other sectors and provide competitive wages (San Francisco Planning, 2002). Toronto Region Board of Trade's 2018 Better Business Policy Playbook lists protecting employment areas as one of its key actions to maintaining Toronto's competiveness. If Toronto continues to experience a similar rate of employment land loss, all vacant industrial land could be absorbed by 2031 and new 
industrial production would rely on redeveloping existing properties (TRBT, 2018). One recommendation to preserve these spaces is to harmonize the conflicting land-use issues between industrial and other, more sensitive uses (TRBT, 2018). While not all PDR is compatible with mixed-use development, it is important to encourage these uses as and explore compatibility in Toronto's development landscape.

The focus of this research and study area will be Geary Avenue, a 1.2 kilometer stretch of commercial and light industrial activity, nestled alongside a rail corridor in the Davenport neighbourhood. The current land use designation is primarily Core Employment, which allows for a range of PDR activities and conditionally allows for small-scale restaurants and service uses, among others. Ancillary small-scale retail is permitted, which has become a critical aspect to the identity of the neighbourhood and promotes patronage and street activation. The study area also has a small section of area specific policy, which includes a conditional mix of employment and residential uses providing they are found compatible. This policy covers a block that has single or semi-detached residential adjacent to industrial buildings, indicating that a certain degree of mixing already exists.

Described as "a perplexing street of contrasts" and "one of the ugliest streets in Toronto" (Guided Toronto, 2019), Geary Avenue has a mixed-use legacy going back nearly a century, and today has evolved from being dominated by automotive repair shops to an eclectic employment area featuring small businesses and creative enterprises, and increasingly restaurants and bars, making it a popular social destination (City of Toronto, 2019a). The loss of industrial land and affordable, appropriate space for production, distribution and repair is particularly timely on Geary Avenue. In the past five to ten years, rents have increased (City of Toronto, 2019a) and the surrounding context area is going through change, with new development along Dupont, and the future redevelopment of Galleria Mall, a high-rise mixeduse residential community expected to increase local population by approximately 5,500 people over the next ten years (City of Toronto, 2019a). 
Recognizing the rapid change and growth pressures, Councillor Ana Bailão put out a request to the Planning and Housing Committee in April 2019 to initiate a comprehensive study of the Geary Ave corridor. This included development of urban design guidelines and land use provisions that "promote and enhance the continued non-residential uses through inventory of current applications, including compatibility with, and transition to, adjacent residential uses." (Bailão, 2019). Presently, the Geary Works planning study has been initiated to address this request, and is currently in the process of analyzing and creating a Draft Planning Framework and Economic Development \& Cultural Strategy, with a final report to come in late spring 2020 (City of Toronto, 2020a). While this research is separate of Geary Works, it presents a critical opportunity for collaboration and provides useful context when formulating recommendations. In order to address the question of how different uses could be harmonized along Geary Avenue, this research project seeks to understand how innovative zoning and urban design can work together to support an intensified mixed-use community in the neighbourhood. Furthermore, with many cities defaulting to mixed-use residential/commercial development, what can policy do to protect and incentivize vulnerable uses such as PDR or artist spaces if other mixed-use models were to be tested? In doing so, this research seeks to understand the policy barriers of integrating industrial uses into mixed-use typologies in Toronto, and provide a scope of both the political and financial issues. As well, reinforce the literature that innovative policy and design can foster livable, complete communities that exist not only next to, but in tandem with, light industrial uses. 


\section{Literature Review}

$\underline{\text { History of Industry-City Spatial Dynamics }}$

"Industry has often been perceived in an economic or political context divorced from geographic, locational, or spatial considerations" (Hatuka, Ben-Joseph \& Menozzi Peterson, 2017, p.148). So where does this perception come from? Historically normalized disfavor for manufacturing and Euclidean zoning practices that became prominent in the early 20th century are two reasons that residential and commercial uses have been provided advantages in cities (Cotter, 2012; Hatuka \& Ben-Joseph, 2017; Zuk, 2015). The active separation and large displacement of industrial land to the suburbs has not only led to the loss of industrial land and manufacturing, but also of its vital role in a fine-grained city network where it may provide employment opportunities, and contribute to the interconnectedness and culture. As planners, understanding the history of land-use is an important tool for critical assessment of both past, current and future practice.

Hatuka \& Ben-Joseph (2017) identify three phases from the start of the industrial revolution that highlight the changing spatial relationship between cities and industry. The first phase was the emergence of the industrial city from 1750 to 1880 , when manufacturing and steam engine technologies evolved and revolutionized industrial production (Hatuka \& BenJoseph, 2017). Prior to large-scale industry, most manufacturing was artisanal and managed out of the home. As industry grew and innovated, cities were the logical centre for production at the time because of the labour pool, transportation options and entrepreneurs that were found in these densely populated regions (Rappaport, 2011). With the advent of steam power, industry established in cities near waterways and rail in order to access freight and water transportation. This was crucial to the reduction of transportation costs, and for increasing accessibility and connectivity. Cities experienced unprecedented growth, which created tension between the uses of land and the ability to provide basic human needs such as shelter, water and clean air were compromised from the 'nuisance' of industry. 
The second phase of spatial dynamics (1880 to 1970) was dominated by the search for an ideal industrial city (Hatuka \& Ben-Joseph, 2017). This phase is characterized by various early planning models that sought to meet the needs for industrial lands, while providing livable conditions in cities. A major turn occurred in 1926 in the case of Euclid v. Ambler Realty Company, where the ruling was made in favour for land use zoning at a time when there was contention over whether it was constitutional to restrict land use (Cotter, 2012). Just prior, Ernest Burgess published his concentric ring model in 1925 to indicate how urban areas expand outward. The industrial "zone of transition" outside of the central business district, highlights industrial land's importance as an employment hub and necessitates its central location. However, it is also portrayed as an area of disease and poverty, and a place that should be escaped (Burgess, 1967) and is an early characterization on how uses ought to be separated.

Comparative urban growth models, including i) Burgess' concentric ring model, ii) Hoyt's sector model, and iii) Harris and Ullman's multiple nuclei model. i

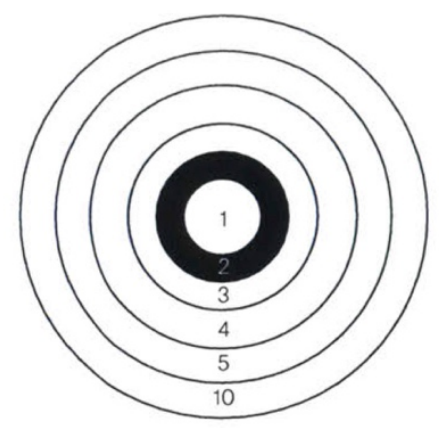

iii

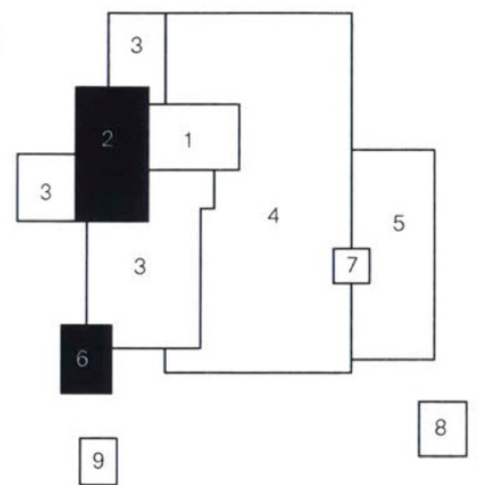

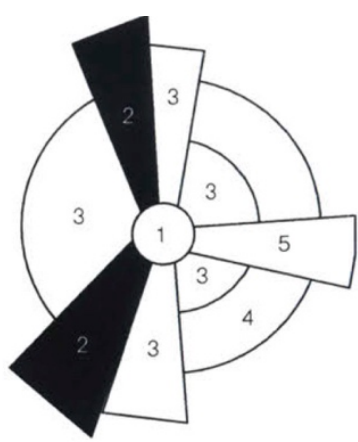

Generalized Land Use Districts

Central Business District Wholesale Light Manufacturing Low-Class Residential Medium-Class Residential High-Class Residential Heavy Manufacturing Outlying Business District Residential Suburb Industrial Suburb

10. Commuter's Zone

Figure 1 Comparative urban growth models (Brown, 2019 adapted from Harris \& Ullman, 1945).

Homer Hoyt refined this model in 1939, showing that growth occurs according to transportation networks, particularly rail infrastructure, and is a more linear spacial form (Hoyt, 
1939). Lastly, Chauncy Harris and Edward Ullman created the multiple nuclei model in 1945, predicated on a central business district but grounded in the reality that growth isn't linear and different districts emerge over time that are clustered based on cohesiveness (Harris \& Ullman, 1945). Sarah Brown (2019) compares these models, noting that the multiple nuclei model is a significant departure from its predecessors as it dispels that the urban core is the main source of use segregation. It does, however, still reinforce "the synchronized relationship between the expansion of cities and the segregation of land uses" (Brown, 2019, p.17). This era, and the post-modern city to come, saw industrial establishment that relied on proximity to highway infrastructure. Much like its freight and water transport predecessors, the automobile allowed for a faster form of transportation for industry. These Euclidean models emphasize how proliferation of personal automobile use was necessary to separating but still allowing access to industrial land and led to the success, and later highly criticized, postwar residential suburbs which also also allowed for immense production facilities that could no longer expand in the city (Brown, 2019; Cotter, 2012; Hatuka \& Ben-Joseph, 2017; Leigh \& Hoelzel, 2014). In many respects, Geary Avenue is an anomaly of modern zoning, as industrial and residential use have existed in very close proximity for decades and has had success as a neighbourhood destination because of it.

The third phase of spatial dynamics involves the process of deindustrialization from 1970 onward (Hatuka \& Ben-Joseph, 2017). Although it is argued that society is now in a fourth industrial revolution with the evolution of the Internet at the turn of the 21 st century, this is an often disputed claim (Pouspourika, 2019). After the 1970s, countries began to reduce industrial capacities and further segregate industrial functions from other land uses such as housing (Lever, 1991). Many explanations for this are given: the transition into knowledge-based industry, the trade specialization and comparative advantage of certain regions, and the weakening of competitiveness driven by multinational companies choosing to situate production geographically to take advantage of lower costs (Pike, 2009; Hatuka \& Ben-Joseph, 2017). This 
"uneven geographical development of capitalism" (Helper et al. 2012 in Hatuka \& Ben-Joseph, 2017, p.13) indicates how political and economic processes impact the spatial dynamics of cities, and shows that negativity or NIMBYism against mixing industrial uses in cities is both indoctrinated and potentially rooted in issues of class and culture. Ultimately, if Geary Avenue and other remaining urban industrial areas have a hope of becoming more integrated with other uses, let alone thrive as they are, strategic communication is required to change the "smokestack perceptions of modern industry" (Leigh \& Hoelzel, 2012, p.90) that cause light industry and creative sectors to be viewed as a nuisance.

\section{Exclusionary and non-cumulative zoning}

While there is supporting evidence for how appropriate light industrial-zoned activity may be conducive in mixed-use zoning, it is important to first understand the benefits and constraints of using zoning as a tool for exclusion, not inclusion. One of the more cited reasons for rigid land-use control is to mitigate against the increasing rezoning for "highest and best use", when land is valued far greater than the built-form it currently supports. This is particularly common in urban centres where land is at a premium, as is the case with Toronto, and while they differ in approach, it is a shared concern for those that support a hybrid-zoning model. At its core, the 'exclusionary zoning' approach aims to protect and maintain land for industry by prohibiting higher uses outright (Heikkila \& Hutton, 1986; Chapple, 2014). 'Non-cumulative zoning', a term with similar intentions, also aims to reduce the degree to which industry is held responsible for nuisance and preserves land from the infringement of sensitive residential users (Hills \& Schleicher, 2010; Chapple, 2014).

The argument is further made that remedial measures, such as grants, subsidies or private-public partnerships, make marginal difference when trying to offset the increasing owner or tenant cost for industrial uses (Heikkila \& Hutton, 1986). Instead, the price of land that is zoned for industrial use will be suppressed by other land that is designated as such, so prices will stabilize, speculation will be discouraged, and new investment will be made into 
manufacturing and industry (Heikkila \& Hutton, 1986; Hills \& Schleicher, 2010; Leigh \& Hoelzel, 2012). A consideration should be made, however, in understanding how the context of neighbouring uses impacts price and speculation. Geary Avenue, the focus of this research, is surrounded by a vibrant residential neighbourhood, commercial businesses, and is adjacent to the future 'Green Line'; a planned five kilometre linear parkway intended to be slowly implemented over the next 0-10 years and involves 45 nearby parcels of land (City of Toronto, 2019b). Arguably, the makeup of Geary Avenue makes it different from other industrial land that cover a larger footprint or don't have ties to an existing neighbourhood.

There are many benefits and costs to exclusionary and non-cumulative zoning. Maintaining industrial zones allows for the diversification of economic and employment base (Heikkila \& Hutton, 1986). However, this exclusion of other uses does not inherently contribute to diversification, it has to be intentionally sought out. It can also take on the role as incubator for industrial development, particularly with the growth of small industry and fragile economies, rationalize the provision of public infrastructure and services, and reduce negative externalities (Heikkila \& Hutton, 1986). The latter, while derived from a time when industry produced unhealthy living conditions, is still very applicable today from the smokestack perception. Conversely, this zoning can inhibit the effective use of scarce land in urban environments, and effect the municipal tax base. In addition, it can prolong already declining forms of industry and artificially retain them, which ultimately reinforces the notion of obsolete sectors (Heikkila \& Hutton, 1986). This is particularly relevant to Geary Avenue, as a street that has become known for its eclectic mix of industry and retail and is a product of slow adaptation rather than intentional intervention.

There is no doubt that exclusionary and non-cumulative zoning has its merits, and in many circumstances is a more applicable model than a form of hybrid zoning. For example, major clusters in inner-cities would benefit from a clear prioritization, if heavy industry is involved, or if the industries play a particularly vital role to the local economy (Heikkila \& Hutton, 
1986). Ultimately, Geary Avenue does not merit the same supply and demand conditions listed above for such isolated zoning measures. Instead, "the most apposite use of exclusionary zoning in an inner city environment would see the application of this instrument in conjunction with other, more sensitive, positive and specific policy tools" (Heikkila \& Hutton, 1986, p.57). This demonstrates that exclusionary zoning does not have to be viewed in isolation; rather, it is a useful tool in a hybrid-industrial model in order to outline clear targets for what the industrial function has to look like. A common tool amongst local industrial policies is to protect and enhance industrial areas by restricting non-industry uses (Leigh \& Hoelzel, 2012). Many businesses on Geary Avenue choose to include a small section of commercial use on their property as an ancillary use to their primary production, distribution or repair facility. These secondary ancillary uses are heavily regulated to ensure that industry is still the primary focus, while also promoting economic development.

Smart Growth and New Urbanism: Industry Ignored

If mixing uses is a planning tool for efficient use of land and creating complete communities, why has industrial zoning been left out of the equation? Leigh \& Hoelzel (2012) argue that there has been a lack of policy direction for industrial development in the 'smart growth' era. This is important to further understand the context and lasting effects of why cities do not think industry and other uses mix. Ultimately, smart growth has two sides: it promotes dynamic, livable, mixed-use urban neighbourhoods focused on the pedestrian experience and active transportation, and it also views industrial land as hindering this process (Bronstein, 2009). Smart growth is "an alignment of multiple policy networks advocating particular planning policies for curtailing sprawl and revitalizing urban areas" (Leigh \& Hoelzel, 2012, p.89). The research found that publications, such as the American Planning Association's Growing Smart Legislative Guidebook (2002), were in favour of mixed-use, however they did not mention specific policy to encourage industrial uses as a means to meet smart growth goals, and in some cases favoured removing it altogether in favour of health and sustainability (Leigh \& 
Hoelzel, 2012). Ultimately, this evidence continues to portray urban industrial areas as unproductive and unattractive and may be a factor in its ongoing negative perception, even as mixed-use typologies became more and more common. Widening the definition of smart growth would be a good way to support industrial revitalization and support economic development in city centres.

There is also the concern about the lack of specificity in the policy of mixed-use zoning, appropriate strategies and breakdowns, and the eradication of industrial districts it often causes. There are three conceptual levels to having mixed-use zoning: increasing intensity of land use, increasing the diversity of uses, and integrating segregated uses (Grant, 2002). The latter often requires overcoming both regulatory and socio-cultural barriers, and "experience shows that the residents of established communities may resent mixing, especially those uses seen as most incompatible or likely to increase urban densities" (Clark-Madison, 1999; McMahon, 1999; Pendall, 1999, in Grant 2002). Furthermore, visions of mixed-use dominated by New Urbanism (traditional neighbourhood design and transit-oriented development) meet the demand for walkability, intensified uses, allowing more people to work from home, and improved transit systems, but say relatively little about options for integrating industrial uses (Grant, 2002). Even as industry has become cleaner and quieter, it remains largely written out of mixed-use policy.

Mixed-use development assists with revitalization or infill to help solve urban issues, but it is also the cause of displacing industrial districts. Small manufacturing is declining as zoning shifts to mixed-use, and industry is replaced with "cleaner" higher density residential-commercial units that provide higher potential rent returns (Shaw, 2015; Grodach, O'Connor \& Gibson, 2017; Chapple, 2014). In particular, "with resistance to infill development in urban neighbourhoods, and high land costs downtown, the industrial land near the core becomes the low hanging fruit for developers" (Chapple, 2014, p.207). This is particularly problematic as urban industrial zones such as Geary Avenue provide well-paid employment opportunities in the city, and is accessible by transit. Ultimately, "cost drives this process [in fast-growing 
communities], as do greater returns to development interests" (Grant, 2002, p.79).

Adaptive reuse, innovation districts and the danger of industrial chic

Industrial districts have gone, and will continue to go through periods of transition, as one type of use is replaced by another. This succession is caused by market forces and changing needs, and is often implicated by gentrification as existing businesses become displaced by new, usually less-industrial functions. The literature has discussed the issues of gentrification caused by mass redevelopment of industrial land into mixed-use communities, but there has to be equal consideration given, if not more, to the current implication of how industrial land occupants are changing and what it means for accessibility and affordability. Geary Avenue is known for having an eclectic mix of users, ranging from auto repair, to pasta and coffee production, to entertainment venues, restaurants and microbreweries. This eclecticism is something that everyone wants to protect (City of Toronto, 2019c; City of Toronto, 2020b), but it's important to be critical of the processes that occurred for it to become the culturallysignificant hub that it is today. What would it mean if more of the "traditional" light industrial functions were replaced by more restaurants and bars? Would industrial zoning have any purpose to preserve and enhance productive industrial employment? At the heart of this issue is one of planning's wicked problems. City-makers have to balance the priorities of the public, and in the case of many urban industrial lands, there is very little business case from a land-use planning perspective to preserve low-density built form. Higher density redevelopment produces community benefits, it opens up land for more housing, and it helps to revitalize formerly unproductive spaces. At the same time, adaptive reuse as the alternative is an outcome in existing industrial lands of relaxed regulations; the staple of planning for use, not users, but use is determined loosely.

Adaptive reuse is discussed widely as having economic, socio-cultural and environmental benefits (Orbalsi, 2008; Yung \& Chan, 2012; Zuk, 2015) and comes with different approaches. Broadly, adaptive reuse may be viewed as any form of change or update that a 
building receives in order for it to meet new conditions and a shift in dynamic (Yung \& Chan, 2012). Architecturally, Orbalsi (2008) argues that the preservation of buildings is important in order to view them as more than just "historic relics" but as a critical part of a city's identity, sense of place, and how the world associates meaning and history. Adaptive reuse can be sustainable and negate unnecessary or unfair redevelopment as it uses what is already available and encourages neighbourhood investment in the process (Orbasli, 2008; Yun \& Chan, 2012; Zuk, 2015). In addition, older buildings are often closer to transport and city centres making reuse more viable (Langston et al, 2008). The advantage of being near underutilized rail corridors, as urban industrial land often is, provides the opportunity for future reuse as light rail transportation for local residents and employees (Smallwood, 2012).

However, excluding affordable industrial-employment land in urban centres and relegating to the periphery causes gentrification, sprawl, and ignores social objectives (Smallwood, 2012; Nasser, 2003). Adaptive reuse often requires heavy upfront costs for renovations, which causes rents to increase. This occurs across major North American cities, and is particularly common in innovation districts. Seattle's South Lake Union is a key example. It started to transform in the late 2000s from degraded low-rise industrial to a hub for some of the West Coast's leading science organizations, and is now home to Amazon which has accelerated residential housing growth and entrepreneurial activity (Katz, 2014). Ultimately, "industrial chic is valued for its potential to attract innovative entrepreneurs - the fabric of these new innovation districts of the metropolitan revolution" (Chapple, 2014, p.213). The concern of course, is that innovation districts perpetuate the misconception that the "messy space" of industrial land is wrong, or that it isn't productive. In order to mitigate gentrification, stakeholder involvement is necessary, as is the intentional inclusion of affordable rent (Langston, et al, 2008; Bullen \& Love, 2009). Ultimately, the decision comes down to opening up land to a variety of uses or preserve land and open it up to a mix of light industrial functions, both of which risk a decrease in affordability and loss of productive users who contribute meaningfully to the 
economy, in an often quiet and unrecognized way.

The issue of gentrification may be viewed further when analyzing the existence of creative industries in manufacturing districts. When this land is subject to rezoning, new knowledge-based or creative uses are commonly gravitating towards these urban industrial pockets (Catungal, Leslie, and Hii 2009; Shaw 2015; Grodach, O'Connor, and Gibson 2017) and the businesses that are displaced are included in the discourse or policy as "outmoded or uncreative relative to these productive forms of work" (Sprague \& Rantisi, 2019, p.301). When policy prioritizes knowledge-based or service activities it risks displacing them and creating a gap in employment opportunities in well-paid, blue-collar positions (Sprague \& Rantisi, 2019; Hum, 2017). Jutgla, Pappares-Barbera and Castellas (2012) distinguishes this phenomenon from other gentrification literature as "productive gentrification", which takes the concept generally focused on the displacement of lower-income individuals by the succession of middle class, and applies it to businesses and the attraction of new, more "productive" uses and how they can both cause and be subject to gentrification.

In their research, Sprague \& Rantisi (2019) look at the implication of state-led intervention with the creation of creative districts. They found that "hard interventions" (state mechanisms) such as rezoning, parking restrictions, the removal of loading docks, and incentivization through tax subsidies played a role in the revitalization and making of the Montreal neighbourhood Mile-Ex into a creative district. Soft interventions (the perception of the neighbourhood) included rebranding and beautification schemes. It shows that "the ways in which the state has intervened has created conflict in the neighbourhood between various actors such as manufacturers and residents and placed pressure on the manufacturing industry" (Sprague \& Rantisi, 2019, p.311) and, as is with any intentional intervention that happens on Geary Avenue, could risk its eclectic ecosystem. These changes do not exist in a vacuum; they are consistent with the 'creative city' rhetoric that has gained notoriety in recent years around the world (Peck, 2005; McCann, 2007). Furthermore, this 'state-led' gentrification is common 
because intervention helps to mitigate the risk of investing in an economically marginalized area (Hackwork and Smith, 2001).

Innovation districts are attractive for their impacts to tourism and regional economy, as well as the different interests that emerge such as non-profits, affordable housing and environmental justice (Chapple, 2014). At the same time, achieving a healthy diversity in innovation districts is not sustainable and a concern is that zoning doesn't change as the market does, it's slower to react so re-evaluation on how much industrial zoning is necessary (Chapple, 2014). This is particularly true in cities with a strong market and high value for urban land, like Toronto, Vancouver, San Francisco, and others. Ultimately there is room for both innovation districts and protected PDR in cities, Chapple (2014) argues, and being accessible to transit or having form-based or permissive mixed-use zoning may be suitable locations for high-end creative firms.

Form over Function: Form-based and transect zoning

It's critical to review different zoning practices in order to understand how allowing for a successful mixed-use industrial district could take shape. Form based zoning controls physical form and focuses less on land use regulation, which allows the market to determine the best use (Woodward, 2013; Chapple, 2014). This theory is beneficial in allowing for formerly deemed incompatible uses to mix, as well as facilitate more efficient use of city infrastructure, returning to the original planning model of a complete, higher-density interlocked grid that is functional and attractive (Leigh \& Hoelzel, 2012; Woodward, 2013; Chapple, 2014). Planners can promote form-based codes "in mixed use areas with light industry; allow some small manufacturers to operate in live-work zones [and] expect industrial facilities that were cleaner and more neighbourhood-friendly" (Leigh \& Hoelzel, 2012, 95).

The urban to rural transect, as envisioned by New Urbanist Andrés Duany, imagines cities in a Euclidean fashion only in the sense that there is transition from the edge to the centre of the neighbourhood. It does not completely separate uses, but instead diminishes their 
importance by creating a matrix of building functions (Woodward, 2013). In essence, the argument is that no matter what form a mixed-use building takes or how excellent it is on its own, it may be inappropriate for the environment.

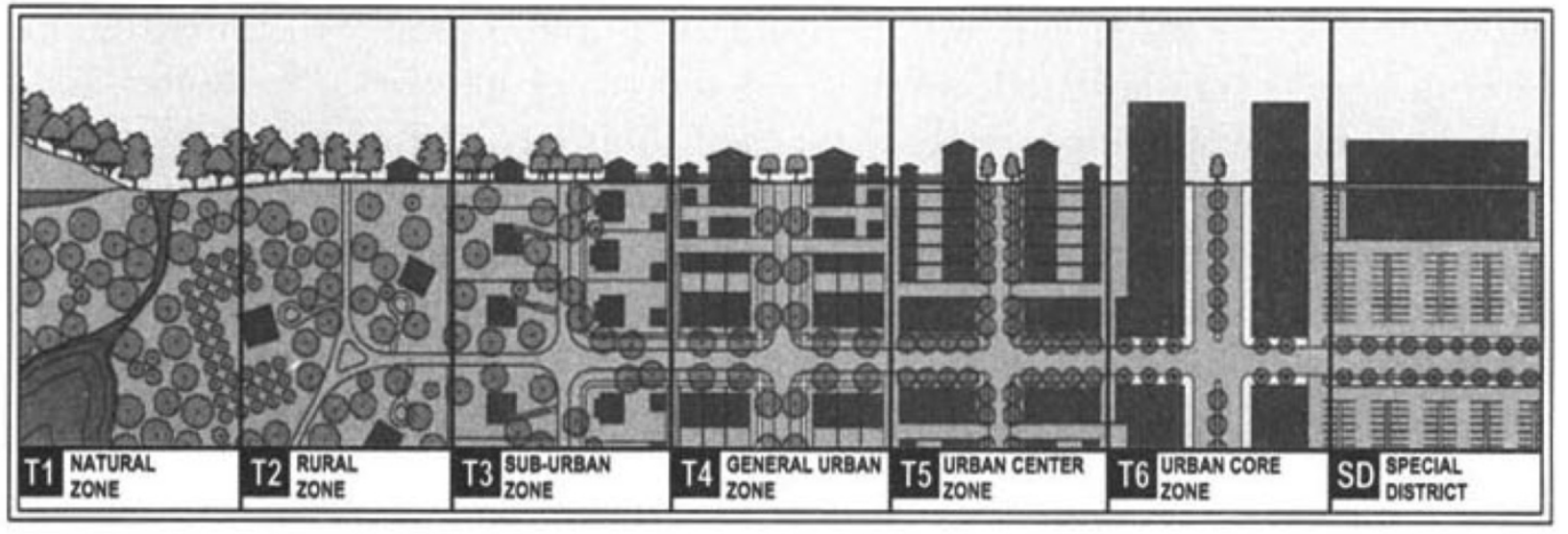

Figure 2 A Typical Rural-Urban Transect, with Transect Zones (Duany Plater-Zyberk \& Co, 2003).

This framework is important as it imagines the city not divided strictly by zoning and bureaucratic policy, but instead as rooted in context with the goal of achieving a specific urban form. It could be the basis for a future planning model for Geary Avenue to promote integration of uses. Woodward (2013) highlights a roadmap important to facilitating form-based zoning, including:

1) A Regulating Plan to outline zones of the transect

2) Building Form and Functional Design Standards to allow for a gradual continuum, which is also important for height and density considerations

\section{3) Public Space Standards}

4) Administrative Provisions to allow for a clear and defined application process and development approval standards

\section{5) Architectural Standards}

These components allow form based codes to be prescriptive rather than proscriptive, so it is better designed for all types of users to maneuver in the quest for city-makers to balance the multifaceted portfolio of public interest.

Mandatory form-based codes may be challenging to implement existing outside of a 
municipal zoning by-law, and politically vulnerable as a result. SmartCode, Duany's version of a form-based code, has been used to design many new towns, largely across the US, gaining initial recognition for the design of Seaside, Florida and Kentlands, Maryland. While Duany's vision stems from early New Urbanist ideals that focused on the public realm, it is highly idyllic and doesn't necessarily consider the realities of an urban context. As Woodward (2013) notes, shifting to a model of form-based zoning is difficult to implement in larger, older cities because pre-established communities and zoning codes are difficult to integrate. It would pose an issue for Geary Avenue, which is relatively small and densely situated. However, that isn't to say that there aren't important practices from form-based codes when considering integrating industrial use in cities. The False Creek Flats Master Plan, a Vancouver Case Study discussed further on, uses site-specific zoning and urban design standards to establish character nodes and intensify the employment lands while gently transitioning into surrounding residential neighbourhoods. Part of the success of this plan is that it's insular and being tested in one area, while also being a large enough site that it allows for some creative planning. San Francisco also organizes its city-wide zoning in a hierarchical way that transitions from most intensive industrial use to least intensive, with the intention that Production, Distribution, Repair (PDR) uses which are used to define light industry, pose relatively little nuisance to residential zones and could either be integrated in one built form or exist side by side. Ultimately, the goals of these two case studies, as will be discussed further, is to protect industrial capacity. Therefore, they are not true examples of form-based zoning as it still relies heavily on land-use in order to achieve desired outcomes.

This model is also helpful to imagining how industrial land can be flexible and can adapt to its occupants. Alternatively, hybrid codes could be implemented where a variance is provided for "the sections of a community that are open to new development and can be crafted according to the principles of transect and form-based codes" (Woodward, 2013, p.2652). Another model is parallel code, where traditional and form-based zoning "exists side by side, 
and developers can choose which one they wish to calibrate their proposals to, increasing the design options available to them" (Woodward, 2013, p.2652). Both these models may be suitable for Geary Avenue given its current physical form and diversity of building typologies. Ultimately, it could be the very tool to incentivize smart, well thought out density increase along the corridor, particularly if compliance with existing zoning is time consuming and difficult so development is hindered. The risk, without finding a healthy balance of regulation, is that these forms would threaten industrial use for higher-end bidders seeking the aesthetics of industrial chic, and developers who favor the higher-paying rent (Chapple, 2014). Ultimately, it highlights the important role that urban design and pedestrian-oriented development will play if intensifying and mixing uses is feasible.

$\underline{\text { Industrial urbanism: protecting and enhancing manufacturing in a mixed-use district }}$

While cities across North America such as Vancouver, San Francisco, Melbourne and Portland have begun to introduce alternative mixed-use zoning, the adoption of it has been slow. There are important spatial interdependencies at play, and "both cultural industries and small manufacturers have specific needs that are overlooked with the emphasis on cultural consumption and the knowledge economy" (Grodach et al., 2017, p.21), as has played out frequently in aforementioned innovation districts. There is precedence for cities to innovate and collaborate on how to mix uses, but working from outdated zoning systems that don't recognize how urban manufacturing or cultural production has changed is the bureaucratic nail in the coffin. Furthermore, cities continue to allow for unregulated redevelopment or adaptive reuse of industrial land under the misconception that manufacturing is better suited to the suburbs to access large greenfield spaces (Grodach et al., 2017; Shaw and Davies, 2014). In reality, this form of manufacturing is not universal. The highly specialized production focused businesses thrive due to proximity of other similar industries, skilled labor, suppliers, transportation, and the large urban market and institutions that support their work (Grodach et al., 2017; Hatuka et al., 2017; Helper et al, 2012; Schmidt, 2014). 
This notion of 'proximity' is one of three interlinking dimensions of manufacturing and city planning that Hatuka et al. (2017) recommend are critical to addressing future needs of industrial urbanism. Tied to the concepts of the Fourth Industrial Revolution, it considers what the spatial needs are for production today. The Fourth Industrial Revolution is "characterized by the fusion of the digital, biological, and physical worlds, as well as the growing utilization of new technologies" (Ndung'u \& Signé, 2020). The difference from the previous Revolution is that the gap between these worlds are shrinking, and technology is evolving faster than it ever has before. Berger (2013) adds that dense ecosystems dissuade companies from moving job opportunities elsewhere, and that real innovation comes from scaling firms and rebuilding their capabilities. Ultimately, the relationships and collaborations that are possible from the proximity of a mixed-use district would support the goals of small-scale production. The second dimension is localism: the refocus on local production, importance of community, and the impact of technology on reducing the need for economies of scale and globalization of manufacturing (Hatuka et al., 2017; Markillie, 2012). Localism allows specialized producers to cluster geographically to prototype and share their knowledge, but in order to do this, cities must allow industrial uses in some areas where they've been prohibited (Hatuka et al., 2017). Ultimately, mixed-use districts may be a solution to facilitating production clustering, but it has implications on cities such as Toronto which may benefit from new investment, growing employment opportunities, and tax revenues (Hatuka et al., 2017). 


\section{Methods}

In order to answer these research questions, three research methods have been selected. The first, is to perform a more in-depth comparative policy analysis using selected case studies. Vancouver, which experiences similar development pressures and availability of urban industrial land as Toronto, has both industrial area studies and completed relevant mixeduse sites which may be drawn upon. This will include review of the innovative rezoning and master plan proposal of the False Creek Flats, which is aiming to become a "flexible and diverse economic zone and a key driver of local economy" (City of Vancouver, 2017a) by supporting live-work artist residences, student accommodation for Emily Carr University, core and back-of house industrial functions, and other employment land designations. San Francisco is the second case study, which coined the term production, distribution repair (PDR) as a way of classifying light industrial activities. An analysis of industrial policy, and review of the mixed-use industrial and office complex at 100/150 Hooper will give critical insight into how San Francisco can have strict protection measures on its industrial land, while incentivizing mixed-use to allow for equitable and affordable rent for PDR businesses.

The second method is to analyze current industrial land use in Toronto. This includes a review of the City of Toronto Zoning By-law, research into site and area specific policies along Geary Avenue, and a scan of the development activity in the surrounding neighbourhood. This will reveal opportunities and constraints of the regulated current use and potential future use of the site. Furthermore, a review of financial mechanisms will provide a financial viability lens that takes into account highest and best use principles, and will inform recommendations. Other relevant local planning studies will be consulted, to offer insight into how to integrate performance standards into zoning review.

The third and final method is to apply a more in-depth and qualitative approach to Geary Avenue through the collection and analysis of secondary data from the Geary Works project. This has included meetings with a City of Toronto planner, who has helped to provide context 
and professional knowledge on the site. To understand the perspective of local businesses, a review of the comments from two public meetings (one in 2019, one in 2020) will offer insight into the strengths, challenges and opportunities along Geary Avenue. Lastly, site visits and field monitoring, as well as photography of Geary Avenue, will contextualize much of this research and act as a visual aid when informing recommendations. 


\section{Case Study 1: False Creek Flats and Strathcona Village, Vancouver}

Vancouver Policy Background

The City of Vancouver is divided into five categories of zoning district schedules, as well as area or site specific comprehensive development districts. Among the industrial district schedule, there are 13 sub-zoning intents which fall under heavy industrial $(\mathrm{M})$, light and medium intensity industry (I), light industrial and commercial mixed-use (IC) and light industrial, commercial and residential mixed-use (MC). Industrial lands area-specific policy was first adopted in 1995, which sought to retain city-serving industry, transport and service uses in the False Creek Flats (City of Vancouver, 1995). It had implementation action to establish a development strategy for future uses, which many years later would become the False Creek Flats Area Plan. Powell Street/Clark Drive was also flagged as an area to retain industrial use, however East Hastings Street between Heatley Avenue and Semlin Drive had been designated in 1990 as one of 10 "let-go" industrial areas, which recognized these areas could be considered for other uses, including residential (City of Vancouver, 2002). This policy decision has had an impact on the area, and is one of the many reasons that development projects such as Strathcona Village have been successfully proposed. Today, the City is undergoing an Employment Lands and Economy Review, expected to be completed in 2020, which is looking at issues regarding intensification and densification of employment lands with limited industrial land and a continually growing population (City of Vancouver, 2020). 

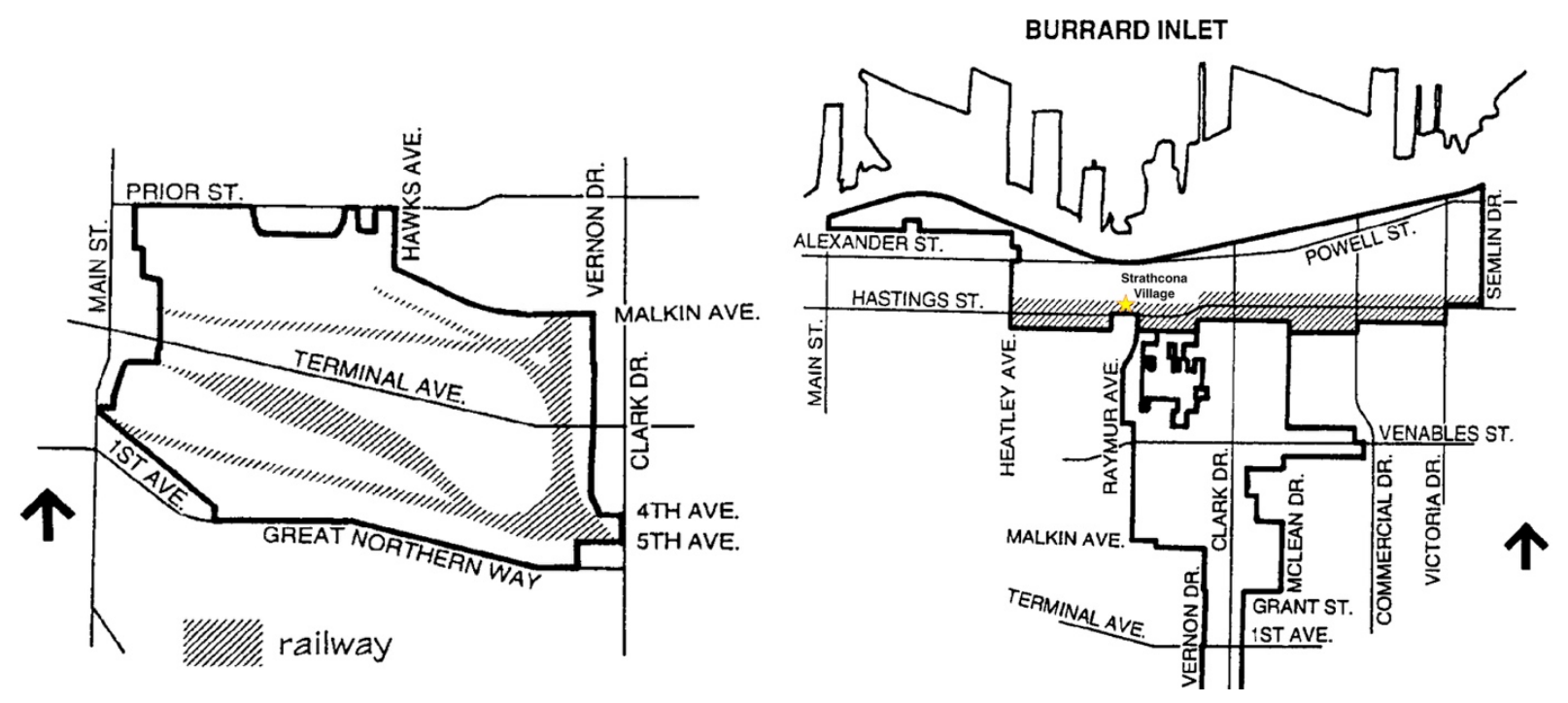

Figure 3 (left) False Creek Flats industrial lands (City of Vancouver, 1995).

Figure 4 (right) Powell Street/Clark Drive industrial lands (City of Vancouver, 1995).

\section{Part 1: False Creek Flats Background}

The False Creek Flats is comprised of $450+$ acres of employment land, located close to downtown Vancouver and the port. It is flanked by many established communities, including Strathcona-Chinatown to the North, Olympic Village and future North-East False Creek to the West, Mount Pleasant to the South, and Grandview-Woodlands to the East. At the time of publication, the Flats was made up of over 600 diverse businesses with approximately 8,000 employees, and has some of the most expensive industrial land in the Metro region (City of Vancouver, 2015). As urban industrial users have shifted away from occupying large spaces over 20,000 square feet, less wholesale traders occupy the area and in the last 15 years has led to a more even distribution amongst manufacturing, retail trade, arts \& culture, and wholesale trade agents \& distribution (City of Vancouver, 2015). The diverse mix of uses is a result of rail service that facilitated the filling of the Flats, and created unmethodical land parcels and roadways. It has also been influenced by the low rent of older buildings, a unique proximity to downtown without pressure to accommodate its functions, and a wide range of employment uses (City of Vancouver, 2017a). 


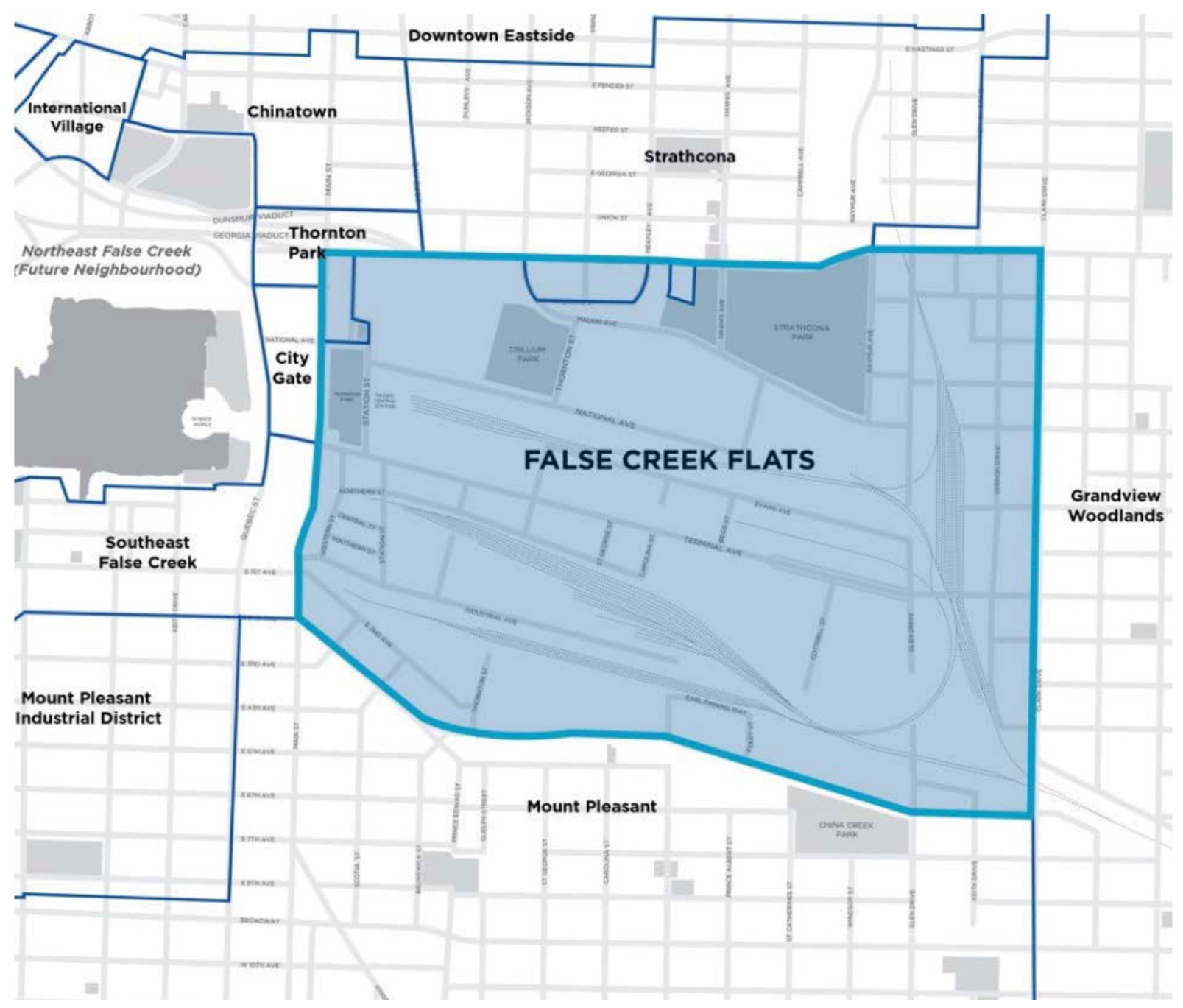

Figure 5 Neighbourhood Context of the False Creek Flats (City of Vancouver, 2017a).

\section{$\underline{\text { The Area Plan }}$}

The Area Plan has five different zoning categories, with a total of thirteen specific sub areas.

Generally, the site is zoned in two distinct halves: the eastern portion (predominantly 1-2 Sub

Area $\mathrm{A}$ and $\mathrm{B}$ ) is zoned for more traditional base economy functions such as light industrial for manufacturing, and production, distribution, repair (PDR). The western portion (predominantly 1-

3 Sub Area A and B), acts as a transition to commercial and residential neighboring uses and seeks to establish higher-density buildings to accommodate mixed-use, in particular lightindustry or PDR. 
I-2 permits use that is "generally incompatible with residential land use but are beneficial in that they provide industrial and service employment opportunities or serve a useful or necessary function in the city" (City of Vancouver, 2017b). The intent of this Schedule is not to permit dangerous or environmentally impactful uses as residential areas are nearby, rather allow for 'Core Industrial Back-of-House' functions (such as products manufacturing, artist studios, service shops and laboratories, storage and packing plants, and public utility) that play a vital role central in the city. While not allowing for residential in the mix, Sub-Area B does call for 'Intensified Industrial', which seeks to increase height and density and welcomes Creative Product Manufacturing at ground floor (City of Vancouver, 2017c).

I-3 provides a transition from the 'Core Industrial Back-of-House' to adjoining residential and commercial districts, as well as supports intensified use that is in close proximity to transit (City of Vancouver, 2017a). The emphasis here is to "permit high technology industry, creative products manufacturing, digital entertainment, information and communication technology, and related industry with a significant amount of research and development activity" (City of Vancouver, 2017d). With its proximity to the proposed St. Paul's Hospital campus, I-3 will focus on uses that include the innovation economy, health science and medical service, and also permit dwelling units for institutional health-related residential (City of Vancouver, 2017c). While I-3 doesn't focus heavily on residential, it does allow for a considerable amount of General Office with delivery of ground floor industrial or Artist Studio. Furthermore, this zone utilizes additional density for density bonus payments to deliver public benefits such as community economic amenities and non-profit industrial space (City of Vancouver, 2017a). This demonstrates initiative to both intensify employment, while also ensuring public space needs are met and affordably spaces are considered. 


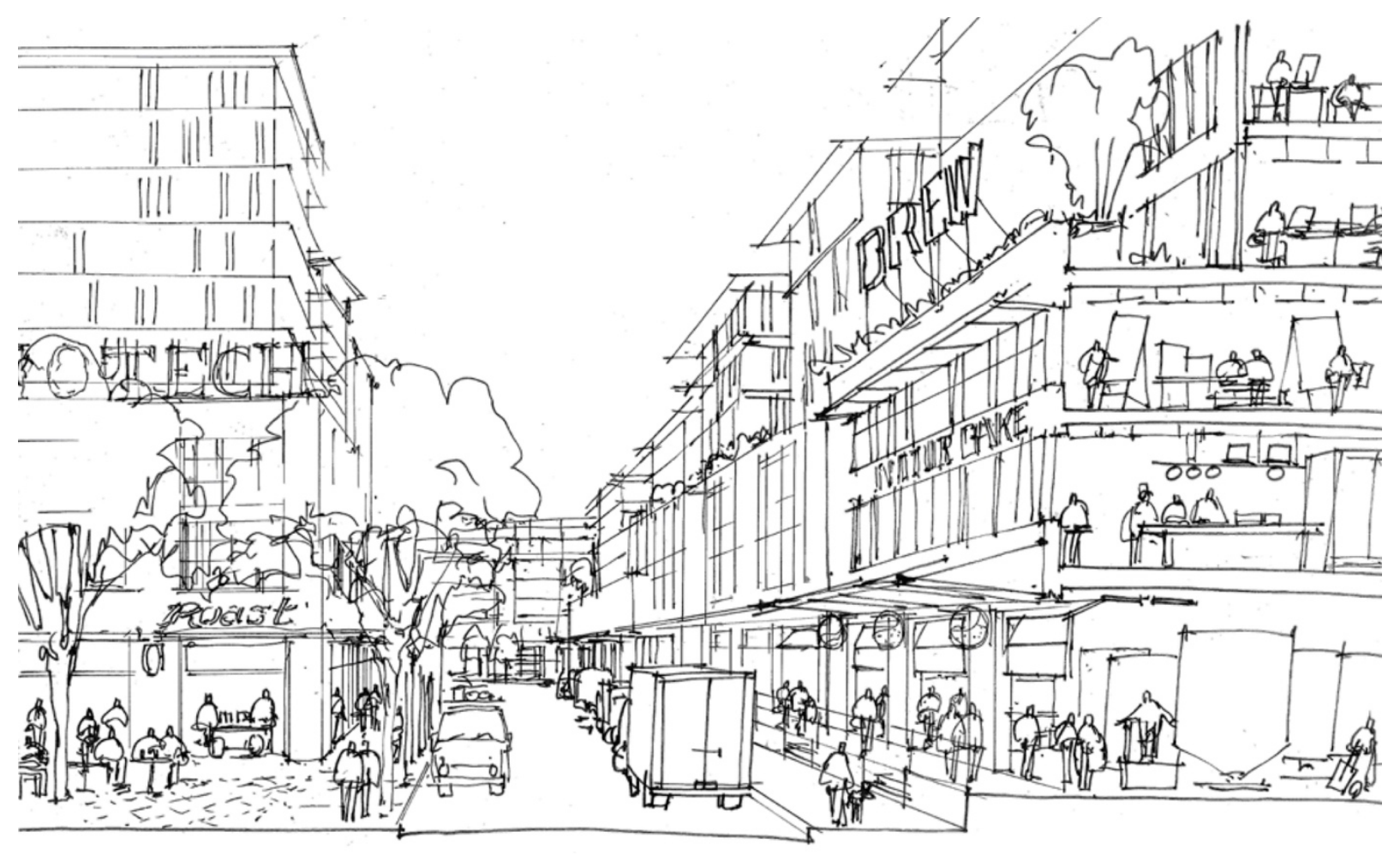

Figure 6 Ground/Second Floor Industrial with Retail at Grade and Office Above (City of Vancouver, 2017a).

Mixed-use prototype \& industrial-to-residential transition

While the Plan pays close attention to the relationship between industrial land and commercial/residential uses in an effort to facilitate effective transition between the two, very little is proposed for actual mixed-use typologies. The exception to this is the IC-3 Sub-Area A in the south-west corner of the site, FC-2 District (and six sub-areas) parallel to Main Street in the western quadrant, and MC-1 Sub-Area A in the northern quadrant next to Strathcona Park. 


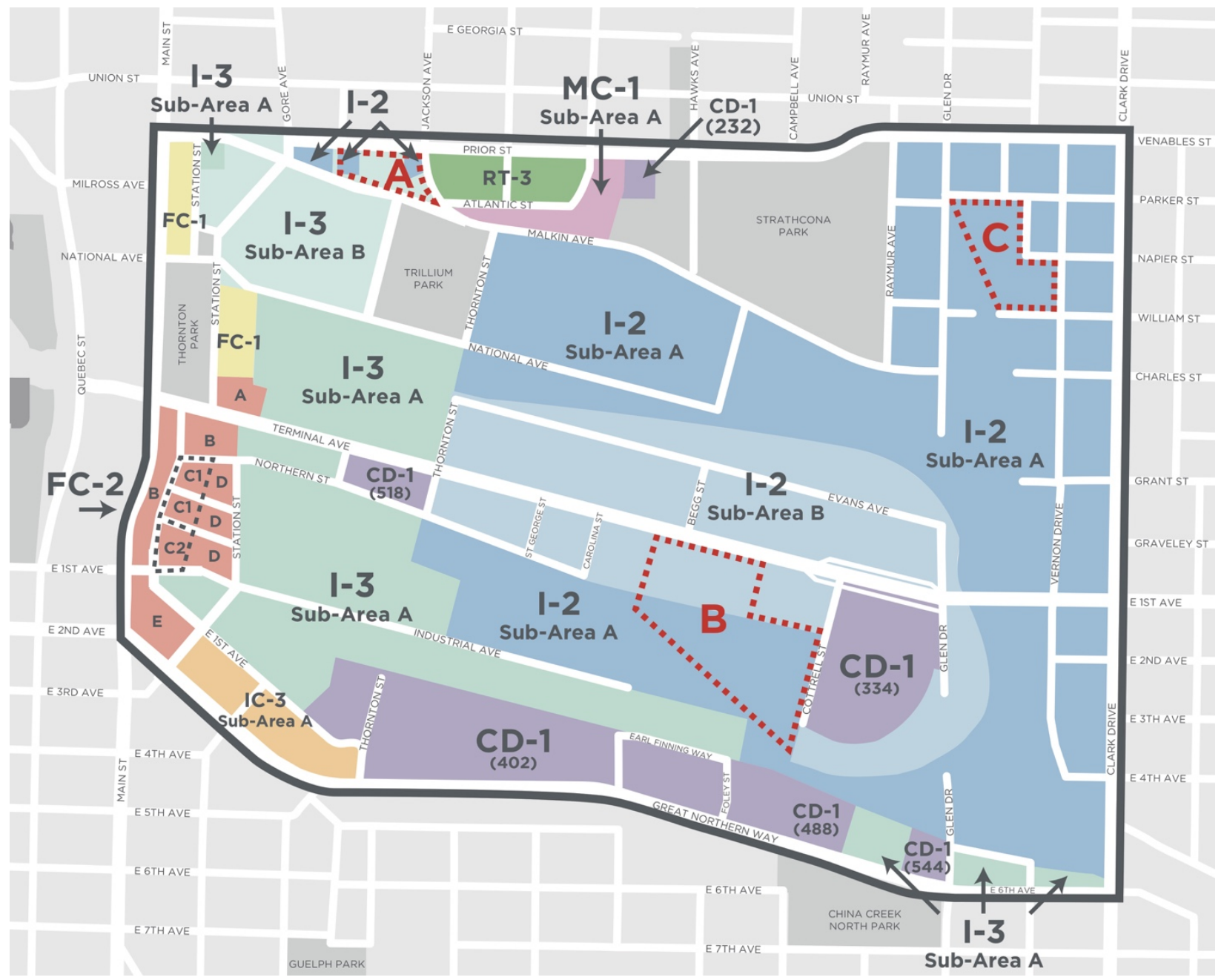

Figure 7 False Creek Flats Zoning Intent (Current as of March 12, 2018), (City of Vancouver, 2017c).

MC-1 Industrial/Residential Mixed-Use Transition is intended to facilitate the transition between the Strathcona residential neighbourhood and the border of the Flats. This is a new and highly innovative zoning model allowing for a "vertical industrial-to-residential transition zone" (City of Vancouver, 2017c), where light industrial or artist studio is required on the ground floor fronting onto Malkin Road, and stacked townhouse residential will sit above. Because of the grade change, the stacked rental townhouses will front onto Atlantic and Prior, giving the illusion of a strictly residential development. 


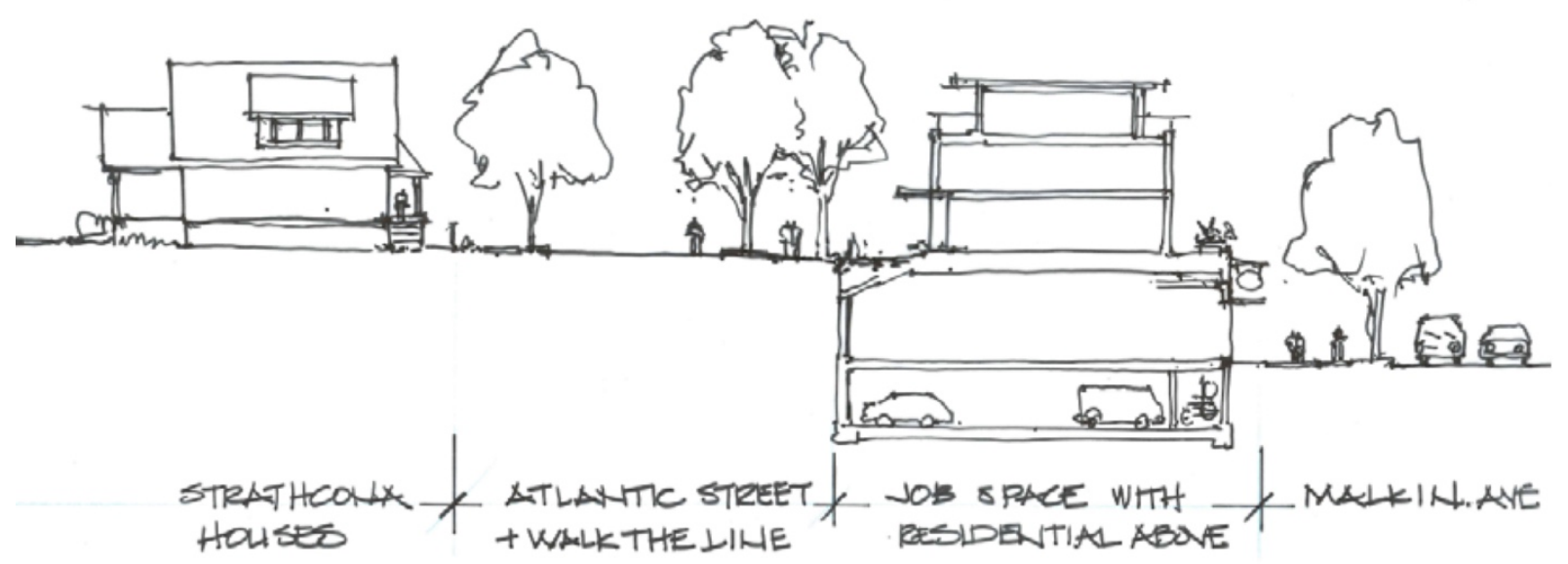

Figure 8 Atlantic/Malkin Transitional Edge (City of Vancouver, 2017a).

- Height: 12.2 m permitted; 13.7 m conditional

- Density: 0.75 FSR permitted; 2.5 FSR conditional

- Conditions: Increase to 2.5 FSR considered with secured market rental housing

A notable regulation includes a $7.6 \mathrm{~m}$ setback minimum for any portion of the building above the first story and below the fourth to the rear property line (City of Vancouver, 2017e). This allows for a narrow "backyard" at-grade with Atlantic and Prior, and provides a physical and visual barrier to the activity on Malkin Road. In addition, relevant acoustic measurement reports are required, with noise levels not exceeding 35 decibels in bedrooms (City of Vancouver, 2017e). This form of study is an important tool for the success of mixing residential and industrial uses, and also indicates how residential occupants may be expected to experience certain noise levels because of the unique environment they choose to live in. IC-3 Rental Incentive Artist Live-Work Mixed Use Zone is another transitional model, where the main prerogative is to mix industrial use with live-work studies and supply secured rental housing.

- Height: 18.3 m permitted; 30.5 m conditional

- Density: 3.0 FSR permitted; 4.0 FSR conditional

- Conditions: additional height and density will be considered if residential component is $100 \%$ secured market rental or $20 \%$ social housing 
Additional conditional requirements are included in the False Creek Flats Urban Design Policies and Guidelines for IC-3. This is important in order to realize the goals of the Creative Campus to enable intensification that allows for flexible industrial workspace with other, potentially less compatible uses, all while facilitating a healthy public space. Both MC-1 and MC-2, and IC-3 are unique by-laws in the City of Vancouver to the False Creek Flats and are small, concentrated areas. As a test-site, future success of this zoning model in the False Creek Flats could be used as its own case study and modified and scaled to other similar sites.

Lastly, the FC-2 Innovation Hub is on the border of Main Street and Terminal Ave, and is adjacent to the Main Street-Science World SkyTrain station. The Innovation Hub will be characterized by a tight block scale, heritage assets, and a people first environment - focusing on building new plazas and open spaces, as well as active transportation connections (City of Vancouver, 2017a, p. 60). This site is seven acres of City-owned land, so there is opportunity to push the envelope with economic experimentation and innovation. Uses include laboratories, research and development, digital or tech offices, arts and cultural facilities, spaces for local food economy; and residential (City of Vancouver, 2017a, p.44). Of the six Sub-Areas, four have outright residential or conditional density in exchange for non-market housing, market rental, strata condominium, and social housing (City of Vancouver, 2017c). 

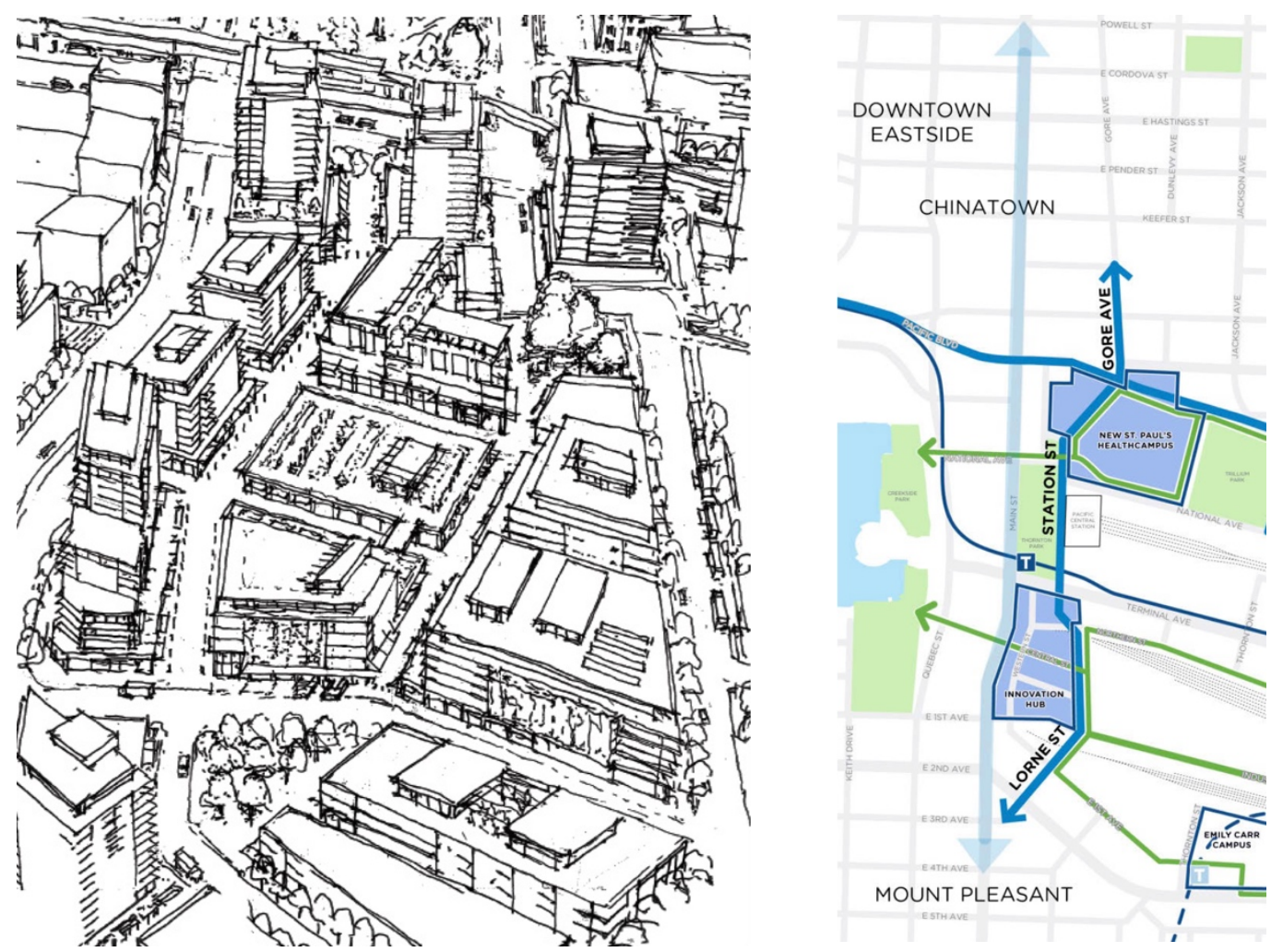

Figure 9 (left) Illustrated Character of Innovation Hub (City of Vancouver, 2017a).

Figure 10 (right) Map of Corridor (City of Vancouver, 2017a).

- Height: $10.7 \mathrm{~m}$ to $22.9 \mathrm{~m}$ permitted; $18.3 \mathrm{~m}$ to $51.8 \mathrm{~m}$ conditional (sub-area specific)

- Density: 3.0 to 7.0 FSR permitted; 2.5 to 7.5 FSR conditional (sub-area specific)

- Conditions: additional density generally granted for delivery of light industrial and nonprofit spaces, artist studios, or various housing models. Sub-Area A being the exception, where additional height is dependent on relationship to Pacific Central Station, and shadow impact on the nearby park.

\section{$\underline{\text { Rezoning policy }}$}

There are three specific sites in the False Creek Flats Area Plan that apply to rezoning policy and guidelines, and could provide future opportunity for more industrial mixed-use. This includes North of New Malkin (Area A) which is planned as a response to neighbouring road realignment, and will act as a transition from the future St. Paul's Hospital campus to existing residential neighbourhood. The Railyard Heritage Hub and Culture Hub (Area B and C) are 
'Amenity-Rich Public Nodes' and play a major role in the provision of the public space network outlined in the Plan. This includes "the presence of plazas and public open spaces for gathering, celebration and business showcasing, unique character elements and heritage buildings, as well as the provision of space for community economic centres to support strategic segments of the economy as outlined in the plan." (City of Vancouver, 2017f, p.1).

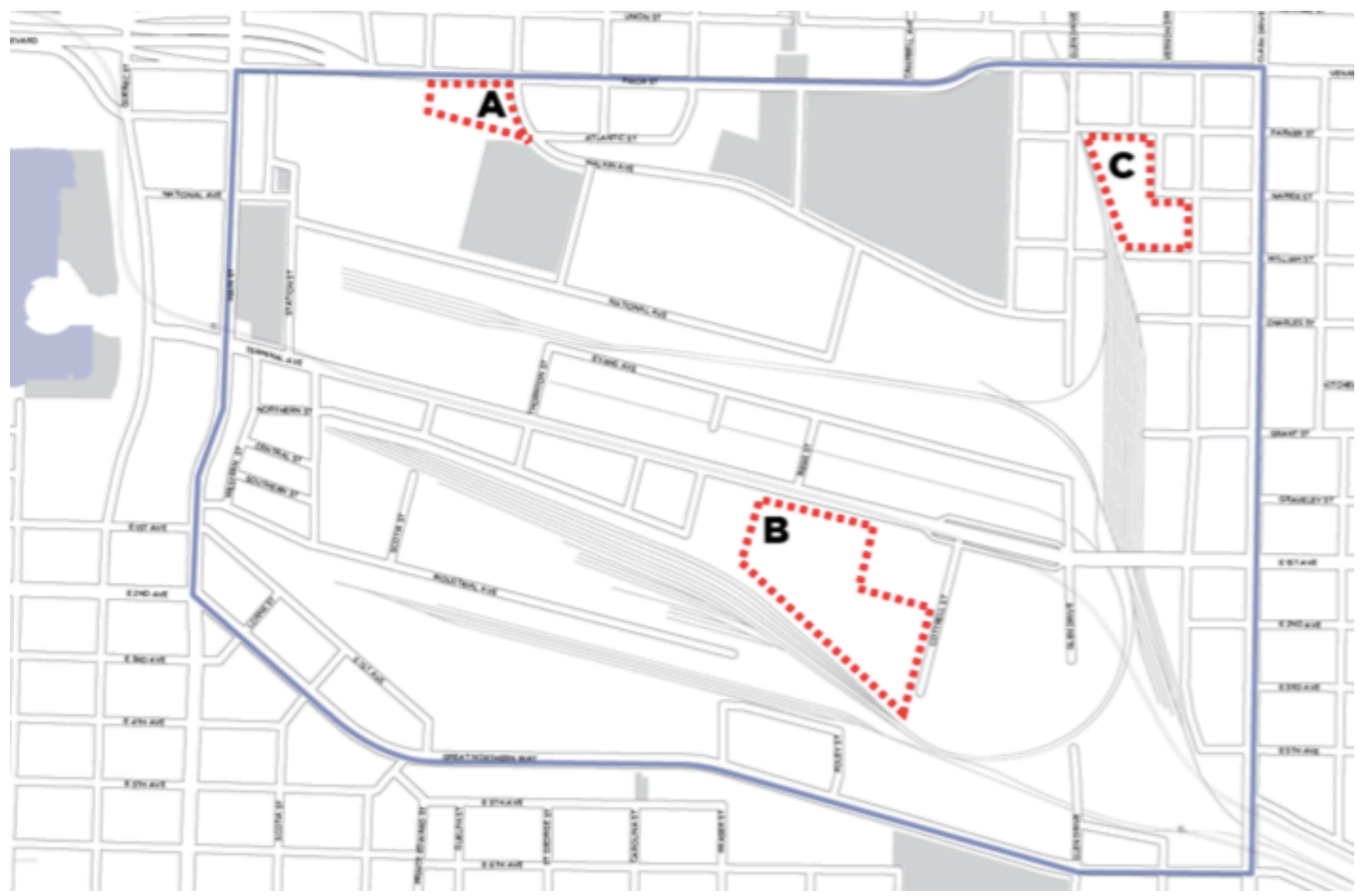

Figure 11 False Creek Flats Planning Area and Rezoning Policy Areas (City of Vancouver, 2017a).

Area A (North of New Malkin) Rezoning applications are supported for the introduction of conditional rental housing and delivery of employment space.

- Height: 18.3 m permitted; $30.5 m$ conditional

- Density: 3.0 FSR permitted

- Uses: Rental residential (contingent on delivery of 1.0 FSR employment space) and I-3 Zone employment (Health Care Office, CPM, DEICT) 
- Conditions: Amenity contribution payment for delivery of light industrial or non-profit space

Area B (Railyard Hub) and Area C (Culture Hub) Rezoning applications are supported for introducing additional employment uses, and will consider additional height and density.

- Height: 18.3 m permitted; 51.8 m conditional

- Density: 5.0 FSR conditional

- Uses: Non-residential (industrial, artist studio, creative products manufacturing)

- Conditions: Provision of public spaces and urban design considerations

$\underline{\text { Critiques }}$

The False Creek Flats Master Plan has been met with criticism from some local developers and planners since its approval in 2017 , citing that more housing is needed. Larry Beasley, the former Co-Director of Planning at the City of Vancouver, has been particularly vocal. Noting that the the Flats will be one of the largest growth areas in the inner-city for the near future, he believes that the density is "way lower than it should be" and that it "should be where we are focusing growth and diversity" (Fumano, May 2019). He goes on to discuss the matter further in his book Vancouverism, stating that it "enshrines a very narrow range of uses, does not foster intensity or mixed-use, makes almost no attempt to bring jobs and homes closer together...and takes only glancing advantage of two new transit stations that will soon serve the area" (Beasley, 2019, p.172).

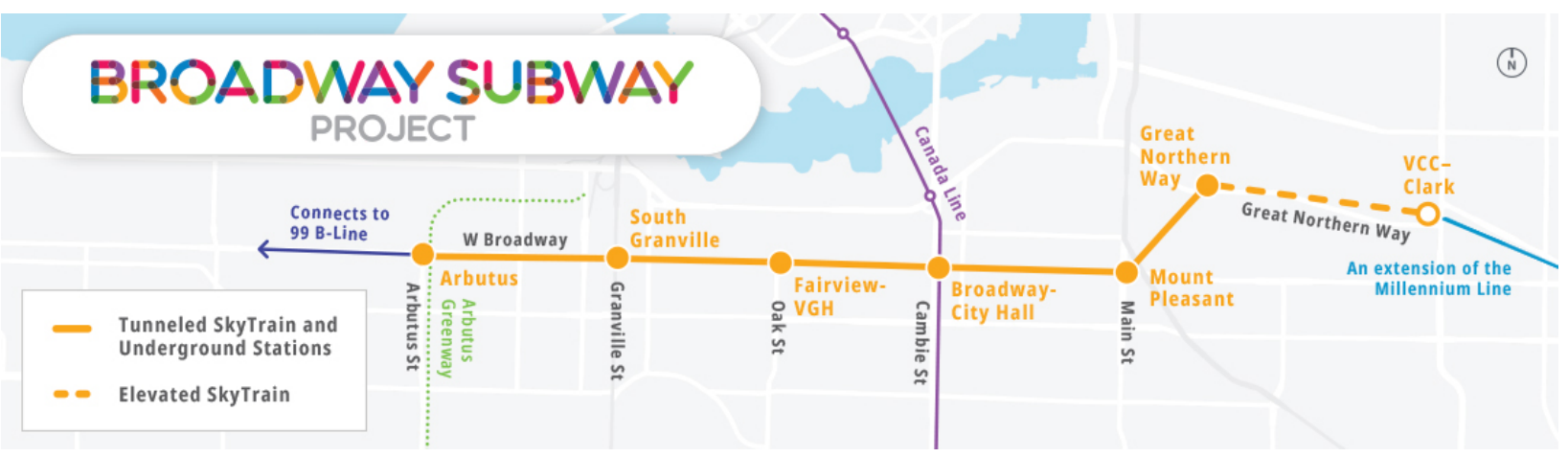

Figure 12 Millennium Line Broadway Extension (TransLink, 2018). 
This includes the existing Main Street-Science World Expo Line station to the north of the site, and the Great Northern Way Millennium Line station to the south which is expected to be completed by 2025. With Vancouver going through both a constant population boom and affordability crisis, he believes that the amount of housing units and density is not enough, particularly with proximity to this higher-order transit, which connects False Creek Flats to downtown in four minutes (Scalena \& Scalena, June 2019).

This critique is also emphasized by the development community. Anne McMullin, President and CEO of the Urban Development Institute that focuses on multi-family developers, argues for a higher density hybrid-industrial model and more incentives for rental housing. Residential development could be achieved through higher buildings mixed in with industrial and office space and transit-oriented development in the Flats would face less community opposition than more established areas (O’Brien, Mitham \& Yoon, 2017; McElroy, 2017). The current plan allows for 1,400 residential units, which is a density of three homes per acre. "There are 20,000 jobs potentially being created in the area and major institutional uses [St. Paul's Hospital and Emily Carr University of Art + Design]. Ideally, we want employees and students living close to their jobs and educational institutions. The plan in its current state, will discourage this and result in much more commuting from other areas" (O’Brien, Mitham \& Yoon, 2017).

Conversely, there is a strong argument for protecting the industrial and commercial space, and the effort has been supported by some economists and commercial real estate professionals. The Vancouver Economic Commission (VEC), an external agency of the City that supports local companies, supports adding density because it means having the space protect these uses (O’Brien, Mitham \& Yoon, 2017). The 2017 VEC Flats Economic Development Strategy was implemented in order for the Flats to accommodate higher employment densities and mixed-use development while protecting its foundational role as a light industrial district. It identifies twenty-four recommendations, many of which address how demand for industrial space outstrip supply, surging lease rates, and the ineffectiveness of policy at suppressing land 
values (The Vancouver Economic Commission, 2017). Vancouver's city council voted in favor of the rezoning 5-4, with all of the Vision Vancouver councillors in favor. They argue that it supports the growing innovation economy and creates more jobs in the core of the city, while preserving job space for working-class Vancouverites (O'Brien; Mitham \& Yoon, 2017; McElroy, 2017).

Ultimately, the decision for rezoning aims to strike a balance between growth in the area while protecting vulnerable jobs, particularly light industrial functions. What remains uncertain is the level of regulation that ensures that the new housing and other amenities don't negatively affect existing businesses, an issue in many industrial districts that are experiencing redevelopment. Adrianne Carr, a Green Party Councillor, voted against the rezoning with concern that new uses will increase the land value and put pressure on industrial lands, risking the loss of affordable and safe artist spaces (McElroy, 2017).

$\underline{\text { Analysis }}$

The False Creek Flats is arguably one the most ambitious examples in Canada of an industrial lands master plan. It has a comprehensive set of existing and new zoning by-laws that emphasize transition of industrial uses to the existing surrounding residential communities. To this end, it includes detailed urban design guidelines for each mixed-use zoning district schedule, which is not currently a practice in Toronto. Given Geary Avenue's close proximity to residential uses, any future change would be subject to and scrutinized for its ability to thoughtfully consider how local residents are impacted and what measures could be taken to improve the synergy as a whole, and not just for the public realm along Geary Avenue. Furthermore, the City of Vancouver's efforts to create unique character nodes in the Master Plan is highly transferrable to Geary Avenue, as there has been public support for emphasizing the community's identity and defining character areas (City of Toronto 2019c; City of Toronto 2020b). Additionally, future development on the Avenue would become more streamlined, if city blocks were rezoned en masse and designated where intensifying but maintaining exclusive 
light industrial functions is the goal, and where a mix with office or residential uses would be feasible.

As the Area Plan is yet to be realized, it is ultimately difficult to determine the success of this project and what opportunities it yields for other industrial neighbourhoods like Geary Avenue. Furthermore, the scale of the two projects are very different, but there are lessons that can be gained. The Area Plan does a good job at considering incompatible uses and setting conditional measures to prioritize industrial functions, even at the behest of public interest in having more residential uses. However, in its specificity it lacks consideration on the issue that industrial land is an increasingly limited and finite resource in Vancouver, and ultimately should consider higher $\mathrm{FSI}$ and height maximums given its proximity to transit, the downtown core, and the scale of the overall plan. While conditional FSI and height is often substantially greater than the as-of-right zoning, there should be clearer direction on how that is achieved so development doesn't default to lower density. During the first phase of City of Vancouver's Employment Lands \& Economy Review held in 2019, some participants from the External Advisory Group noted that "the demand for industrial space, especially small-scale industrial space, is high and will likely increase in the future" (City of Vancouver, 2019). With this in mind, participants put forward that more multi-level industrial with mixed uses should be included, with some also suggesting residential, and that co-location of uses could increase site desirability, and save money (City of Vancouver, 2019). Thus, character and use transition should be prioritized but not impede on the potential to create a truly high-density mixed -se community.

\section{Part 2: Strathcona Village Background}

Strathcona Village situated at 955 East Hastings Street, Vancouver, is the first industrial, office, retail and residential mixed-use development in North America. The Strathcona neighbourhood is bordered by Chinatown to the west, Clark Drive to the east Burrard Inlet to the north, and the Canadian National Railway to the south (Metro Vancouver, 2012). It is traditionally an industrial-employment area with a mix of diverse uses that are in transition. It is 
very near to the False Creek Flats and has a similar character. The site was formerly home to 10 individual small properties, with various one or two level industrial and commercial uses with rear lane access. The development is comprised of a site-wide podium with three separate towers that at its tallest point reaches 12 storeys, and a two-floor basement that faces the rear lane. It is made up of 350 homes, including 280 market residential units and 70 social housing units, the latter of which are named the Belcourt Residence (Chan, 2018). The site was rezoned by the City of Vancouver in 2014 to allow for a mix of residential and light industrial functions, which are defined under the PDR banner. In total, The WorkSpaces at Strathcona Village is made up of over 60,000 square feet on the lower floors dedicated to this light industrial use. The building design is unique, as the laneway is two floors lower than Hastings Street, allowing for additional PDR space and parking access off of the lane at Raymur level (Metro Vancouver, 2012).

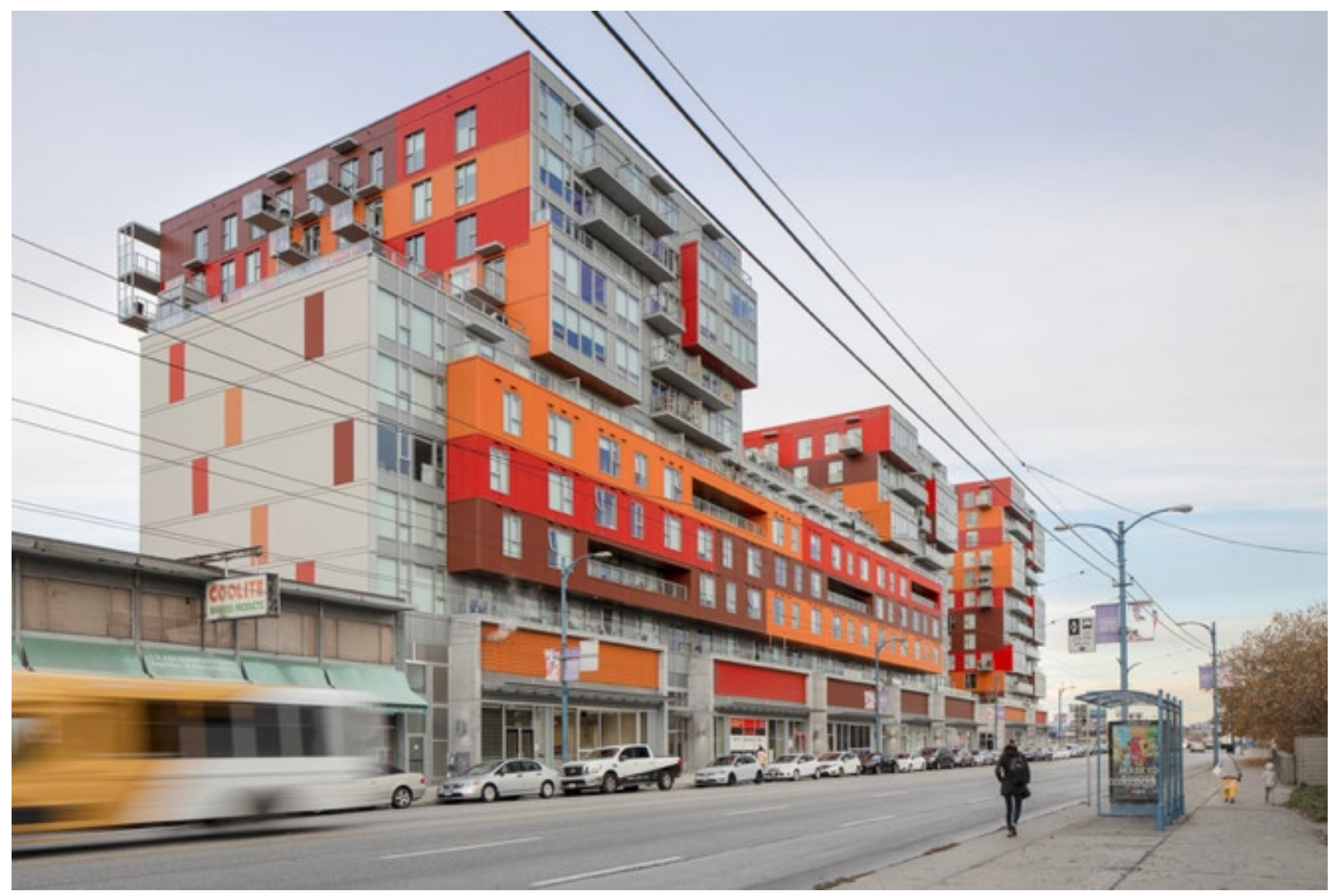

Figure 13 GBL Architects - Strathcona Village - East Hastings, Vancouver BC (KRJ Photography, n.d.). 

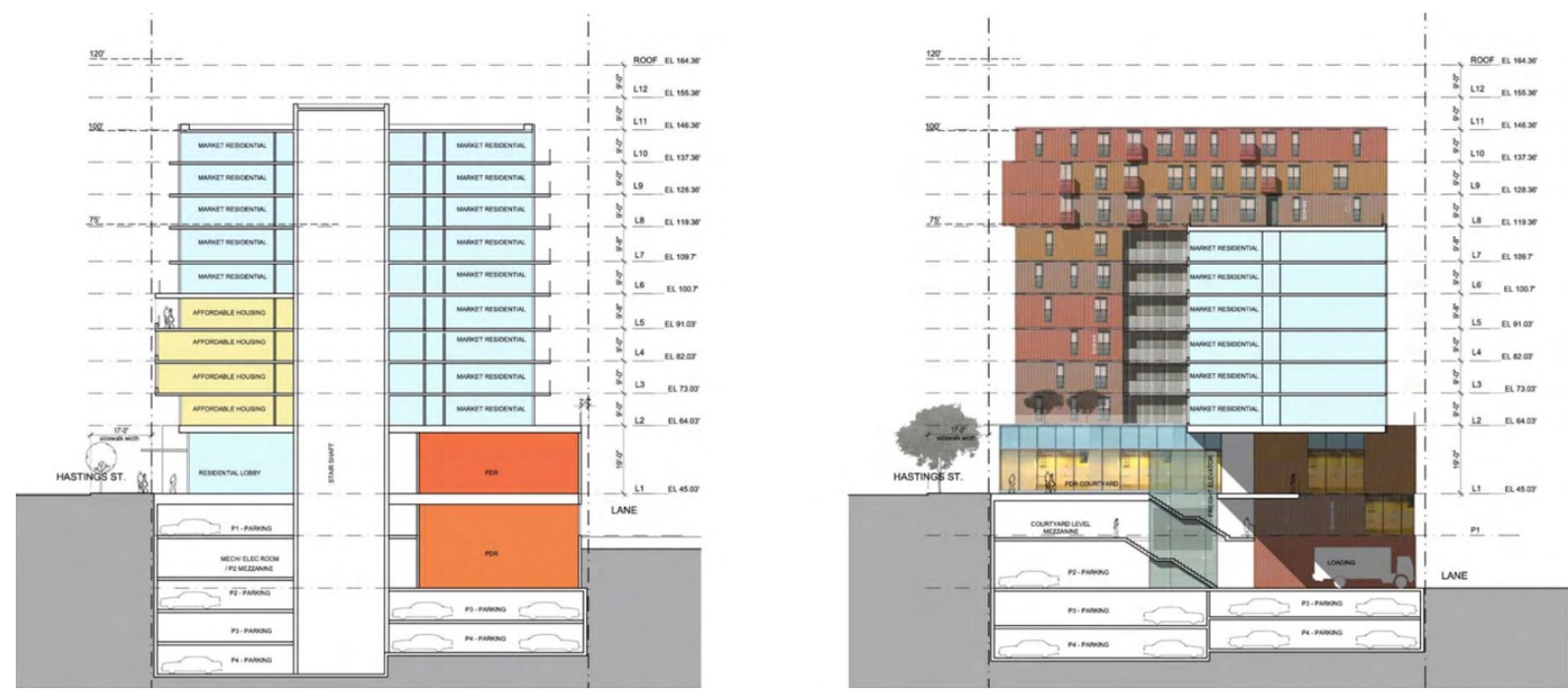

Figure 14 Cross Section of 955 East Hastings Street (GBL Architects, 2011).

Zoning

Strathcona Village was rezoned from M-1 (Industrial) to CD-1 (Comprehensive Development), which includes but is not limited to allow for general manufacturing, artist studio, office, retail, services, utility and communication, wholesaling, barber shop, beauty salon, neighbourhood public house and restaurants (Colliers International, 2018). Marketed as "unlimited possibilities" that allows for "a variety of commercial businesses that will be able to capitalize in the ever growing and flourishing Strathcona neighbourhood" (Colliers International, 2018, pg.1) it is evident that there are few restrictions in place to protect The WorkSpaces as light industry. However, retail uses and certain service uses are only permitted on the first storey of the building fronting Hastings Street and the pedestrian realm, and office uses are only permitted on the first storey with a setback of $10.7 \mathrm{~m}$ from the front wall of the building (City of Vancouver, 2017g, s.4.3).

- Height: $36.6 \mathrm{~m}$ permitted

- Density: 6.15 FSR permitted

- Notable conditions: dwelling units are in an "activity zone" defined by the Noise Control By-law and is subject to the levels of noise allowed in industrial and downtown districts 

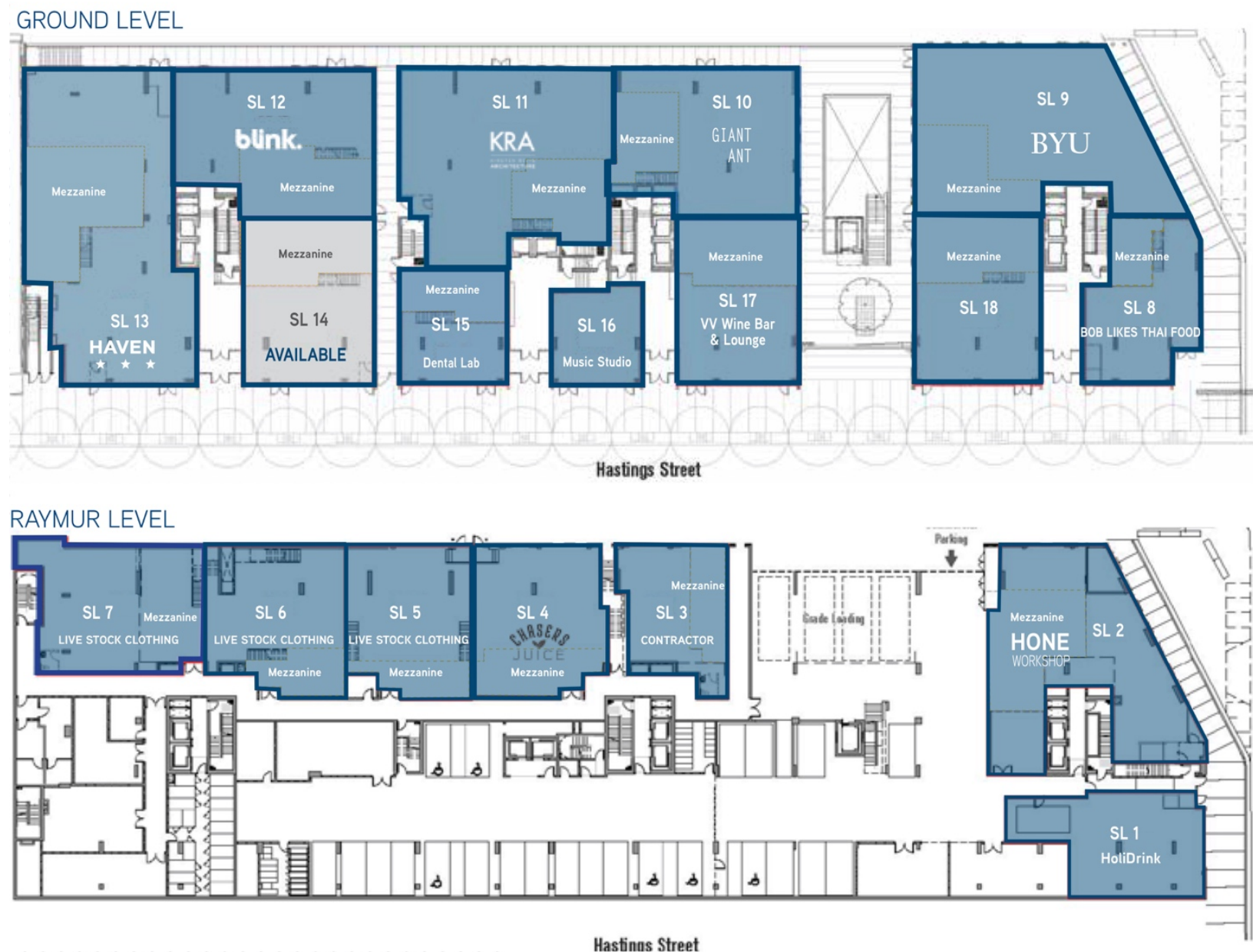

Figure 15 Floor Plan of the The WorkSpaces and Current Tenants (Colliers International, 2019).

\section{$\underline{\text { Critique }}$}

This project, while arguably very ambitious, has received mixed-reviews from the neighbourhood. Critics such as the Downtown Eastside Local Area Planning Committee argue that the project will increase property values and speculation, and displace lower-income people and businesses. Furthermore, the ratio of units rented at the welfare rate (the shelter component of the project) to the other social housing units and market rent units is very low (Stueck, 2012; Cole, 2012). This is a concern not only for many redevelopment projects in industrial areas, but the broader conversation of redevelopment and neighbourhood resurgence as whole. In contrast, the Strathcona Business Improvement Association supports the preservation of industrial space, while others suggest that adding more residents and small 
businesses can help improve the streetscape and conditions of the neighbourhood (Stueck, 2012).

\section{Analysis}

Strathcona Village is a unique development and has achieved a high mix of harmonized use in one large development, and demonstrates how residential uses can be incorporated without defaulting to a commercial mixed-use development. From an urban design perspective, it aims to be visually engaging and uses materials that are visually permeable and conducive to creating an engaging at-grade pedestrian experience, such as corrugated metal to acknowledge its industrial history. As a major redevelopment, it will put pressure on surrounding low-rise industrial uses which could increase affordability concerns, particularly as Strathcona Village has provisions for affordable housing, but no programs to maintain affordable employment uses. Regarding the zoning schedule, Comprehensive Development is inherently flexible in the types of employment uses it allows, but measures such as the set-back for office use at-grade and prohibiting commercial use on the sub-level units aims to ensure a more active façade in the public right-of-way along Hastings Street, and encourages PDR in the alley that has closer proximity to adjacent industrial uses.

As outlined in the floor plans of The WorkSpaces from 2019 [Figure 15], Hastings ground level tenants include restaurants, offices, an animation studio, music production, and a dental office. Of particular note, a retailer's corporate head office which includes their clothing design and photo studio, and wholesale distribution operations (Zhang, February 2020). The sub-level at Raymur is home to manufacturing use, food production, a contractor's office, and a maker space. While not strictly protecting PDR uses, Strathcona Village contains an eclectic mix reminiscent of Geary Avenue. Many tenants have a dual primary and ancillary use, predominantly commercial/office and production. This is very similar to how many of the businesses on Geary operate, and Strathcona Village could be a useful comparison to highlight how relaxed restrictions on primary and ancillary uses can be imagined. Ultimately Strathcona 
Village is not physically similar to Geary Avenue, but it provides context for how future redevelopment (particularly on sites allowing for higher density) could successfully include residential and office use without compromising allocation for PDR.

\section{Case Study 1: Key Takeaway and Applicability to Geary Avenue}

The key takeaway from the False Creek Flats Master Plan and Strathcona Village is that planning for innovative mixed-use development requires very intentional zoning by-laws in order to execute a specific vision. There is a benefit to enacting site-specific zoning and design guidelines to addressing unique neighbourhood character and urban challenges. For the False Creek Flats, a primary challenge that applies to Geary Avenue is transitioning between uses. The establishment of character sub areas and area-specific conditions helps to distinguish nodes within the community to aid with these points of transition. Geary Avenue would benefit from a similar practice, particularly as a street known for its eclecticism and close proximity to conflicting residential neighbourhoods. The attention to detail in the FCF Plan may have a direct correlation to its modest proposal, which has garnered critique for not optimizing land use and adding more density. Strathcona Village is almost diametrically opposed; it is a development that doesn't match its surroundings, instead adding significant density, housing, and a large mix of businesses. The differences between these two examples highlight some of the considerations for Geary Avenue moving forward: when it is appropriate to push the envelope to intensify and mix use, and when cohesiveness of the greater neighbourhood takes priority. Conditional density, as used in the FCF Plan, is a tool that would be applicable to Geary Avenue on a small scale, as a method to incentivize different policy objectives in the area. 


\section{Case Study 2: 100/150 Hooper, San Francisco}

Overview - PDR and Mixed-Use Zoning

In 2001, The City of San Francisco implemented the Eastern Neighbourhoods Program in order to understand how some of the conflicts that exist between residential, office and industrial uses could be reconciled (San Francisco Planning, 2020). This program led to the creation of PDR (Production, Distribution, Repair) Districts, both as a solution to these conflicts and acknowledge the important role PDR has and continues to have on San Francisco's economy in the east end (San Francisco Planning, 2020). Uses in PDR Districts are heavily regulated in order to guarantee that industrial land is protected, while intensification and mixing uses (predominantly office or institutional space) is promoted in order to ensure that the PDR spaces are economically viable and can be subsidized during the construction of mixed-use projects. When redeveloping in PDR Districts, industrial square footage must be replaced to match or exceed what currently existed. If the building is greater than $0.4 \mathrm{FSR}$, then the replacement needs to match the square footage demolished, and if the building is $0.4 \mathrm{FSR}$ or less, then the replacement requires double the square footage of Industrial Use demolished (San Francisco Planning Code, 2020a). Other requirements include roll-up doors, delivery access, 10 to $30 \mathrm{ft}$. ceilings (approximately 3 to $9 \mathrm{~m}$ ) and a minimum building depth of $35 \mathrm{ft}$. (approximately $10.7 \mathrm{~m})$ (Poole, 2016).

There are four PDR Districts in San Francisco that range in intensity: PDR-1-B Light Industrial Buffer, PDR-1-D Design, PDR-1-G General, and PDR-2 Core Production Distribution, and Repair. All Districts prohibit residential uses, and either prohibit or limit retail, institutional and office use. Light Industrial Buffer has the lowest intensity, and is intended to retain lessintensive PDR and act as a buffer between residential neighbourhoods and light industry (San Francisco Planning Code, 2020b). Core PDR is the highest intensity. It encourages a wide range of industrial uses and permits certain non-industrial uses, providing they "are compatible 
with the operational characteristics of businesses in the area" (San Francisco Planning Code, 2020b).

San Francisco has a very comprehensive zoning map, and includes multiple Mixed-Use Districts, a few of which promote both intensifying mixed-use development and including PDR. The Urban Mixed Use (UMU) District as an example, "is intended to promote a vibrant mix of uses while maintaining the characteristics of [the] formerly industrially-zoned area" (San Francisco Planning Code, 2020c). It acts as a buffer between the PDR Districts in the Eastern Neighbourhoods and residential districts and allows PDR functions such as light manufacturing, arts activities and wholesaling, as well as retail, institutional uses, and nighttime entertainment. Housing is encouraged but conditional; it is subject to affordability requirements and at least $40 \%$ of all dwelling units must have two or more bedrooms or $30 \%$ must have three or more bedrooms to target multi-family dwelling. Office uses are also conditional, and are restricted to upper floors of multi-story buildings (San Francisco Planning Code, 2020c). The difference between Mixed-Use zones and PDR zoning is that it does not protect PDR uses outright and allows for greater diversity in uses.

San Francisco's policy to protect PDR uses is one of the more stringent examples amongst urban centres in North America that experience similar loss of industrial activity to suburbanization, globalization and increasing land value. The concern with new development, then, is how to incentivize developers to build affordable units in PDR districts, and also be a profitable investment. In 2014, the City passed two important amendments for PDR-zoned land. The first, was to allow the sharing of accessory retail in multi-tenant PDR space, which allows manufacturers to have retail space facing the street and keep operations in the back (Poole, 2016). This helps to encourage large, flexible ground floor spaces. According to SFMade, the member-based, non-profit, economic development organization that advocates for San Francisco manufacturing, "manufacturers target space anywhere between 500 and 10,000 square feet...most manufacturers can work well in diverse settings, with other makers, and 
residential, or retail uses around them" (Poole, 2016). The second, was to adopt a pilot for 'inclusionary PDR' which allows a developer the one-time opportunity to build new office space in PDR districts as long as one-third remains designated for PDR (Poole, 2016). This allows developers to mitigate some of the risk that comes with PDR tenants and helps to subsidize affordable rent for PDR users too.

\section{The Hooper Campus (100/150 Hooper)}

$100 / 150$ Hooper, otherwise known as the Hooper Campus, is a recently completed project in the PDR-1 Design District. 100 Hooper contains two four-storey buildings that collectively have 142,800 gross square feet of ground floor PDR, and over 284,000 gross square feet of office space above. 150 Hooper, also known as The Manufacturing Foundry, is over 56,000 square feet exclusively designated as affordable production space, and focuses on employing low-income community members. It is the first new construction of industrial space in the City of San Francisco in almost 20 years (PlaceMade, 2019).

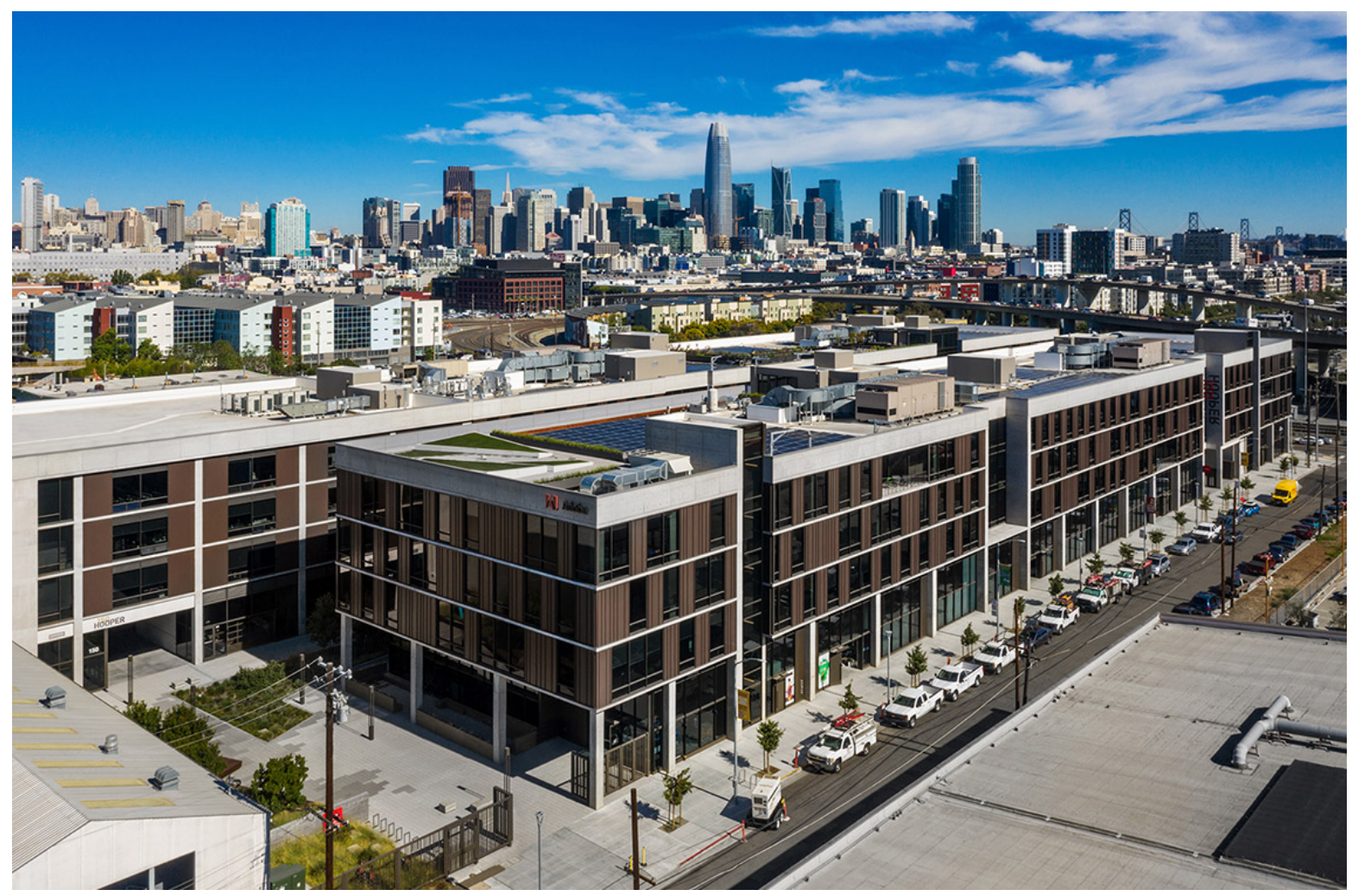

Figure 16 Aerial photo of 100/150 Hooper (Kilroy Realty, n.d.). 


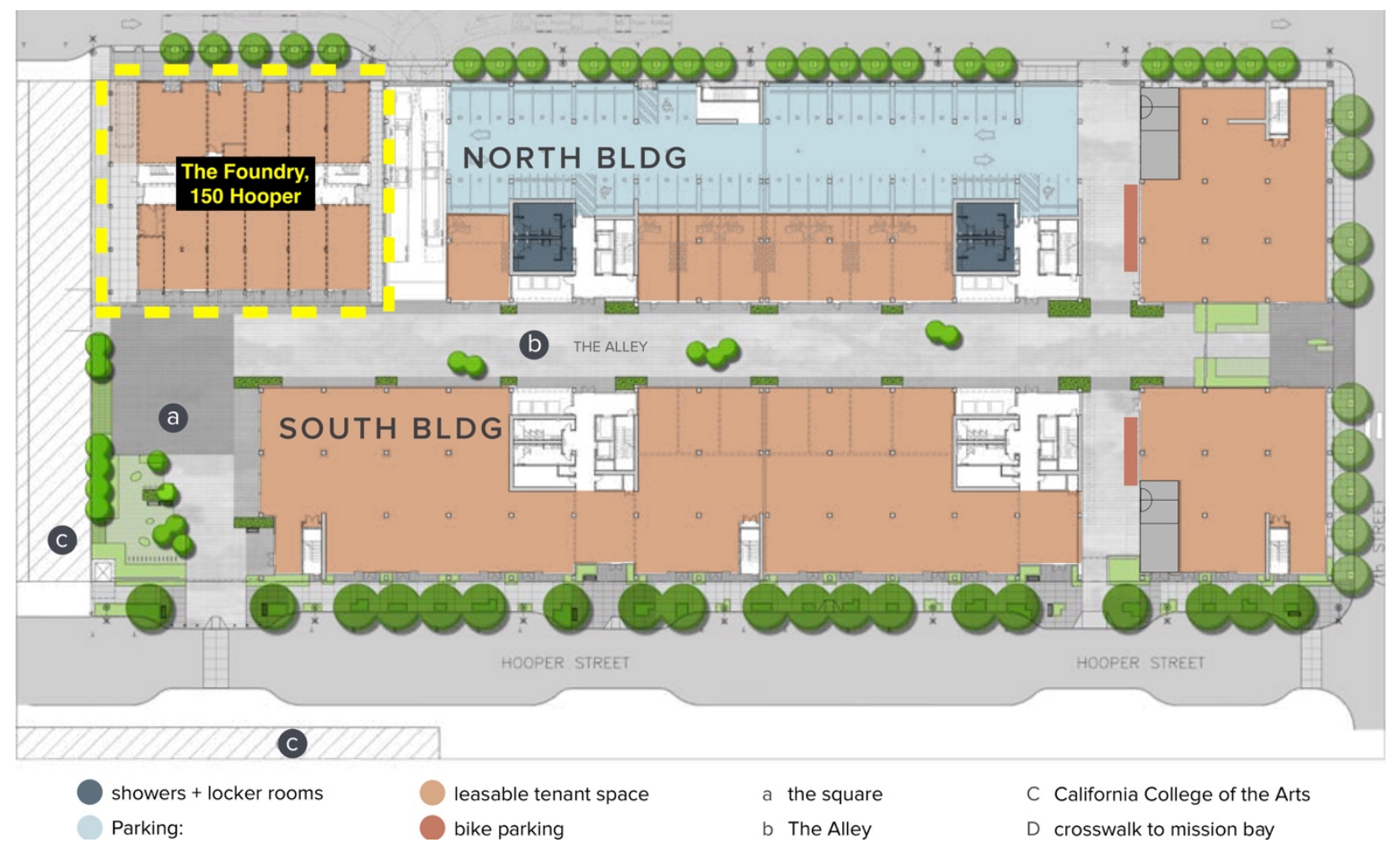

Figure 17100 Hooper Floor Plan (edited to indicate 150 Hooper), (Kilroy Realty, 2017).

100 Hooper features manufacturing, retail, office space and outdoor amenities. It took advantage of the 2014 ordinance that amended the San Francisco Planning Code to permit "inclusionary PDR", thus allowing for the development of over 400,000 square feet of hybrid manufacturing/office development (PlaceMade, 2019). This hybrid allows for the conditional development of office space in PDR zoned land, which supports the subsidization of construction costs for the $33 \%$ of a building which must be maintained for PDR uses in return (Seifel Consulting, UP Urban, Pfau-Long Architects, 2012). By facilitating mixed-use development, and only permitting office in conjunction with new PDR space, it directly supports PDR creation (Seifel Consulting, UP Urban, Pfau-Long Architects, 2012). Ultimately, this zoning strategy addresses a market gap in San Francisco, which otherwise "given the economics of industrial development, prevents the development of several large vacant PDR parcels" (Pratt Center, 2016, pg. 2), as was the case of the Hooper site prior to construction. This policy still ensures rigorous checks and balances, as it requires a Conditional Use Permit to ensure it 
meets public objectives, and any further development of this kind in San Francisco will be subject to public review as well as provides negotiation grounds for the community benefits attached to the permit (Pratt Center, 2016). Lastly, to ensure that occupants are abiding by this policy, the Certificates of Occupancy are directly linked, and periodic reporting is required (Pratt Center, 2016). This aims to address some of the many challenges with planning cities, where even the most well intended policy can become marred by lack of regulation or maintenance.
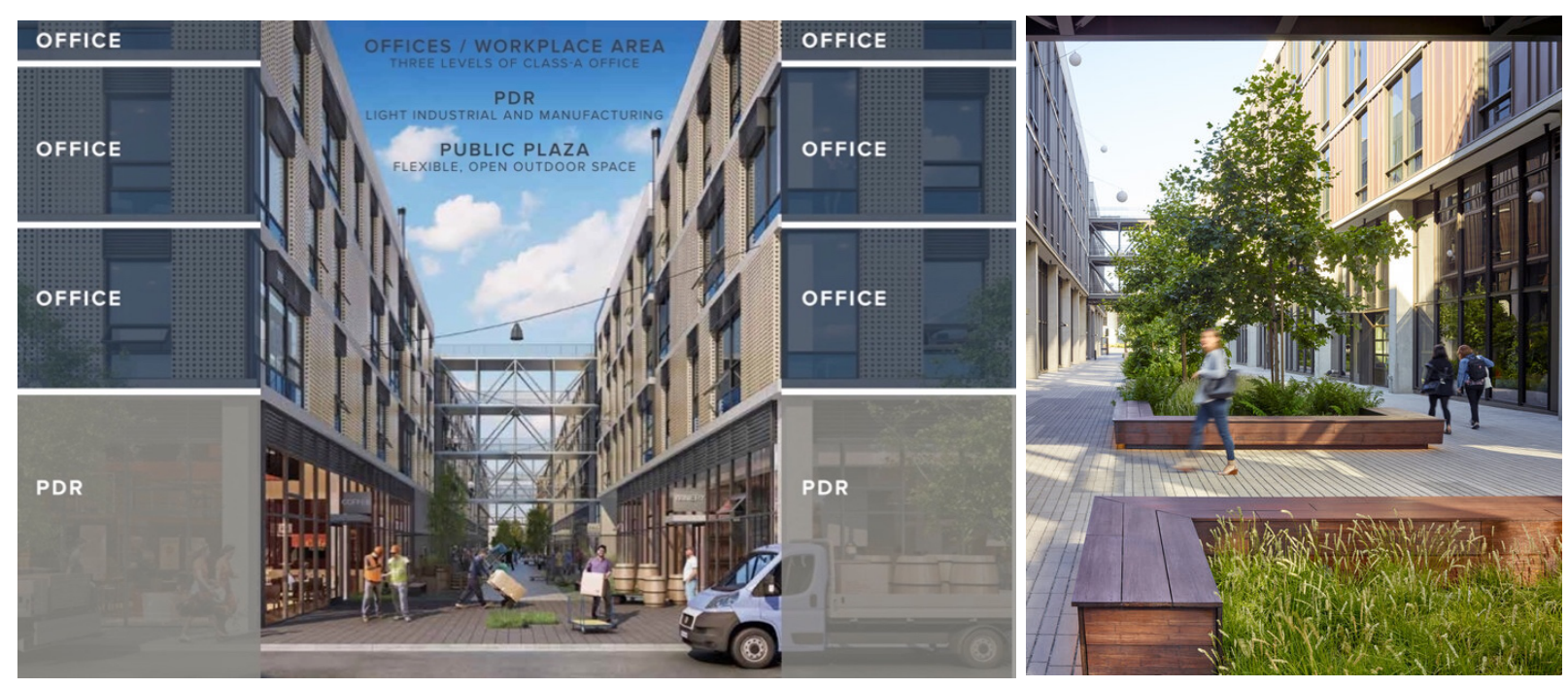

Figure 18 (left) 100 Hooper Project Breakdown (Kilroy Realty, 2017).

Figure 19 (right) The Breezeway (Kilroy Realty, 2017).

The third building rounding out the PDR campus is The Foundry at 150 Hooper, which was recently completed in 2018. PlaceMade, which owns the building, is San Francisco's first non-profit industrial real estate development corporation. It has a mandate to "collaborate with both the private and public sector to ensure that the Bay Area has adequate, quality industrial space to support a vibrant and growing manufacturing sector" (PlaceMade, 2019). It was launched in 2013 by its sister non-profit, the aforementioned SFMade, which focuses solely on San Francisco's economic base through the growth and sustainable development of the local manufacturing sector (PlaceMade, 2019). Each tenant has between 1,100 and 13,000 square feet allowing for flexibility and in order to meet the needs of companies of different types and sizes (O’Meara, 2018). 
To ensure a high level of affordability, the Manufacturing Foundry is offering below market rate rents, at roughly half the price of comparable market rates (O'Meara, 2018) Financing was made possible for the Manufacturing Foundry from PlaceMade purchasing the land at cost from the developer of the rest of the project, Kilroy Realty Corporation. The sale was incorporated as part of the community benefits, recognizing that $K R C$ received their return on investment through the office bonus in the other two buildings (Pratt Center, 2016). In addition, PlaceMade received financing through public and private contribution, namely $\$ 23.4$ million from the New Market Tax Credit (NMTC) fund from the US federal government (O'Meara, 2018). In essence, this tax credit is offered to organizations that provide for and invest in low-income communities. Tenant companies must commit to employing at least 60 percent low-income individuals prior to hiring, and in return receive the affordable rents (Tinner, January 2019). Ultimately, keeping local manufacturing jobs for low-income individuals in a city as unaffordable as San Francisco is very difficult. The NMTC ensures the needs of these community members are met, and by charging their employers below market rent it prioritizes the employees by leaving funds for competitive salaries.

\section{Analysis}

From a policy perspective, San Francisco has one of the most comprehensive industrial land management plans in North America, and is integral as the originator of the Production, Distribution, Repair designation to define light industry and begin to change the perception on what modern industrial uses entail and how it connects to the broader city. The policy to allow for 'inclusionary PDR' takes note from affordable housing, and allows market rate employment use to help pay for below market rate industrial use. This model could be a useful tool to implement on Geary Avenue as protecting industrial land does not inherently guarantee its affordability, and the supporting of living wages and employing low income individuals is mutually beneficial to supporting broader socio-economic goals in the city. Maintaining nonprofit ownership, and receiving government tax credits development grants, was critical for 
PlaceMade to succeed as an affordable rental provider at The Foundry. The Executive Director of SFMade acknowledges the challenge for ongoing funding, and said that non-profits "have to look at cities creating some sort of affordable industrial trust, similar to the way [there are] trusts for housing" (Nonko, October 2018). The time and resources required to launch this project is indicative of why it is currently so uncommon, and the level of investment that would be needed to recreate it in the Toronto context. At the very least, it sets an aspirational precedent and concretely demonstrates how having hybrid-industrial land can provide the leverage to offset the cost to provide industrial function, not harm it.

Although 100 and 150 Hooper does not include residential use, it is a useful example for a form of mid-rise and mixed-use development that could occur in the western portion of Geary, where there isn't generally pre-existing residential zoning and would arguably be a less contentious form of rezoning. In addition, the project is an example of how urban design and public space considerations can change the perception and status quo in the role of industrial development in an urban centre by providing unrequired privately-owned public space. "A public plaza, communicating service space dubbed The Alley, and sky bridges that span the two main buildings establish a work environment that feels more like a community" (Forge, 2019). In addition, the project has a streetscape plan which "provides comprehensive improvements to the public realm" (San Francisco Planning, 2015, p.11) and creates a PDR campus-like character that is integrated into its light-industrial surroundings. It creates pedestrian connections throughout and has a compatible mass and scale of the surrounding neighbourhood (San Francisco Planning, 2015). This includes street bulb-outs on the two adjacent roads, new planters, trees and benches (San Francisco Planning, 2015). Facilitating design that allows for 8 loading bays and at-grade paved areas for light vehicle loading frees up road space. Providing The Alley for public use and vehicle circulation ensures that all needs of the site are met, and doesn't disrupt human or vehicular traffic patterns (San Francisco Planning, 2015, p.15). Regarding transportation, the development provides 181 new bicycle 
racks when it is only required to provide 79 . It only provides $30 \%$ of the maximum permitted amount of off-street parking "thereby encouraging the use of alternative modes of transportation" (San Francisco Planning, 2015, p.15) as it is close to downtown San Francisco. Finally, a Commercial Transportation Demand Management Program is requested in order to reduce traffic added by the development and promote alternative forms of transportation. These are important considerations for Geary Avenue to take into account, as there is minimal onstreet parking and increasing intensity along the corridor would add significant pressure to the neighbourhood.

\section{Case Study 2: Key Takeaway and Applicability to Geary Avenue}

A key takeaway of $100 / 150$ Hooper is that providing for and ensuring long-term sustainability of affordable industrial space requires extensive resources to be successful. The broader conversation of non-profit industrial development and associated funding is something to take note of in Toronto. Another takeaway is that mixing uses on industrial land does not inherently mean that the primary function of industrial use will take a back seat. Nor does it mean that a mixed-use employment typology has substandard urban design guidelines, or attention given to the public realm, as is the outdated status quo with business parks. As a neighbourhood concerned with both the loss of affordable employment land and with public realm/circulation challenges, these takeaways are relatable to Geary. It is evident that industrial use is the priority in both cases, and Toronto can consider leveraging additional density and mixing office use in order to subsidize its PDR as San Francisco has done. 


\section{Study Area: Geary Avenue}

\section{Employment Land in Toronto}

The Employment Industrial category in Toronto "includes a variety of manufacturing, warehousing, distribution and office uses within different zones. Some zones have permissions for parks, hotels, small scale retail and services serving area businesses" (By-law 569-2013, 2013a). The City of Toronto has four designations: Employment Light Industrial, Employment Industrial, Employment Heavy Industrial, and Employment Industrial Office which provide for varied levels of intensity. At the time of the 2019 Toronto Employment Survey, $27 \%$ of all jobs in the City, which is 423,920 jobs total, were located in the Employment Areas (Toronto City Planning, 2019). While employment land shrunk nearly $10 \%$ from 8,941 hectares to 8,063 hectares between 2006 and 2018 (Dingman, 2018), and there is a popular misconception that need for industrial zoning is diminishing, the 2019 Growth Plan forecasts that Employment will grow to $1,720,000$ jobs by 2041 (Toronto City Planning, 2019). In addition, the average rate of growth between 2014 and 2019 was $2.5 \%$, and if that trend continues Toronto will reach the forecast set out by the Growth Plan between 2023 and 2025, which is at least 16 years early (Toronto City Planning, 2019). This demonstrates the risk and negative impact land conversion has and will continue to have on industry, and the conflict between industrial land and more sensitive areas can result in "employment loss and erosion of available areas for business

formation and expansion" (Toronto City Planning, 2019, p. 23). It also suggests that even if land is preserved, the growth trends with outpace the existing land stock, and alternative measures such as industrial intensification will become increasingly necessary. 


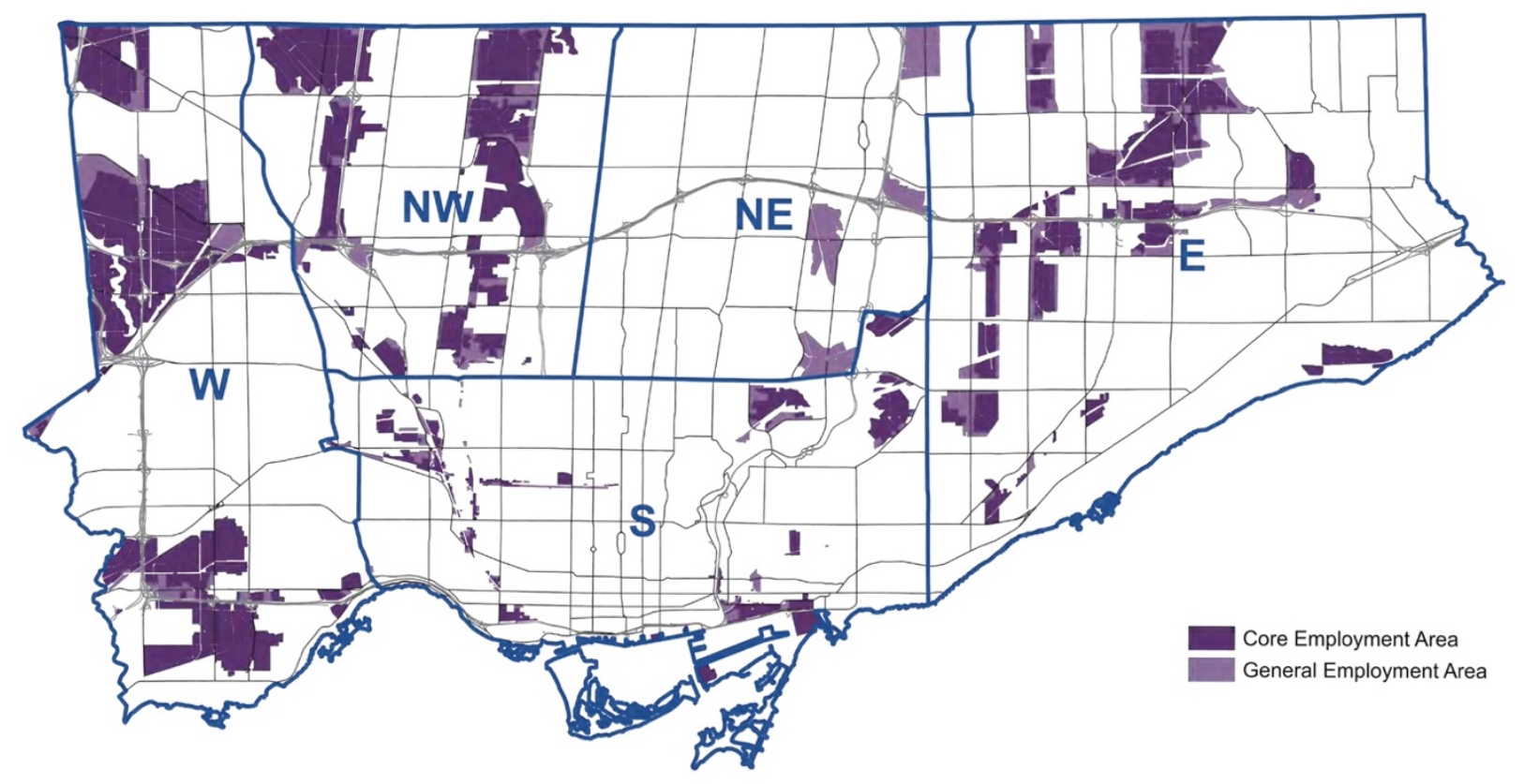

Figure 20 Toronto's Employment Areas and Employment Monitoring Areas (Toronto City Planning, 2019).

There has been effort in the past decade to slow down the degradation of these vulnerable sectors. In 2013, the City of Toronto implemented Official Plan Amendment (OPA) 231 during the Official Plan Review. It shifted use of the term "industrial" to "employment". This created General Employment Areas and Core Employment Areas, and in doing so primarily reserves Core Employment Areas for manufacturing, warehousing/distribution, transportation, research and development and utilities, and restricting retail activity and restaurants. The City states that both of these areas will "have great potential for additional employment growth through the incubation of new business, the nurturing of small business to become large business, attracting new and expanding employment clusters, and intensifying the form of development in our employment lands" (City of Toronto, 2013, p.8). This indicates a clear policy directive for the growth of employment, and supporting adding growth and enhancing the diversity of use in employment neighbourhoods such as Geary Avenue.

\section{Background}

Geary Avenue is an employment area in the Davenport neighbourhood of Toronto, Ontario. It was once predominantly home to industrial warehouse space and automotive use, a 
result of early settlement patterns and the impact of rail. The first passenger train ever to run through Ontario was established in the 1850s, and the Davenport Station on the Northern Railway was built in 1857 at the intersection of what now is Caledonia Park Road and Davenport Road. Prior to the 1880s the Davenport neighbourhood was "heavily treed and dotted with a small farming and market gardening community of homesteads" (Fudge, June 2019). With the addition of more rail lines, Davenport Village experienced significant growth and in 1886 the Dovercourt Land Building and Savings Company divided the land south of Davenport Road into 23 building lots which would become North Dovercourt, and other neighbouring subdivisions followed suit (Byers \& Myrvold, 2008). This residential neighbourhood was just north of Arlington Avenue which was laid out in 1885, and Main Street in 1887 by different developers. These two streets would become Geary Avenue in 1910 when the area was annexed to Toronto (Byers \& Myrvold, 2008).

The neighbourhood subdivisions were marketed to the working class who were moving to the area for work as industrial sectors grew in the early 1900s. As an outlying area, the land was cheaper and building restrictions and permits were non-existent allowing for self building. A reporter in 1907 "noted it was without plan, the streets were unpaved, uncurbed, and without ditches, and that no two shacks were alike, rather each had its own personality." (Byers \& Myrvold, 2008, p.52). Overtime significant post-industrial redevelopment saw the neighbourhood gentrify into a more expensive residential neighbourhood, however pockets of manufacturing, like Geary, still dot the neighbourhood (Fudge, June 2019). Geary Avenue has transformed in recent years and now has an eclectic mix of light industrial uses, creative enterprises or 'maker spaces', food production, restaurants, cultural and arts organizations, recording studies, small commercial businesses and more. For these reasons and more, Geary Avenue has been a successful, albeit best kept secret of Toronto. Part of its success comes from the at times, random and "unplanned" moments throughout its history that has led to the diverse neighbourhood it is today. The key issue for Geary Avenue is its continued success as a diverse 
employment hub, as gentrification from residential mixed-use development often displace local businesses that seek affordable rental space in current city building. Without very intentional, careful and creative planning, much of its unplanned character risks becoming undone.

In April 2019, Councillor Ana Bailão requested that the Planning and Housing Committee initiate a comprehensive study of the Geary Avenue corridor. This came as a direct result of the pressures that local businesses face with land price, development and growth (Bailão, 2019). The request of a planning study was to inventory current applications and development proposals, existing establishments and permitted land uses, and lastly develop urban design and built form guidelines and land use provisions that promote and enhance non-residential uses (Bailão, 2019). In addition, it requests attention be paid to park and public realm improvements, as well as an economic development study to consult with local businesses to understand challenges and opportunities, and financial or regulatory mechanisms that could be used to "promote the continued arts-based, cultural, light industrial and employment uses in the area" (Bailão, 2019, p.1).

As a result, the planning study Geary Works launched in late 2019. Led by City Planning and Economic Development \& Culture, it seeks to determine "how best to support businesses and creative enterprises on Geary Avenue and improve the public realm" (City of Toronto, 2020a). While the research direction of this MRP aligns with many of the goals set out in Geary Works, it is not intended to produce the same results. Rather, it provides research context and secondary data to understand how intensifying employment land and allowing hybrid-industrial mixed use may be a model for furthering economic viability for this important Toronto neighbourhood.

\section{Site Overview}


Geary Avenue is a 1.2 kilometer east-west arterial that is just north of Dupont Street, between Ossington Avenue to just past Dufferin Avenue. A rail corridor runs parallel past the land parcels on the southern side of the street.

\section{Official Plan Review}

The majority of Geary Avenue is designated as Core Employment. Allowable uses include all types of manufacturing, processing, warehousing, wholesaling, distribution, storage, transportation facilities, vehicle repair and services, utilities, and waste management systems. Additional conditional uses include parks, small-scale restaurants, catering facilities, and smallscale service uses such as courier services, banks and copy shops. Small scale retail uses that are ancillary to and on the same lot as the principal use are also permitted. The goals of development here are to contribute to the creation of competitive, attractive, highly functional Employment Areas predominantly by supporting and protecting employment uses, and contributing to a high quality public realm. In addition, negative impacts that may come from industrial activity should be mitigated, and adequate parking should be provided (City of Toronto, 2019d).

There are currently two parks in the neighbourhood, Geary Avenue Parkette and Bartlett Parkette. Parcel 17ABC and Parcel 18A are designated as Utility Corridors, and are part of a currently in-use electric transmission corridor. Following policy which supports secondary uses such as parks, pedestrian and bike trails, parking and public facilities, Parcel 17BC, and Parcel $18 \mathrm{~A}$ will be turned into new parks as part of major streetscape improvements along Geary Avenue. This is part of the larger project, the Green Line park system, which is transforming the greater corridor into 5-kilometer-long park and open space (City of Toronto, 2019b). Parcel 17A still has demand as a parking lot, so the Green Line will move to the right-of-way for on-street connection along Geary Ave (City of Toronto, 2019b). 


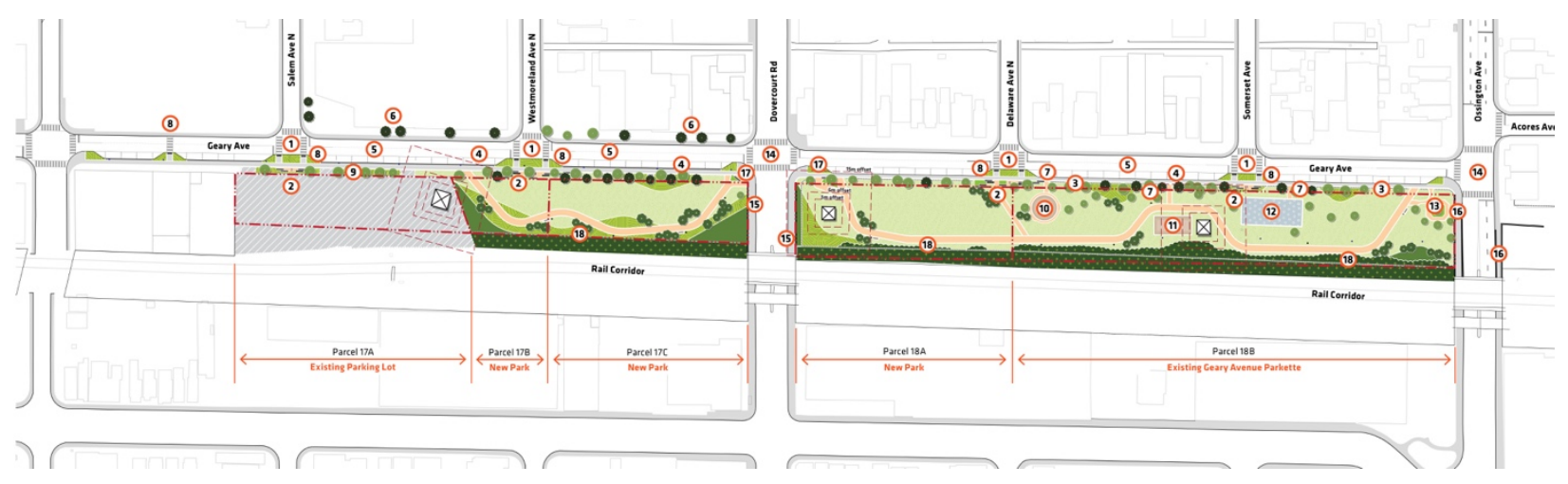

Figure 21 Character Area 3.0 / Geary Davenport Park, The Green Line (City of Toronto, 2019b).

Area specific policy \#154, which applies to the north side of Geary Avenue between Dovercourt Road and Ossington Avenue, allows for a conditional mix of employment and residential uses. As they are in Employment Areas, these properties along Geary must provide "for a satisfactory living environment compatible with the employment uses in the building and adjacent area" (City of Toronto, 2015, p.104). The majority of the rest of Geary Avenue applies to area specific policy \#234, which states that automobile body repair shops are not permitted on lands designated as Employment Areas (City of Toronto, 2015).

\section{Zoning By-Law Review}

Geary Avenue follows the city-wide Zoning By-law 569-2013, and is largely zoned Employment Industrial $(E)$, with a small section of Residential $(R)$ zoning between Dovercourt Road and Ossington Avenue. In this same block, there are a few properties on the north side that are still covered by former City of Toronto Zoning By-Law 438-86 and are designated Industrial (I1 D2), which does not permit office uses. The heights along Geary Avenue range from 12 to 18 meters. The as of right density for Employment Industrial allows for a Floor Space Index of 2.0, and the Residential a Floor Space Index of 0.6 (Map Your Property, 2020).

Notable outright permissible uses in the $\mathrm{E}$ zone include artist studios, all manufacturing uses except heavy industry, offices, performing arts studios, production studios, and wholesaling use. Conditional uses include eating establishments, take-out eating and retail 
service, all of which must not exceed greater than 300 square meters, or $10 \%$ of the gross floor area of the buildings on the lot to a maximum of 500 meters (By-law 569-2013, 2013b). A retail store is also conditionally allowed; it must be associated with a manufacturing use, not take up more than $20 \%$ of the interior floor area, and the two uses must be separated by a wall (By-law $569-2013,2013 b)$ These conditional measures regulate the size of allowable commercial uses in an attempt to curb loss of production, distribution, repair jobs while still providing flexibility.

\section{$\underline{\text { Recent and Proposed Development }}$}

For the purpose of this research, the following section presents an overview of the immediate neighbourhood near the study area to gain an understanding of local context and greater development trend implications. The development activity and proposals along Geary Avenue itself and the nearby Dupont Street corridor are indicators of the changes occurring in the neighbourhood, and what sort of impact development may have on Geary's future. While no mixed-use development is permitted outside of an MCR designation, there have been appeals to OPA 231 in the area and rezoning applications, in order to allow mixed-use.

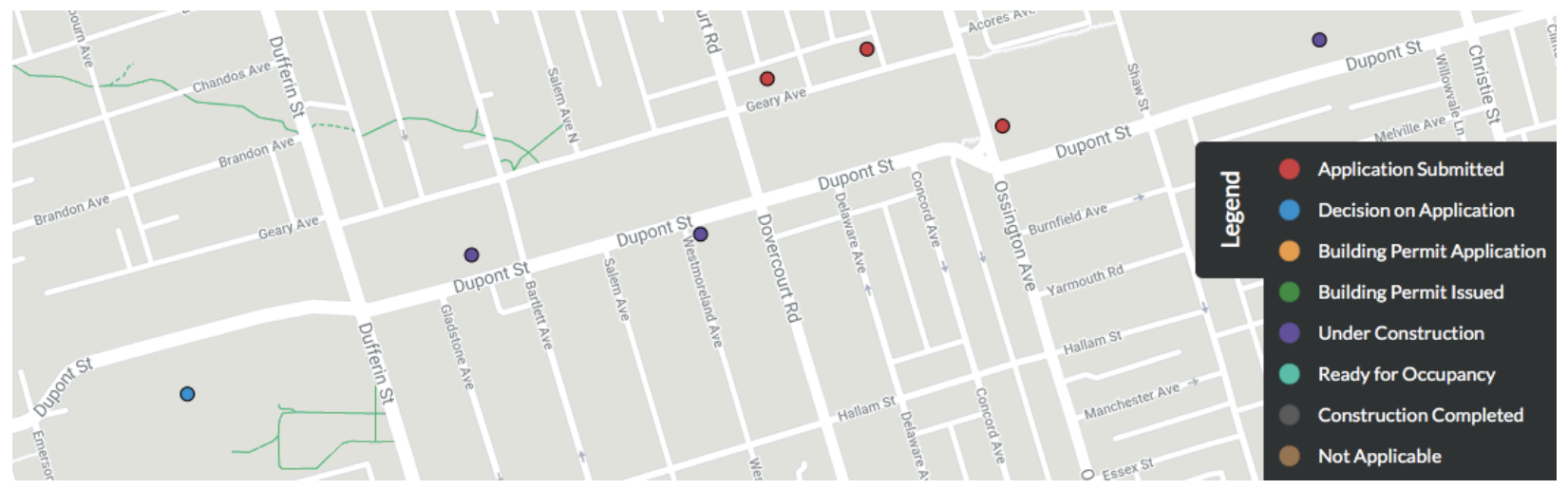

Figure 22 Geary Avenue and Dupont Street Development Tracking, 2014-2020 (Map Your Property, 2020).

22 Geary Avenue, the site of a single storey auto service shop, is the only current active application on the street. A site plan approval proposal was submitted in late 2017 for a new four-storey office building with commercial space at street level, and the site is still zoned under former Zoning By-law 438-86. Of note, the Parking Study indicates that it would construct four 
boulevard parking spaces, which is nine less than the by-law minimum parking supply rates. However, the reduction is justified "given the proper access to transit, cycling and pedestrian networks under existing and future conditions" (LEA Consulting Ltd, 2017, p.15). Addressing issues of the public realm, the report notes that the current "disorganized depot of vehicles has caused undesirable street view" (LEA Consulting Ltd, 2017, p.3). This is indicative of the transition Geary Avenue is experiencing. Businesses that create 'nuisance' are deemed as less desirable, and emphasis is placed on the opportunities for facilitating a more enjoyable pedestrian realm that focuses on the street's location in relation to downtown and higher-order transit.
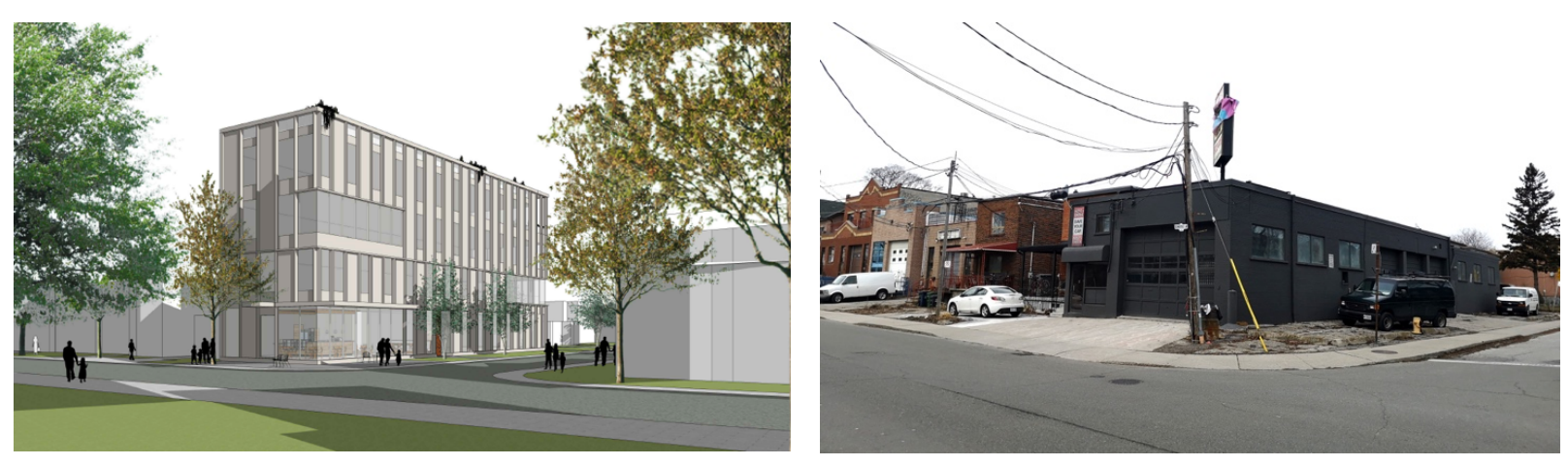

Figure 23 (left) Rendering of 22 Geary (RAW Design, 2018).

Figure 24 (right) 22 Geary existing use. (2020).

This scale of development, albeit small comparative to many nearby applications, is largely unprecedented on Geary Avenue. There is currently no property zoned for office, nor do many buildings exceed two storeys. While the application seeks to add employment, it does not consider the opportunity for PDR functions on the ground floor. By contrast, a development proposal in 2015 for 62 Geary Avenue, currently the location of a one-level industrial building, proposed a 3-storey mixed-use building including industrial space on the ground level and 7 residential units above. It was ultimately unsuccessful, however residential use could be considered appropriate at this site as it is in the block between Dovercourt and Ossington where there is scattered residential use. 
There is one active Official Plan \& By-law Amendment application at 888 Dupont Street by developer TAS Design Build. The site is currently a four-storey industrial loft building that is home to 30 commercial tenants, photographers, fashion designers and jewelers (McLean, February 2019). The proposal includes a 13-storey, 55-metre mixed-use building comprising of 99 residential live-work units, which includes 13 affordable dwelling units, $7256 \mathrm{~m}^{2}$ of nonresidential floor area, which includes urban agriculture, retail, commercial and restaurant, and dedicates a small portion abutting the rail line to light industrial activity (Appia, February 2020). Similar to Geary Avenue, Dupont has traditionally been the location of many affordable studio spaces, however redevelopment is causing the disappearance of this community.

The developer of 888 Dupont Street has cited that the intention is to create "the most diverse mixed-use building in the City of Toronto" (Appia, February February 2020). It is unlikely the existing built form and proximity to low-rise residential would ever justify a similar scale of development on Geary Avenue, however the pressure of highest and best use could result on property value increase throughout the neighbourhood. In addition, the example of 888 Dupont Street calls into question the scalability of the mixed-use output, and whether there is financial feasibility to create such a high mix of non-residential uses without the leverage of market rate condominium or rental. An opportunity if this development is approved and sets a precedent, is for TAS Design Build to develop 259 Geary Avenue, which they recently purchased. Currently a big-box store building, it will likely result in a redevelopment application in the future. Given the large site, it could be the optimal location for higher-density mixed-use, combining a mixture of PDR, office and residential functions. Furthermore, it could draw in similar characteristic elements of 888 Dupont Street to tie the neighbourhoods together. 

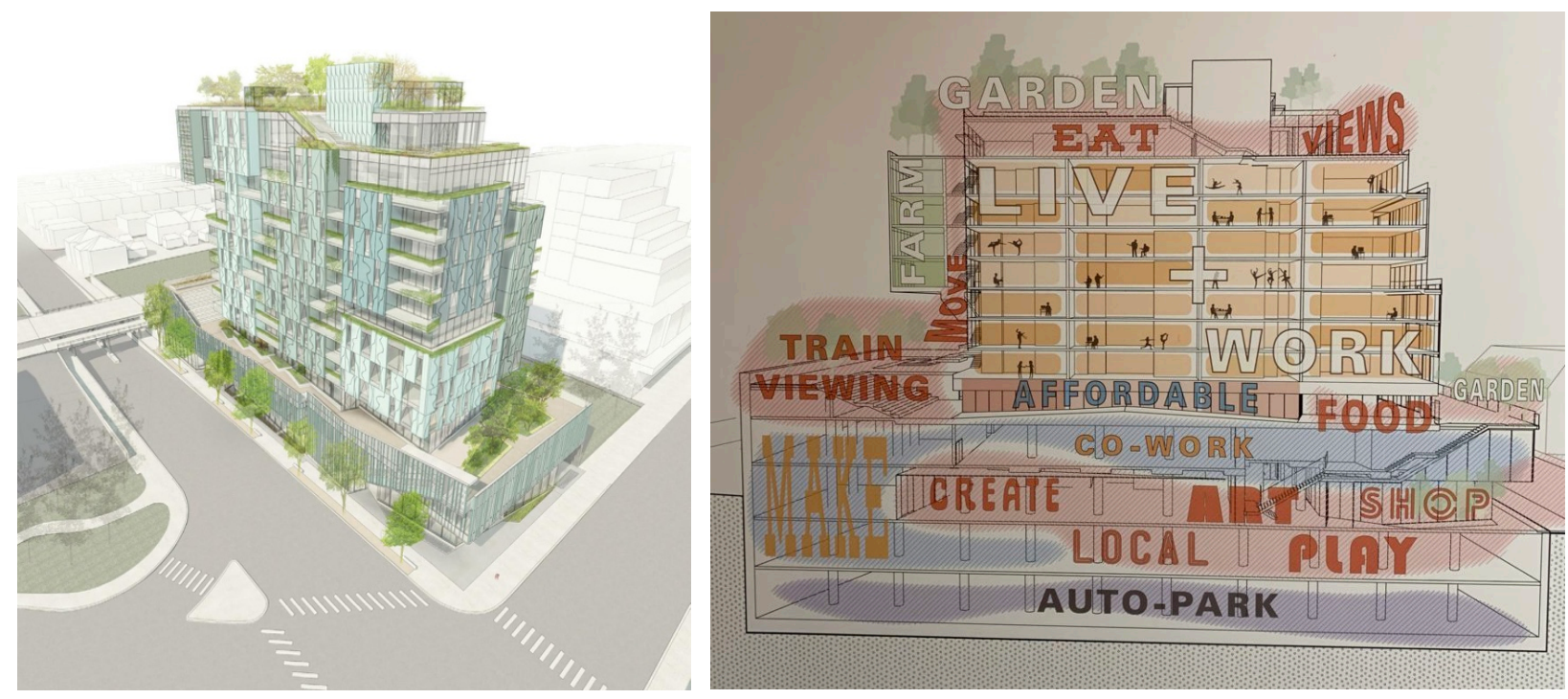

Figure 25 (left) Aerial view of 888 Dupont Street looking northeast (TAS LLP \& Suulin Architects Inc, 2019).

Figure 26 (right) Illustrated mix of uses for 888 Dupont Street. (TAS LLP \& Suulin Architects Inc, 2019).

Current projects under construction or recently completed along Dupont Street further highlight the change occurring in the surrounding neighbourhood. 740 Dupont Street received Notice of Approval Conditions (NOAC) in 2018. A two-storey retail podium with a 9 storey midrise residential will replace an existing one storey auto dealership (City of Toronto, 2020c). This site is on Employment Area property, and does not allocate PDR use. The current block that contains Galleria Mall and and Wallace Emerson Community Centre is zoned CommercialResidential and Open Space. An application is seeking Site Plan and Subdivision Approval to create a new street and block configuration which includes a new community centre, park space, and 8 mixed-use residential towers. This block is not industrially zoned, and the scale of development is not transferable to Geary, however the change it will bring to the surrounding neighbourhood could greatly affect the way future development occurs.

\section{$\underline{\text { Opportunities and Constraints }}$}

The following section is a physical assessment of Geary Avenue to highlight opportunities and constraints that will influence final recommendations. On the north side, the general built form consists of one or two storey flat roof industrial buildings, characterized by 
high ground floors, garage doors, and an inconsistent street wall and setback from the street. The south side features parks and open space, and a more consistent built form and massing. A current overall constraint is that the study area is fragmented and reduces pedestrian access, largely due to the wide intersections that divide it into three distinct sub-areas. This issue is exacerbated by a lack of public realm amenities, such as consistent wide sidewalks, street furniture and greenery, and adequate lighting. An opportunity for further traffic calming measures and right-of-way improvements would improve circulation across the entirety of the study area, improve the safety, and add to the overall look and feel of the neighbourhood. Further analysis is provided based on the three distinct sub-areas in between these intersections:

Ossington Ave to Dovercourt Rd

A unique feature of this sub-area are the 14 single and semi-detached residential units dispersed between industrial development, which currently includes auto repair, glass and metal manufacturing, and a dog daycare. A constraint of the narrow lots and mixed built form is a lack of visual continuity, as well as fewer uses that activate the street or give customers a reason to spend time there. There is an opportunity for higher density mixed-use, and there is precedent from the current residential and industrial uses existing side-by-side. Future redevelopment could provide a consistent, enclosed streetwall and public realm improvements, including patio designation for commercial tenants. Other opportunities include circulation and connectivity improvements with the underutilized laneway that is parallel to the north side of the street, and overall design and public realm improvements in Geary Avenue Parkette on the south side of the street.

Dovercourt Rd to Dufferin St.

As the centre of the Avenue with the most employment use, this is the most activated sub-area. It is characterized by some of the new types of uses that have become local 
attractions, including Blood Brothers Brewing and the restaurant Parallel. The built form is larger and more consistent, including the block-long Artisan factory, 165 Geary Avenue which has historic significance, and the business park block between Bartlett Ave and Dufferin St. Due to the intensive use of both PDR and commercial, there is a constraint in the lack of available parking, with many cars parking on the sidewalk or filling up driveways that creates an unsafe and unattractive built environment. There is opportunity in the adaptive reuse of the larger business blocks, whether for heritage feature preservation or for adding additional density to. In particular, the building and massing to the south is set back further from the street than the north side and has potential for future improvements for both pedestrian and employee use. There are "missing teeth" in the parks and open space network, and there is opportunity for improvement with the Green Line plan, and for new development or reuse on the private parking lot under the hydro corridor. Bartlett Parkette has opportunity as a central feature for the study area, and could be reimagined as a public square with more diverse features.

\section{West of Dufferin St.}

The quietest and most removed sub-area, this part of Geary Avenue receives very little foot traffic, with the main draw currently being The Brick situated on the corner of Dufferin St. Other current uses include auto shops, recording studios, and occasional event space. There is also a newer townhouse development on Grogan Mews. Ending in a cul-de-sac, a constraint of this sub-area is effective vehicle and pedestrian circulation. The lack of designated parking, sidewalks and parks or open space further discourages use. The largest opportunity is future redevelopment or adaptive reuse of the The Brick site, and could provide for a high mix of PDR, commercial, residential and office use, and new open space from development benefit charges. With a perceivably higher ratio of incompatible uses, there is opportunity to emphasize intensification of PDR and office in this sub-area. 


\section{Public Consultation}

In order to better understand what measures could be taken to maintain and improve the eclectic employment of Geary Avenue, as well as promote PDR uses and understand the feasibility of mixing uses, it is imperative to review public and stakeholder input. Geary Works held its first meeting with local stakeholders on December 4, 2019 and a consultation with approximately 100 members of the local community on January 28, 2020 (City of Toronto, 2019c; City of Toronto, 2020b). A summary of each was published on the Geary Works website. In addition, two online-surveys ran from December until February 2020 but that feedback summary is not yet publicly available and is not included in this report. I was not in attendance at either meeting, and in repurposing and highlighting feedback published by the City of Toronto do not claim accuracy of events that occurred, nor that my highlights represent the entirety of either discussion. In addition, the feedback given at the public meeting is by no means representative of the entire neighbourhood or city at-large, but it is a helpful tool to parse out themes around the strengths, challenges and opportunities of Geary Avenue. Major themes include: land use, building typology, affordability, urban design and public realm, and parking. The following is a summary of the published City of Toronto feedback.

\section{Table 1 Geary Works Planning Study Stakeholder Feedback}

\begin{tabular}{|c|c|c|}
\hline Theme & Factors & Comments \\
\hline \multirow{3}{*}{ Land Use } & Strength & $\begin{array}{l}\text { - Mix of small-scale industrial and commercial uses } \\
\text { - Creative entrepreneurial community } \\
\text { - Available industrial space that is close to downtown, people's homes, and public } \\
\text { transportation } \\
\text { - Generally no issue with the uses and entities of Geary }\end{array}$ \\
\hline & Challenge & $\begin{array}{l}\text { - Existing zoning restrictions } \\
\text { - Minor variance and rezoning processing time, uncertainty of approval } \\
\text { - Mixed opinion on event venues (some participants feel it conflicts with existing } \\
\text { residential use) }\end{array}$ \\
\hline & Opportunity & $\begin{array}{l}\text { - Non-residential uses would benefit business operations (such as restaurant and } \\
\text { office use, which is currently limited in the by-law) }\end{array}$ \\
\hline
\end{tabular}




\begin{tabular}{|c|c|c|}
\hline & & $\begin{array}{l}\text { - Interest in live-work units, but important to define in policy and suggested that } \\
\text { character areas would be useful method to define where residential capacity } \\
\text { would be appropriate } \\
\text { - Explore flexible zoning; participants suggested } 20 \% \text { ancillary use is too low and a } \\
50 / 50 \text { split would allow for more retail and restaurants } \\
\text { - Provisions needed for a vibrant mix that includes creative industry } \\
\text { - Increase density, ensure change is facilitated but not over planned } \\
\text { - Allow more uses in general, but limit certain uses to a percentage of properties on } \\
\text { Geary or the Gross Floor Area of a building }\end{array}$ \\
\hline \multirow[b]{3}{*}{$\begin{array}{l}\text { Building } \\
\text { Typology }\end{array}$} & Strength & $\begin{array}{l}\text { - Raw, open concept spaces with high ceilings } \\
\text { - Flexible space for small scale manufacturing, food production and commercial } \\
\text { tenants }\end{array}$ \\
\hline & Challenge & $\begin{array}{l}\text { - Insufficient space for tenant expansion } \\
\text { - Not enough small scale units for new uses, including PDR }\end{array}$ \\
\hline & Opportunity & $\begin{array}{l}\text { - Allow for larger buildings with flexible space to accommodate growth } \\
\text { - Participants generally didn't mind if development included } 3 \text { to } 5 \text { floors, or the } \\
\text { provision of some } 6 \text { to } 8 \text { floor development } \\
\text { - Remove requirement for floor to ceiling wall to separate ancillary use to make } \\
\text { floor plans more flexible }\end{array}$ \\
\hline \multirow{2}{*}{ Affordability } & Challenge & $\begin{array}{l}\text { - Originally drawn to Geary for affordable rent, but noted that it has gotten less } \\
\text { affordable and stability is needed }\end{array}$ \\
\hline & Opportunity & - Research rent subsidy programs run by the city \\
\hline \multirow[b]{2}{*}{$\begin{array}{l}\text { Urban Design } \\
\text { \& Public } \\
\text { Realm }\end{array}$} & Challenge & $\begin{array}{l}\text { - Geary Avenue is an undesirable location for customers to visit } \\
\text { - Traffic hazards, poor lighting at night, status quo as a rough area (one participant } \\
\text { said the area attracts users, not customers) }\end{array}$ \\
\hline & Opportunity & $\begin{array}{l}\text { - Widen sidewalks, add street trees and bike lanes, and include traffic calming } \\
\text { measures with safer pedestrian crossings } \\
\text { - Many public realm concerns are addressed in Green Line Plan } \\
\text { - Amend by-laws to provide for more patios, providing it doesn't impede parking } \\
\text { and delivery, and rooftop space } \\
\text { - Participants interested in sense of community identity; suggested neighbourhood } \\
\text { branding, more public art such as wall murals }\end{array}$ \\
\hline \multirow{2}{*}{$\begin{array}{l}\text { Parking \& } \\
\text { Loading }\end{array}$} & Challenge & $\begin{array}{l}\text { Parking is a major concern, one participant said properties along Geary are too } \\
\text { small to provide on-site parking, and curb cuts would require the removal of } \\
\text { remaining on-street parking }\end{array}$ \\
\hline & Opportunity & $\begin{array}{l}\text { - Protect and enhance loading bays } \\
\text { - Leave street parking as is, a public parking lot would be beneficial in the future }\end{array}$ \\
\hline
\end{tabular}

Note: Feedback taken from Stakeholder Meeting \#1 Summary (City of Toronto, 2019c).

Table 2 Geary Works Planning Study Community Member Feedback

\begin{tabular}{|c|c|c|}
\hline Theme & Factors & \multicolumn{1}{|c|}{ Comments } \\
\hline Land Use & Strength & $\begin{array}{l}\text { - Geary works because it's informal } \\
\text { - Participants like that it has a diversity of uses and small town character }\end{array}$ \\
\hline
\end{tabular}




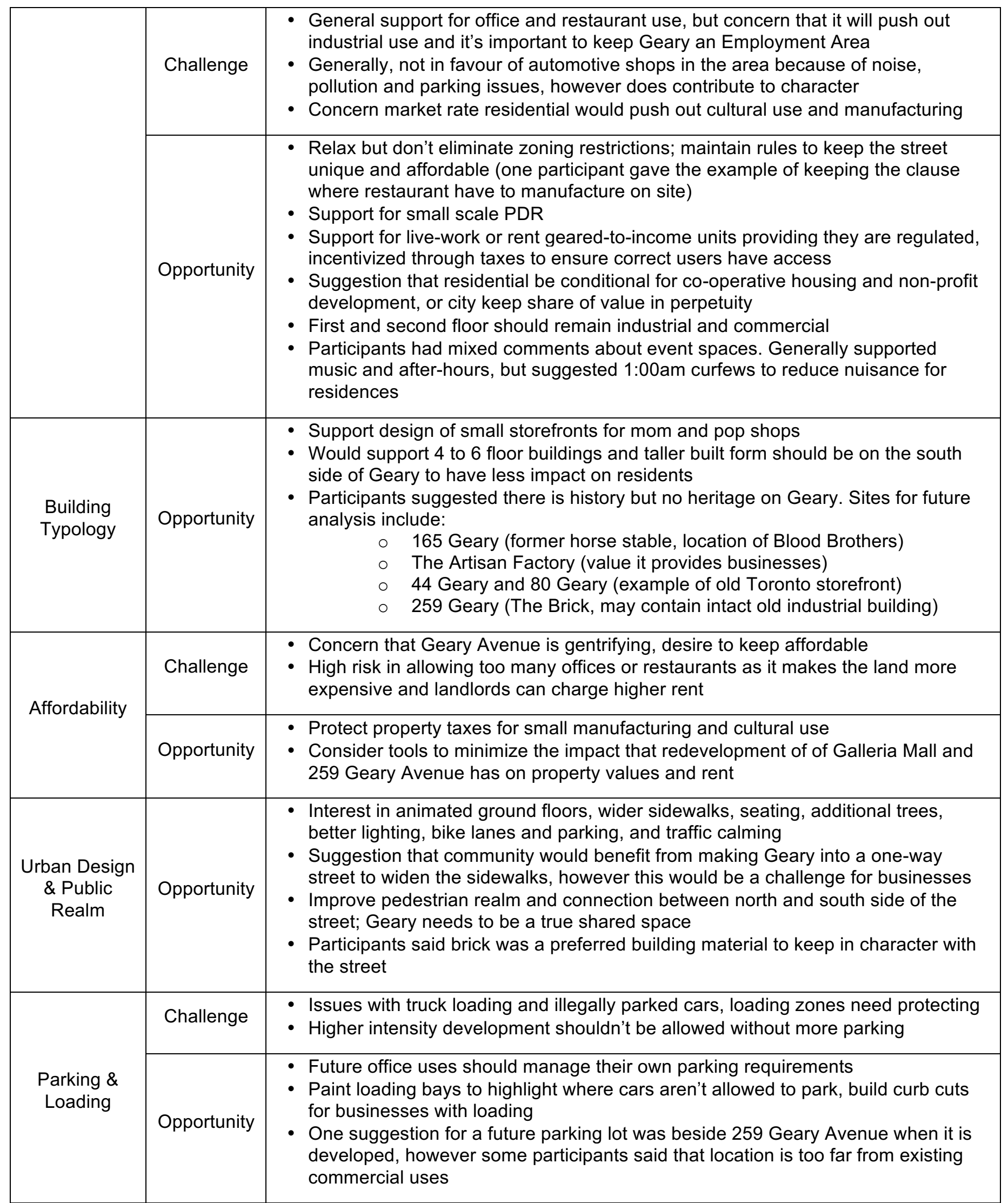

Note: Feedback taken from Community Consultation \#1 Summary (City of Toronto, 2020b) 


\section{Recommendations}

The following is a list of site and area specific recommendations for Geary Avenue. This research initially sought to understand how a mixed-use industrial district could support growth initiatives while also protecting and enhancing economic development of PDR uses. However, these recommendations cover a much broader scope as it has become clear that greater policy and design consideration is necessary if a mixed-industrial typology is to succeed, and if Geary Avenue is to intensify.

\section{Explore the opportunity for future Public Parking on the private lot at the intersection of Salem}

Avenue and Geary Avenue. The leaseholder of this property maintains a private parking lot that is still in demand (City of Toronto, 2019b), but there is opportunity in the future for a multi-storey parking lot to accommodate increased activity on Geary Ave as it grows. This site is in a utility corridor that is mostly owned by the Province of Ontario, so as of right development is limited to Utility and Transportation Zone (UT) zoning, and Public Parking is permitted under the condition that it be developed in association with a transportation use or a park (By-law 569-2013, 2013c). The existing site is large, so it is recommended that it be severed to allow for the Green Line to extend further west where new sections of the park are already expected to be completed in the next three years (City of Toronto, 2019b). Parking has been an issue for residents and businesses alike, with many stakeholders saying intensification on Geary can't occur until parking is addressed (City of Toronto, 2020b). Community members had suggested looking into 259 Geary Ave as a potential site, but others indicated it was too far from the majority of existing businesses. The benefit of the proposed scenario is twofold: it lessens the impact of "missing teeth", allowing for a more continuous pedestrian experience on the Green Line, and it provides the neighbourhood with central parking. Street parking on Geary could be removed altogether, which would benefit intended ROW improvements, allowing for widened sidewalks and provision of a bike lane. Collaboration with the Toronto Parking Authority would ensure that the long-term strategy for parking is addressed, in validating business and patron concern that more parking is needed in the area, but also to plan for a future that relies less on personal automobile use. Future consideration should be given to the policy initiatives outlined in Strategic Outlook: Enabling Mobility for the Next 21 Years, in particular exploring parking taxes to reduce congestion and generate revenue, and the allocation of space for care sharing and bicycle parking (Toronto Parking Authority, 2011).

The parking lot is suggested to be three or four storeys, in keeping with the permitted 18 metre height and scale of the neighbourhood. Future retrofitting should be a design consideration to allow for PDR or commercial use. Although above ground parking lots are often deemed as an outdated land use, building underground is more expensive and the current needs of the community need to be met with the assumption that in the future, alternative transportation methods will be in higher demand and would allow for the parking function to be fazed out. As seen in both San Francisco Case Study and the development 
application for 22 Geary Avenue, developers are making parking proposals that are below the minimum municipal requirement, in favour of promoting alternative modes of transportation. This includes the provision of bicycle racks or transit passes for employees, and the creation of a Transportation Demand Management Program to mitigate traffic issues.

If a ZBA is approved for the site, commercial or PDR could be included at ground level fronting Geary with interesting façade treatment above to increase employment and improve the public realm, as seen in Kensington Market and Detroit, MI examples [Figure 28 and 29]. Similarly, a rooftop park could be designed like the recently completed Ketcheson Park in Richmond, BC. This would be an opportunity to visually connect the Green Line, and would be a unique public space for locals and visitors. It could also be a chance to integrate the history of the adjacent rail line, as an elevated park would act as a train viewing platform (similar to the design feature proposed at 888 Dupont Street) and could take design inspiration from other elevated public space networks, such as the New York High Line.

The challenge of this proposal would be financing the project. The City could use the public parking lot as leverage to waive parking requirements for new development along Geary Avenue, instead asking developers for cash in lieu that could be put towards financing the parking lot. A second challenge would be receiving approval to build a multi-storey building as it is in a hydro corridor, and activities under high tension wires is generally discouraged (Warren, October 2015). However, as the hydro line diverts northwest towards Bartlett Park the parking lot could be bypassed altogether [Figure 27].

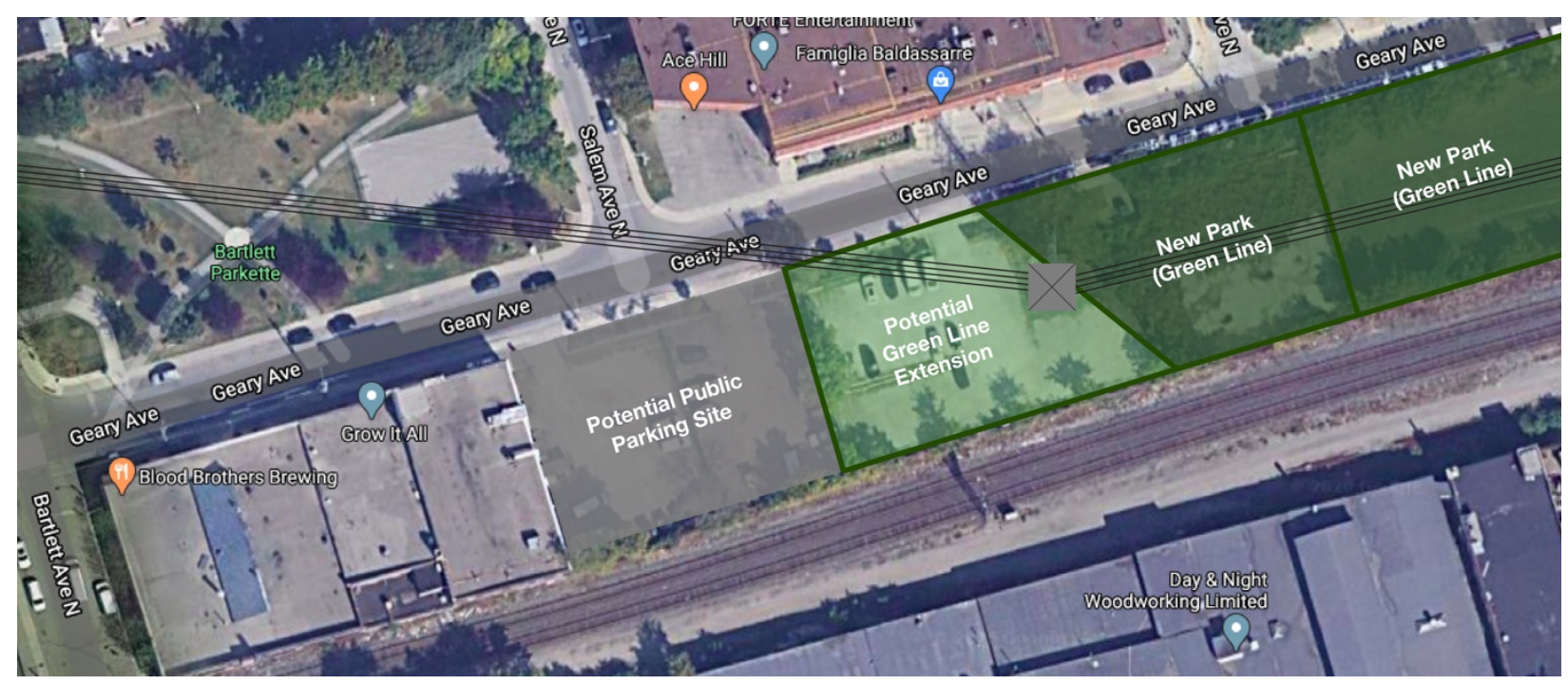

Figure 27 Conceptualization of a future public parking lot and Green Line extension (Base map: Google Maps, 2020) 

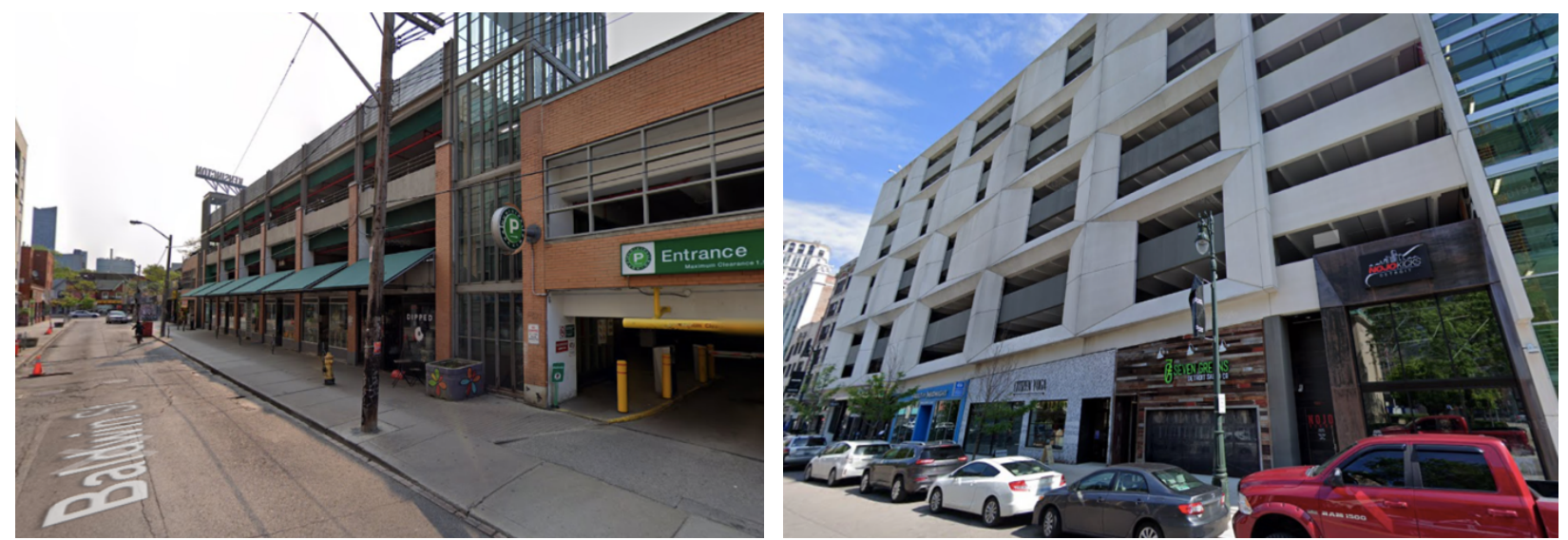

Figure 28 (left) Kensington Market Parking Lot with retail at-grade (Google Maps, 2020).

Figure 29 (right) Detroit parking lot with retail at-grade.

Widen the laneway between Westmoreland Avenue and Somerset Avenue to maximize pedestrian and vehicle circulation, and aid in the conflict mitigation between Geary Avenue intensification and the residential neighbourhood. Official Plan Policy 2.2.3.c) requires the City of Toronto to acquire land to widen public lanes over time. For industrial lands, at least six metres is required (City of Toronto, 2019f). An easement should be taken from lots redeveloped on Geary Avenue. In doing so, it offers benefit to both the public realm and the residential properties to the rear of the site. Since parking, access to loading bays and the pedestrian thoroughfare are common challenges on Geary Ave (City of Toronto, $2020 \mathrm{~b}$ ) this would allow loading functions to be moved to the rear of the building and clear up the main road for ROW improvements, such as wider sidewalks and a more activated street front. Extra unallocated space would allow for privacy landscaping between the residential buildings and the laneway, to both minimize disturbance and make the lane an inviting space. Orienting the bulk of other activity fronting Geary minimizes the overlooking of residential yard space. A challenge is that significant easements would reduce the development potential, and completely eradicate opportunity for adaptive reuse of the buildings that have a zero lot line with the current laneway conditions. 


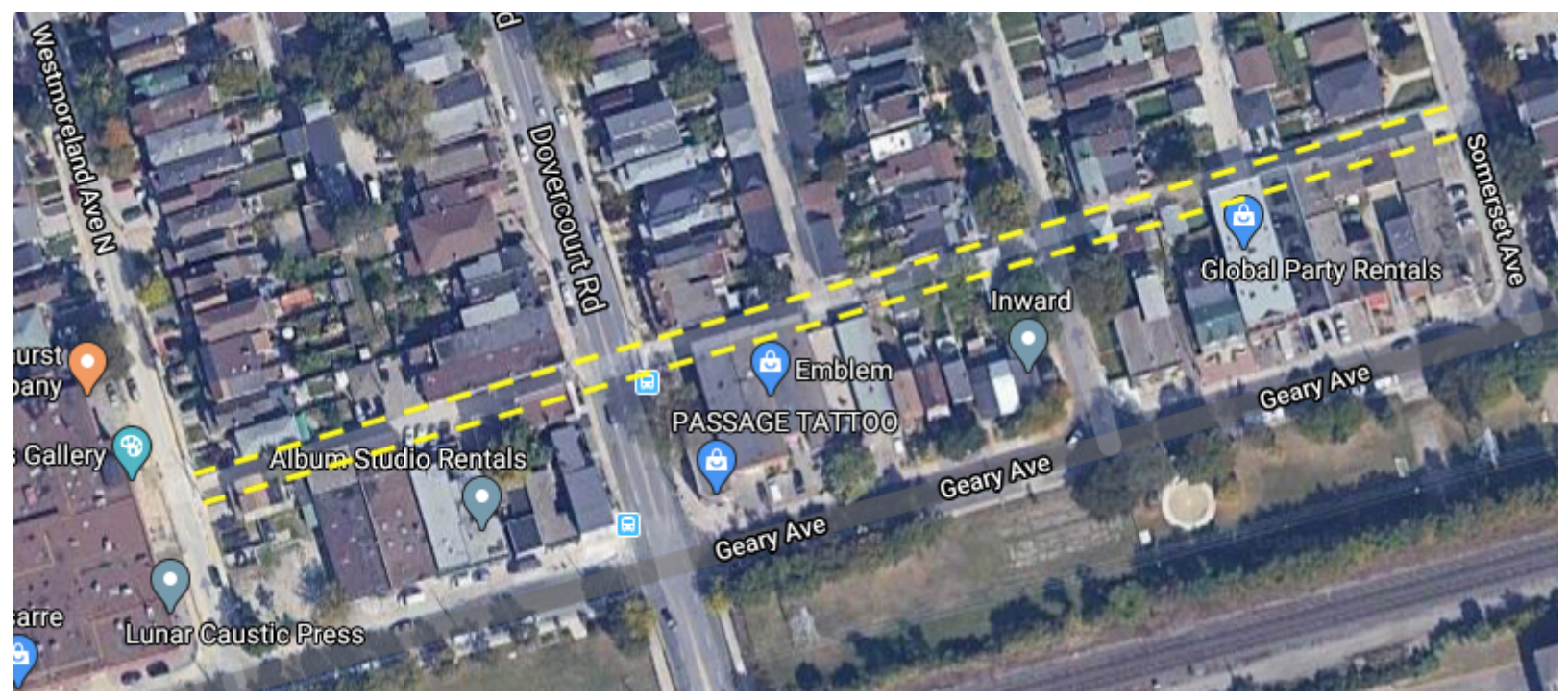

Figure 30 Aerial of laneway (Base map: Google Maps, 2020).
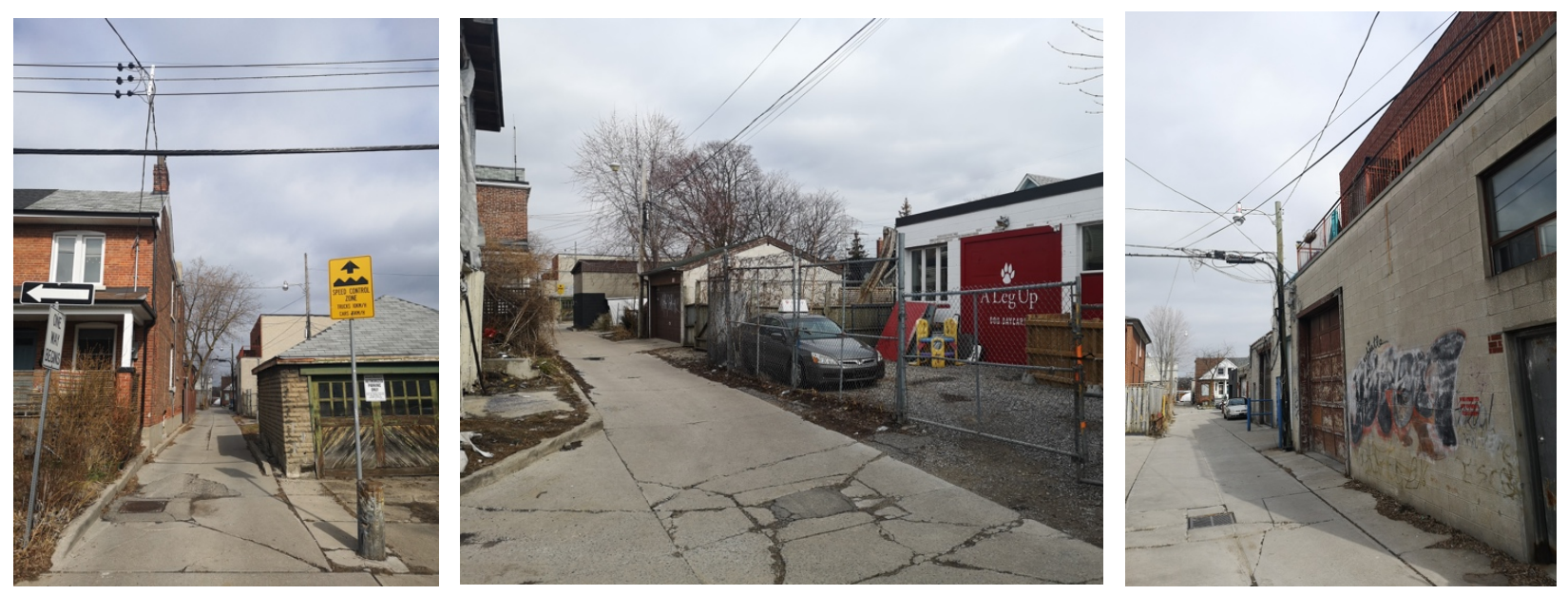

Figure 31, 32, and 33 (left to right) Photos of existing conditions in laneway.

Designate the eastern portion of Geary Avenue between Dovercourt Road and Ossington Avenue as a character area and allow for mixed-use development that combines residential and light

industrial use. As this portion of Geary Avenue has scattered properties in pre-existing $R$ zone, it is the most eligible candidate for future integration of residential capacity. Based on local feedback and concern about gentrification, it is recommended that residential use be limited to live-work units and affordable rental. Properties should not exceed existing height zoned to 12 metres, which allows for three to four storeys. An additional storey, for a total of five, may be allowed conditionally, providing that at least half of that added density be allocated for affordable rental housing. This proposed height aims to limit shadow impact to the open spaces of the directly adjacent residential units to the north. As an east-west arterial, wide massing on Geary Avenue could potentially cast long shadows. Therefore, it is best that higher intensity development be kept to the south-side of the street, to allow for a more appropriate transition to low rise communities to the north and make use of appropriate setbacks and angular plane. The first two 
storeys of any development should be preserved for Core Employment use, in keeping with the integrity and character of the neighbourhood. Although the performance standards of the City's Avenue and MidRise Buildings does not apply to Geary Avenue, it provides an important jumping off point for site specific urban design policies and regulations. In particular, the streetwall should not exceed three storeys, in keeping with the built form of the area. This will ensure a setback that will mitigate shade impact on the surrounding residences. Furthermore, ground floors should be tall and animated and implement features such as sliding garage doors for continuity with the existing older warehouses on the street.

In keeping with the recommendations from the King-Spadina Cultural Spaces Retention Study, the City of Toronto should work with MPAC to widen the definition of cultural space that is eligible for lower tax rates and expand the list of permitted use in the Creative Co-Location Facilities Property Tax Subclass to include light industrial activity. The Creative Co-Location Facilities Property Tax Subclass "provides property tax relief to qualifying properties housing a cluster of creative enterprises, and incentivizes the provision of below market rent and the retention of affordable spaces for the arts and culture sector" (City of Toronto, 2019e). In July 2018, six properties were designated including the aforementioned 888 Dupont Street, which is now slated for redevelopment. The Subclass reduces commercial and industrial tax rates up to $50 \%$, and sustains affordable space by incentivizing Below Average Market Rent (BAMR) wherein each property must charge BAMR, ranging from $30.1 \%$ to $96 \%$ below average (City of Toronto, 2019e). This ensures that property owners that benefit from the tax benefits pay it forward to the susceptible tenants that rent these spaces, in very similar fashion to the way The Foundry is operated in the San Francisco Case Study. Focusing on the value of net leases instead of highest-and-best-use would promote a more comprehensive protection of Geary Avenue as it intensifies.

While Geary Avenue is not a designated arts and culture centre, it does have a mix of creative uses that has similar affordability and flexible space needs. The King-Spadina Cultural Spaces Retention Study acknowledges that the cultural uses in Toronto's 'Commercial-Residential Employment' (CRE) Zoning Bylaw is narrowly defined, and may leave out many important cultural spaces that are described in more generalized land use terms (R.E. Millward, 2017). For example, while not all encompassing, many bars, clubs, offices and manufacturing uses serve a cultural function but would not be included under the existing zoning. Even then, there is a grey area in terms of manufacturing use, which constitutes a lot of Geary's building stock, as carpenter's furniture manufacturing, metal products, printing and wood product manufacturing, among others, could be interpreted as cultural use (R.E. Millward, 2017). It emphasizes how it can be difficult to delineate use, and that while it might be of interest to apply more generalized land use terms in order to be eligible for grants and tax credits, it can create "unintended loopholes in the Zoning By-Law" (R.E. Millward, 2017, pg.20). It illustrates that applying financial mechanisms to traditional zoning might not be the most effective route to incentivize specific use retention across Geary Avenue. 
Formalize the co-location of small businesses in larger PDR spaces. This tool allows PDR tenants to adapt to rising costs and competing land use, and promotes innovation which strengthens the local economy. An example of a service that already facilitates this sort of work is Places to Make, SFMade's industrial real estate service, which provides a service linking available industrial space with SFMade member companies (City of San Francisco \& SFMade, 2016). An online data base would ensure that companies would be compatible, and could set up the infrastructure for people to work together such as lease agreements for multitenant rentals.

Implement design guidelines in new development that is conducive to flexibility and collaboration. The San Francisco Case Study 100/150 Hooper provides inspiration for the potential design of future space on Geary Avenue. A mandate of Hundred Hooper is to "build a range of well-designed PDR spaces that will provide space for PDR users at all stages of development - to enable PDR tenants to start, grow, and stay." (San Francisco Planning, 2015, p.109). With this in mind, the standalone 150 Hooper has communal spaces on each floor to provide social connection and collaboration, and the ground floor the building is designed to be flexible and have shared common or accessory areas or traditional rental spaces (San Francisco Planning, 2015). This building typology would be best suited to large sites, like 259 Geary Avenue, as assembling existing smaller lots is resource intensive, and threaten existing character.

Examine the feasibility of incorporating a Business Improvement Association on Geary Avenue. BIAs are a catalyst for civic improvement and significant contributors to both local economy and the quality of life of Toronto neighbourhoods (TABIA, 2019). The City of Toronto Economic Development \& Culture Division offer assistance programs to enhance this initiative. Predicated on participant interested in improving Geary Avenue's sense of community identity (City of Toronto, 2019c), a Geary BIA could help to promote neighbourhood branding and cohesion, while also working in the best interest of businesses to support economic development, vitality of PDR users, and promote mixed-use typologies. Furthermore, it could help fill an important funding gap for public realm improvements, such as landscaping and landscaping.

\section{Broaden the zoning ordinance to include classifications similar to Production, Distribution, Repair} (PDR) on Geary Avenue. As defined by San Francisco, PDR helps to differentiate light industry from traditional heavy industry. This would not only help better define the boundary of uses typical to Geary Avenue, it could also streamline the creation of another tax subclass for subsidy or grant purposes. As Geary Avenue is made up of small businesses and artists, light industrial and cultural organizations it is an appropriate use in mixed-use development, and would be a useful classification for the proposed character area in the eastern portion that includes residential uses. As exhibited in the False Creek Flats, creating a greater zoning spectrum for industrial uses allows for more attention to urban design, character sub-areas, and facilitates transition easily between uses. PDR is compatible in this regard, and is also a 
useful term to reduce some of the stigma around industrial uses.

\begin{abstract}
Amend the Toronto Zoning By-law to allow for live-work use on Geary Avenue that includes clear language and conditions to promote affordability and emphasizes productivity. It is clear from both case study analysis and public consultation review that there is an interest and possibility to include housing in the use mix on Geary Avenue. Allocating residential uses in location appropriate spaces along Geary could provide much needed housing for artists and people who work in the area. However, the primary concern is how residential use would impact land value, how it is appropriately regulated, and ensure that it doesn't replace Geary's core function to serve as an employment area. It is clear from this research that most forms of residential should be conditional and only granted upon meeting appropriate industrial requirements.
\end{abstract}

The criticism of the live-work model is that without effective regulation, units digress from their intended purpose and often are solely used as residential. Los Angeles' hybrid-industrial zone follows strict regulations in order to prioritize employment and ensure development provides affordable small units that maximizes productive areas within each unit. The first condition is that all live-work units must meet a minimum of 750 square feet, with $48-50 \%$ of that square footage allocated to work space. Second, in order to ensure PDR space is accounted for, the ordinance requires a minimum provision of 200 square feet per live-work unit and 25 square feet per hotel room be required on site for non-residential productive uses (Brown, 2019). Lastly, the ordinance also allows a density bonus if a development provides a minimum 500 square feet of non-leasable resident production space for manufacturing or gallery use, which is a resident amenity to increase production capacity (Brown, 2019). This is innovative as Los Angeles' model clearly set requirements for size and allowable use is innovative, and could be scalable to the Geary Avenue context.

\title{
Incentivize development to maintain traditional warehouses and other character buildings on
}

Geary Avenue. Although there is no formal heritage designation, multiple sites have been flagged as having potential value. Adaptive reuse is a popular, if not a complex reality in many formerly industrialheavy areas, and much of Geary's identity comes from this built form. While the notion of 'industrial chic' has ramifications around gentrification, the concern over aesthetics on Geary Avenue "illustrat[es] that industrial scenery is a highly valuable trait in contemporary development trends" (Brown, 2019, p.73). Los Angeles' zoning by-law included incentives to encourage reuse of existing buildings by excluding the existing floor area from the FSI calculation. In addition, parallel code is used in order to allow for different maximum FSI depending on the type of construction in an attempt to promote specific development and design standards. This is intended to elevate functionality and "promote compatibility with existing development" (Los Angeles City Planning Commission, 2015) Toronto could model a similar policy to protect Geary's existing built form and incentivizing restoration by allowing developers the benefit of additional storeys. 
The south side of Geary Avenue has been flagged as potential sites for higher density, and incentivizing maintenance of existing building stock may be appropriate, particularly at 165 Geary Avenue, 80 Geary Avenue, and 259 Geary Avenue. If the latter does have a salvageable character building underneath the current facade, additional density could facilitate necessary upgrades to the existing structure. Additional density may be granted if the City deemed that brick, or steel and concrete, as mentioned in the Los Angeles context, would be suitable construction types to best integrate new development into an existing base and enhance the character of the neighbourhood.

\section{Complete a comprehensive review of Geary Avenue's street activation and pedestrian oriented}

design. The changing priorities to making urban industrial neighbourhoods liveable and usable spaces is a unique challenge as historic development of these areas wasn't concerned with creating green spaces or public places (Collette, 2014, in Sprague \& Rantisi, 2019, p.311). In the Los Angeles context, the hybrid-industrial ordinance "has a number of provisions that are intended to enhance the livability of industrial mixed use areas and to ensure that new development is context-sensitive" (Los Angeles City Planning Commission, 2015, p.A-4). The hybrid-industrial ordinance includes maximum building frontage width and mandatory separation between buildings in order to promote pedestrian circulation (Brown, 2019). In addition, the ground floor is reserved for "active" non-residential use such as workshops and production spaces, and requires a minimum $50 \%$ of street facade to have transparent windows or openings (Brown, 2019). Finally, as large blank walls are often a feature of industrial buildings, the ordinance has provisions for murals or a green wall. In the Mile-Ex neighbourhood of Montreal, beautification schemes were implemented to attract 'creative' industries, and create more green space while improving connections to other parts of the city (Sprague \& Rantisi, 2019).

It highlights the potential benefit of how urban design could support a more unified brand or identity of Geary Avenue as an eclectic, creative centre. The public benefit of green and open space further indicates that the street would benefit from as much integration with The Green Line project as possible. With this in mind, public realm improvements are drastically needed on Geary Avenue, and would benefit from sidewalk widening, street trees, and urban activations such as a mural festival. Furthermore, including design provisions that challenge the status quo of industrial development by adding in new sightlines and having diverse, activated at-grade use both improves the feel of the street, but helps to contribute to its brand as a local community hub and location for creative, collaborative production.

\section{Ensure that the functionality of Geary Avenue for truck access and loading bay distribution and} warehousing is protected. Many urban design initiatives are in "direct conflict with the operations of traditional production and distribution uses" (Brown, 2019, p. 73). The intervention of removing loading docks and adding green space has consequences on the vitality of industry (Sprague \& Rantisi, 2019). This is indicative of the challenge Geary Avenue faces with the future potential of having its own form of 
hybrid-industrial zoning, and of what it is currently dealing with in the present day as both a site of production and movement and a popular residential area.

Develop performative measures to ensure compatibility between different uses is met and allow for ongoing evaluation and adjustments. Using the acoustic measurement system outlined in the False Creek Flats Case Study as a guide, adopt regulations in mixed-use development to ensure that co-use is beneficial to all parties involved, and helps to improve livability standards. This should be reviewed periodically, to meet shifting expectations as they arise. Should residential use eventually exist, development should clearly outline a reasonable level of noise and disturbance expectations, as is done in residential areas that are adjacent to night life activities. 


\section{Bibliography}

American Planning Association. (2002). Growing smart legislative guidebook: Model statutes for planning and the management of change. Retrieved from http://www.planning.org/growingsmart/guidebook/print/index.htm

Appia, V. (Feburary 2020). Community expresses several concerns over Dupont development proposal. Toronto.com. Retrieved from: https://www.toronto.com/news-story/9840604community-expresses-several-concerns-over-dupont-development-proposal/

Bailão, A. (April 2019). Re: Initiating a Comprehensive Study of the Geary Ave corridor. Retrieved from: https://www.toronto.ca/legdocs/mmis/2019/ph/bgrd/backgroundfile-132452.pdf

Beasley, L. (2019). Vancouverism. On Point Press.

Berger, S. (2013). Making in America. Cambridge, MA: MIT Press.

Bronstein, Z. (2009). Industry and the smart city. Dissent, 56(3), (pp. 27-34).

Brown, S. S. D. (2019). Hybrid-industrial zoning: a case study in Downtown Los Angeles. (Masters Thesis). Massachusetts Institute of Technology.

Bullen, P. A., \& Love, P. E. D. (2009). Residential regeneration and adaptive reuse: Learning from the experiences of Los Angeles. Structural Survey, 27(5), (pp. 351-360).

Burgess, E. (1967). The Growth of the City: An Introduction to a Research Project. In The City, edited by Robert Park and Ernest Burgess. (pp. 47 -62). Chicago: University of Chicago Press.

Byers, N., Myrvold, B. (2008). St. Clair West in Pictures: A history of the communities of Carlton, Davenport, Earlscourt, and Oakwood. Third Edition. Toronto Public Library: Toronto, Canada. Retrieved from: https://static.torontopubliclibrary.ca/da/pdfs/2483046.pdf

Catungal, J. P., Leslie, D., \& Hii (2009). Geographies of displacement in the creative city: The case of Liberty Village, Toronto. Urban Studies, 46(5-6), (pp. 1095-1114).

Chan, K. (2018). New container-inspired building with 350 homes opens in Vancouver. Daily Hive. Retrieved from: https://dailyhive.com/vancouver/strathcona-village-belcourt-residencevancouver?auto=true

Chapple, K. (2014). The Challenge of Mixing Uses and the Secret Sauce of Urban Industrial Land, in Planning sustainable cities and regions: Towards more equitable development. (pp. 207-222). Routledge.

Chapple, K. (2014). The Highest and Best Use? Urban Industrial Land and Job Creation. Economic Development Quarterly, 28(4), (pp. 300-313).

City of San Francisco \& SFMade (2016). Make to Manufacture: Strengthening the Advanced Manufacturing Sector in San Francisco. Retrieved from:

https://oewd.org/sites/default/files/Documents/Make to Manufacture\%20\%282\%29.pdf 
City of Toronto. (2013). By-law No.231-2013. Retrieved from:

https://www.toronto.ca/legdocs/mmis/2013/pg/bgrd/backgroundfile-63574.pdf

City of Toronto. (2014). Making Space for Culture. Retrieved from:

https://www.toronto.ca/legdocs/mmis/2014/ed/bgrd/backgroundfile-69273.pdf

City of Toronto. (2015). Official Plan. Chapter 7 Site and Area Specific Policies. Retrieved from: https://www.toronto.ca/wp-content/uploads/2017/11/9832-city-planning-official-plan-chapter-7saps.pdf

City of Toronto. (2019a). Stakeholder Consultation Meeting \#1. Geary Works. Retrieved from: https://www.toronto.ca/wp-content/uploads/2019/12/92b4-CityPlanning-GearyWorks-

Stakeholder-Presentation-Nov-27-19.pdf

City of Toronto. (2019b). The Green Line: Implementation Plan Summary Report. Retrieved from: https://www.toronto.ca/wp-content/uploads/2019/07/89a2-Green-

Line Implementation Report 2019-07-25.pdf

City of Toronto. (2019c). Stakeholder Comments - December 4, 2019. Geary Works. Retrieved from: https://www.toronto.ca/wp-content/uploads/2019/12/8d7a-CityPlanning-GearyWorksStakeholder-Comments-Summary-Dec-4-19.pdf

City of Toronto. (2019d). Official Plan. 4.6 Employment Areas. Retrieved from: https://www.toronto.ca/wp-content/uploads/2019/06/8f06-OfficialPlanAODA Compiled-3.0.pdf

City of Toronto. (2019e). Impact of the 2018 Creative Co-Location Facilities Property Tax Subclass and 2019 Implementation. Retrieved from: https://www.toronto.ca/legdocs/mmis/2019/ex/bgrd/backgroundfile-129974.pdf

City of Toronto. (2019f). Changing Lanes: The City of Toronto's Review of Laneway Suites City-wide Expansion of City-Initiated Official Plan Amendment and Zoning Amendment - Final Report. Retrieved from: https://www.toronto.ca/legdocs/mmis/2019/ph/bgrd/backgroundfile135115.pdf

City of Toronto. (2020a). Geary Works Planning Study. www. Toronto.ca. Retrieved from: https://www.toronto.ca/city-government/planning-development/planning-studies-initiatives/gearyworks-planning-study/

City of Toronto. (2020b). Community Feedback. Geary Works. Retrieved from: https://www.toronto.ca/wp-content/uploads/2020/03/8d78CityPlanning GearyWorks CCM1Feedback Mar-5-20.pdf

City of Toronto. (2020c). 740 Dupont St. Development Applications. Retrieved from: http://app.toronto.ca/DevelopmentApplications/associatedApplicationsList.do?action=init\&folder $\underline{\mathrm{Rsn}=3592627 \& \text { isCofASearch=false }}$

City of Toronto Zoning By-law 569-2013. (2013a). 1.40.60 Employment Industrial Zone Category. Retrieved from: https://www.toronto.ca/zoning/bylaw amendments/ZBL NewProvision Chapter1 40.htm 
City of Toronto Zoning By-law 569-2013. (2013b). 60.20.20.100 Conditions. Retrieved from: https://www.toronto.ca/zoning/bylaw amendments/ZBL NewProvision Chapter60 20.htm\#60.2 $\underline{0.20 .100}$

City of Toronto Zoning By-law 569-2013. (2013c). Chapter 100 Utility and Transportation. 100.10.20.100 Conditions. Retrieved from: https://www.toronto.ca/zoning/bylaw amendments/ZBL NewProvision Chapter100 10.htm

City of Vancouver. (1995). Industrial Lands Policies. Land Use and Development Policies and Guidelines. Retrieved from: https://vancouver.ca/docs/eastern-core/industrial-land-policies.pdf

City of Vancouver. (2002). Amendments to the MC-1 District Schedule and Rezoning of the Hudson Street and East Hastings Street Industrial "Let-Go" Areas. Policy Report Urban

Structure. Retrieved from: http://former.vancouver.ca/ctyclerk/cclerk/020314/p1.htm

City of Vancouver. (2015). The Flats Area Profile: An Overview of Your False Creek Flats. Retrieved from: https://vancouver.ca/files/cov/false-creek-flats-area-profile.pdf

City of Vancouver. (2017a). False Creek Flats Area Plan. Retrieved from: https://vancouver.ca/files/cov/false-creek-flats-plan-2017-05-17.pdf

City of Vancouver. (2017b). I-2 District Schedule. Retrieved from: https://bylaws.vancouver.ca/zoning/zoning-by-law-district-schedule-i-2.pdf

City of Vancouver (2017c). False Creek Flats Plan - Zoning Intent. Retrieved from: https://vancouver.ca/files/cov/false-creek-flats-zoning-policy-reference-map.pdf

City of Vancouver (2017d). I-3 District Schedule. Retrieved from: https://bylaws.vancouver.ca/zoning/zoning-by-law-district-schedule-i-3.pdf

City of Vancouver (2017e). MC-1 and MC-2 District Schedule. Retrieved from: https://bylaws.vancouver.ca/zoning/zoning-by-law-district-schedule-mc-1-2.pdf

City of Vancouver (2017f). Rezoning Policy and Guidelines for the False Creek Flats. Land Use and Development Policies and Guidelines. Retrieved from:

https://guidelines.vancouver.ca/R034.pdf

City of Vancouver. (2017g). CD-1 (561) 955 East Hastings Street By-law No. 10872. Zoning and Development By-law. Retrieved from: https://cd1-bylaws.vancouver.ca/CD-1(561).pdf

City of Vancouver. (2019). What We Heard: External Advisory Group Meeting \#3. Employment Lands \& Economy Review. Retrieved from: https://vancouver.ca/files/cov/employment-landsand-economy-review-what-we-heard-171019.pdf

City of Vancouver. (2020). Employment Lands and Economy Review. Vancouver.ca. Retrieved from: https://vancouver.ca/home-property-development/vancouver-employment-lands-andeconomy-review.aspx

Clark-Madison, M. (1999). Urban on the rocks: Neighborhood juries still out on smart growth. The Austin Chronicle 18(35). 
Cole, Y. (2012). East Hastings housing project brings out critics in Downtown Eastside. The Georgia Straight. Retrieved from: https://www.straight.com/news/east-hastings-housing-projectbrings-out-critics-downtown-eastside

Collette, O. (January 2014). Urban Villages: Mile-Ex’s Multiple Personalities. Montreal Gazette. Retrieved from:

http://www.montrealgazette.com/Urban+Villages+Mile+multiple+personalities/9372469/story.ht $\underline{\mathrm{ml}}$

Colliers International. (2018). The WorkSpaces @ Strathcona Village. Retrieved from: https://static1.squarespace.com/static/577d662b9de4bb51ae5e774e/t/5b901399758d4602635c 00eb/1536168867425/Strathcona Brochure P011826 FINAL+E.pdf

Cotter, D. (2012). Putting Atlanta Back to Work: Integrating Light Industry into Mixed-Use Urban Development. Atlanta, Georgia: Georgia Tech Enterprise Innovation Institute.

Dingman, S. (September 2018). Toronto land zoned for employment use is shrinking. The Global and Mail. Retrieved from: https://www.theglobeandmail.com/real-estate/article-torontoland-zoned-for-employment-use-is-shrinking/

Dot Jutgla, E., Pallares-Barbera, M., \& Casellas, A. (2012). Productive gentrification, deindustrialization and industrial relocation (Gentrificació productiva, desindustrialització i relocalització industrial). Treballs De La Societat Catalana De Geografia, 73.

Forge. (2019). 100 and 150 Hooper. Forge-sf.com. Retrieved from: https://forgesf.com/projects/100-and-150-hooper/

Fowler, R. (2012). Personal Interview, in Cotter, D. (2012). Putting Atlanta Back to Work: Integrating Light Industry into Mixed-Use Urban Development. Atlanta, Georgia: Georgia Tech Enterprise Innovation Institute.

Fudge, S. (June 2019). From Brownfield to Playing Field: A Brief History of Toronto's Davenport Village. Urbaneer.com. Retrieved from:

https://www.urbaneer.com/blog/brief history of davenport village toronto

Fumano, D. (May 2019). Dan Fumano: Vancouver's ex-chief planner on past successes, misses, and a recent 'huge mistake'. The Vancouver Sun. Retrieved from:

https://vancouversun.com/news/local-news/dan-fumano-vancouvers-former-chief-planner-onhis-new-book/

Grant, J. (2002). Mixed use in theory and practice: Canadian experience with implementing a planning principle. Journal of the American Planning Association, 68(1), (pp. 71-84).

Grodach, C., O'Connor, J., \& Gibson, C. (2017). Manufacturing and cultural production: Towards a progressive policy agenda for the cultural economy. City, Culture and Society, 10, (pp. 17-25).

Guided Toronto. (July 2019). How to Spend a Day in Toronto: Geary Avenue. Retrieved from: https://www.guidedtoronto.com/blog/how-to-spend-a-day-in-toronto-geary-avenue 
Hackworth, J., and N. Smith. (2001). The Changing State of Gentrification. Tijdchrift Voor Economische, 92(4), (pp. 464-477).

Harris, C., Ullman, E. (1945). The Nature of Cities. The Annals of the American Academy of Political and Social Science, 242. (pp.7-17).

Hatuka, T., \& Ben-Joseph, E. (2017). Industrial urbanism: Typologies, concepts and prospects. Built Environment, 43(1), 10-24.

Hatuka, T., Ben Joseph, E., \& Menozzi Peterson, S. (2017) "Facing Forward: Trends and Challenges in the Development of Industry in Cities:" Built Environment 43(1):145 - 155.

Heikkila, E., \& Hutton, T. A. (1986). Toward an evaluative framework for land use policy in industrial districts of the urban core: A qualitative analysis of the exclusionary zoning approach. Urban Studies, 23(1). (pp. 47-60).

Helper, S., Krueger, T. and Wial, H. (2012). Locating American Manufacturing: Trends in the Geography of Production. Washington DC: The Brookings Institution.

Hills, R. M., \& Schleicher, D. (2010). The steep costs of using noncumulative zoning to preserve land for urban manufacturing. The University of Chicago Law Review, 77(1), (pp. 249-273).

Hoyt, H. (1939). The Structure of Growth of Residential Neighborhoods in American Cities. Washington, D.C: Federal Housing Administration.

Hum, T. (July 2017). "Get Ready Sunset Park, Brooklyn Is Coming: The Real Estate Imperatives of an Innovation Ecosystem." Progressive City: Radical Alternatives.

Katz, B. [Video] (June 2014). The Rise of Innovation Districts: A New Geography of Innovation in America. YouTube. Retrieved from: https://www.youtube.com/watch?v=uJ6BFm3hra8

Langston, C., Wong, F. K. W., Hui, E. C. M., \& Shen, L. Y. (2008). Strategic assessment of building adaptive reuse opportunities in Hong Kong. Building and Environment, 43, (pp. 17091718).

LEA Consulting Ltd. (2017). 22 Geary Avenue Parking Study Report. Retrieved from:

http://app.toronto.ca/DevelopmentApplications/associatedApplicationsList.do?action=init\&folder $\underline{\mathrm{Rsn}=4300387 \& \text { is CofASearch=false }}$

Leigh, N. G., \& Hoelzel, N. Z. (2012). Smart growth's blind side: Sustainable cities need productive urban industrial land. Journal of the American Planning Association, 78(1). (pp. 87103).

Lever, W.F. (1991). Deindustrialization and the reality of the post-industrial city. Urban Studies, 28(6). (pp. 983-999).

Los Angeles City Planning Commission. (2015). CPC-2015-1938-CA. Retrieved from: https://planning.lacity.org/ordinances/docs/hybrid/HybridlndustRecommendationRpt.pdf 
Map Your Property. (2020). Geary Avenue. Zoning By-law. Retrieved from:

https://app.mapyourproperty.com/login\#/by-

law?address $=$ Geary $\% 20$ Avenue\&lat $=43.67198904949847 \& \operatorname{lng}=-79.44052250307158$

Markillie, P. (April 2012) A Third Industrial Revolution. The Economist. Available at: www.economist.com/node/21552901

McCann, E. J. (2007). Inequality and Politics in the Creative City-Region: Questions of Livability and State Strategy. International Journal of Urban and Regional Research, 31(1), (pp. 188196).

McElroy, J. (October 2017). Vancouver passes rezoning for False Creek Flats plan. CBC. Retrieved from: https://www.cbc.ca/news/canada/british-columbia/false-creek-flats-rezoningapproved-1.4321395

McLean, S. (February 2019). TAS provides updates on its Toronto developments. Real Estate News Exchange. Retrieved from: https://renx.ca/tas-updates-toronto-developments-7-labatt/

McMahon, E. (1999). Cooperation instead of confrontation (from Planning Commissioners Journal, 33)

Pendall, R. (1999). Opposition to housing NIMBY and beyond. Urban Affairs Review, 35(1), (pp. 112-136).

Metro Vancouver. (2012). Discussion Paper: Best Practices for the Intensive Use of Industrial Land.

Nasser, N. (2003). Planning for urban heritage places: Reconciling conservation, Tourism, and sustainable development. Journal of Planning Literature, (pp. 467-479).

Ndung'u, N., Signé, L. (January 2020). The Fourth Industrial Revolution and digitization will transform Africa into a global powerhouse. Brookings. Retrieved from:

https://www.brookings.edu/research/the-fourth-industrial-revolution-and-digitization-willtransform-africa-into-a-global-powerhouse/

Nonko, E. (October 2018). Can Zoning Actually Save Manufacturing Space in San Francisco? Next City. Retrieved from: https://nextcity.org/daily/entry/can-zoning-actually-save-

manufacturing-space-in-san-francisco

O’Brien, F., Mitham, P., Yoon, S. (May 2017). False Creek Flats a last opportunity, say developers. Business in Vancouver. Retrieved from: https://biv.com/article/2017/05/false-creekflats-lost-opportunity-say-developers

O’Meara, M. (2018). Despite Rising Rents, Nonprofit Creates Affordable Manufacturing Space in San Francisco. Nocogradac. Retrieved from:

https://www.novoco.com/periodicals/articles/despite-rising-rents-nonprofit-creates-affordablemanufacturing-space-san-francisco

Orbasli, A. (2008). Architectural conservation: principles and practice.

Peck, J. (2005). Struggling with the Creative Class. International Journal of Urban and Regional Research, 29(4), (pp. 740-770). 
Pike, A. (2009) Deindustrialisation, in Kitchin, R. and Thrift, N. (eds.) International Encyclopedia of Human Geography. Oxford: Elsevier. (pp. 51-59).

PlaceMade. (2019). Home Page. Placemade.org. Retrieved from: https://placemade.org

Poole, R. (July 2016). Filling those Ground Floors with San Francisco Makers. San Francisco Housing Action Coalition. Retrieved from: https://www.sfhac.org/filling-ground-floors-sanfrancisco-makers/

Pouspourika, K. (June 2019). The 4 Industrial Revolutions. Institute of Entrepreneurship Development. Retrieved from: https://ied.eu/project-updates/the-4-industrial-revolutions/

Pratt Centre. (2016). Creating an Innovative Mix: What We Can Learn from San Francisco. Retrieved from: https://prattcenter.net/sites/default/files/25 kent policy brief final 0.pdf

Rappart, N. (May 2011). Vertical urban factory. Urban Omnibus.

R.E. Millward + Associates Ltd. (January 2017). King-Spadina Cultural Spaces Retention Study: Strengthening the Creative Economy in Toronto's Downtown Core. Retrieved from: https://www.toronto.ca/wp-content/uploads/2017/10/90a0-City-Planning-TOcore-REM CulturalSpaces.pdf

San Francisco Planning. (2002). Industrial Land in San Francisco: Understanding Production, Distribution, and Repair. Retrieved from: http://sfplanning.org/sites/default/files/FileCenter/Documents/4893-CW DPR chapter5 2.pdf

San Francisco Planning. (2015). Executive Summary: Conditional Use Authorization, Planned Unit Development \& Office Allocation 100 Hooper Street. Retrieved from:

https://commissions.sfplanning.org/cpcpackets/2012.0203BC.pdf

San Francisco Planning. (2020). Eastern Neighbourhoods. Sfplanning.org. Retrieved from: https://sfplanning.org/eastern-neighborhoods-plans

San Francisco Planning Code. (2020a). SEC. 202.7. DEMOLITION OF INDUSTRIAL BUILDINGS IN PDR DISTRICTS, REPLACEMENT REQUIREMENTS. Retrieved from: http://library.amlegal.com/nxt/gateway.dll/California/planning/article2usedistricts?f=templates $\$ \mathrm{fn}$ =default.htm\$3.0\$vid=amlegal:sanfrancisco ca\$anc=JD 249.32

San Francisco Planning Code. (2020b). SEC. 210.3. PDR DISTRICTS. Retrieved from: http://library.amlegal.com/nxt/gateway.dll/California/planning/article2usedistricts?f=templates $\$ f n$ =default.htm\$3.0\$vid=amlegal:sanfrancisco ca\$anc=JD 249.32

San Francisco Planning Code. (2020c). SEC. 843. UMU - URBAN MIXED USE DISTRICT. Retrieved from:

http://library.amlegal.com/nxt/gateway.dll/California/planning/article2usedistricts?f=templates $\$ f n$ =default.htm\$3.0\$vid=amlegal:sanfrancisco ca\$anc=JD 249.32

Scalena, A., Scalena, M. (June 2019). [podcast] Episode \#175 Vancouverism Revisted with Larry Beasley. Retrieved from: 
https://www.vancouverrealestatepodcast.com/podcast/vancouverism-revisited-with-larrybeasleyl

Schmidt, M. (October 2014) Changing Technologies Panel. Industrial Urbanism Symposium at the Massachusetts Institute of Technology. Retrieved from: http://www.industrialurbanism.com/

Seifel Consulting, UP Urban, Pfau-Long Architects. (2012). Summary Report: PDR Economic Analysis. Retrieved from:

https://static1.squarespace.com/static/54ef9e69e4b031e068b1eb69/t/54f5f449e4b099c7be64ba a0/1425405001544/PDREconomicAnalysisDecember2012 final.pdf

Shaw, K. (April 2015). Dereliction of duty: The impact of planned land redundancies on new urban manufacturing. Paper presented at the association of American Geographers Conference, Chicago.

Shaw, K., \& Davies, B. (2014). Making ends meet. In C. Whitzman, B. Gleeson, \& A. Sheko (Eds.), Melbourne What Next? Research Monograph No. 1 (pp. 34-46). Melbourne Sustainable Society Institute, The University of Melbourne.

Smallwood, C. (2012). The role of adaptive (re)use. Paper presented at PMI® Global Congress 2012-North America, Vancouver, British Columbia, Canada. Newtown Square, PA: Project Management Institute.

Sprague, M., Rantisi, N.M. (2019). Productive gentrification in the Mile- Ex neighbourhood of Montreal, Canada: exploring the role of the state in remaking urban industrial clusters, Urban Research \& Practice, 12(4), (pp. 301-321).

Stueck, W. (October 2012). Vancouver council approves Downtown Eastside condo project. The Globe and Mail. Retrieved from: https://www.theglobeandmail.com/news/britishcolumbia/vancouver-council-approves-downtown-eastside-condo-project/article4787094/

TABIA. (2019). Benefits of a BIA. Retrieved from: https://www.toronto-bia.com/whats-abia/benefits-of-a-bia/

The Vancouver Economic Commission. (2017). The Flats Economic Development Strategy. Retrieved from: https://council.vancouver.ca/20170517/documents/cfsc1-AppendixBFalseCreekFlatsPlan.pdf

Tinner, N. (January 2019). The Manufacturing Foundry is Open for Business. The Potrero View. Retrieved from: https://www.potreroview.net/the-manufacturing-foundry-is-open-for-business/

Toronto City Planning. (2019). Toronto Employment Survey 2019. profileTO. Retrieved from: https://www.toronto.ca/wp-content/uploads/2020/01/9453-Toronto-Employment-Survey-2019Bulletin.pdf

Toronto Parking Authority. (2011). Strategic Outlook: Enabling Mobility for the Next 21 Years. Retrieved from: https://www.toronto.ca/wp-content/uploads/2017/08/9699-TPA-StrategicOutlook.pdf

Toronto Region Board of Trade (2018). Better Business Policy Playbook. Agenda for Growth. (pp. 1-8). Retrieved from: 
https://www.bot.com/Portals/0/BOARD AFG Municipal02 Better\%20Business playbook FINA $\underline{\text { L.pdf }}$

Warren, M. (October 2015). Will the dream of Toronto's Green Line ever become a reality? Toronto Star. Retrieved from: https://www.thestar.com/news/gta/2015/10/08/will-the-dream-oftorontos-green-line-ever-become-a-reality.html

Woodward, K. A. (2013). Form over use: Form-based codes and the challenge of existing development. Notre Dame Law Review, 88(5), 2627.

Yung, E. H., \& Chan, E. H. (2012). Implementation challenges to the adaptive reuse of heritage buildings: Towards the goals of sustainable, low carbon cities. Habitat International, 36(3), (pp. 352-361).

Zhang, C. (February 2020). HAVEN Unveils Newly Designed HQ Office \& Studio Space. Hypebeast. Retrieved from: https://hypebeast.com/2020/2/haven-hq-office-studio-space-info

Zuk, D. (2015). Old Buildings, Great Beer: Lessons of Adaptive Reuse and Microbreweries in the City of Toronto (Masters Thesis). Queen's University.

\section{$\underline{\text { Figures }}$}

Fig 1. Brown, S. (2019). Comparative urban growth models [image] Redrawing from Harris, C., Ullman, E. (1945). The Nature of Cities, in Brown, S. S. D. (2019). Hybrid-industrial zoning: a case study in Downtown Los Angeles. (Masters Thesis).

Fig 2. Duany Plater-Zyberk \& Co. (2003). A Typical Rural-Urban Transect, with Transect Zones [image], in SmartCode. Version 9.2. Retrieved from: https://transect.org/codes.html

Fig 3. City of Vancouver. (1995). False Creek Flats industrial lands [image], in Industrial Lands Policies. Retrieved from: https://vancouver.ca/docs/eastern-core/industrial-land-policies.pdf

Fig 4. City of Vancouver. (1995). Powell Street/Clark Drive industrial lands [image], in Industrial Lands Policies. Retrieved from: https://vancouver.ca/docs/eastern-core/industrial-landpolicies.pdf

Fig 5. City of Vancouver. (2017a). Neighbourhood Context of the False Creek Flats [map], in False Creek Flats Area Plan. Retrieved from: https://vancouver.ca/files/cov/false-creek-flatsplan-2017-05-17.pdf

Fig 6. City of Vancouver. (2017a). Ground/Second Floor Industrial with Retail at Grade and Office Above [image], in False Creek Flats Area Plan. Retrieved from: https://vancouver.ca/files/cov/false-creek-flats-plan-2017-05-17.pdf

Fig 7. City of Vancouver. (2017c). False Creek Flats Zoning Intent (Current as of March 12, 2018) [map]. Retrieved from: https://vancouver.ca/files/cov/false-creek-flats-zoning-policyreference-map.pdf 
Fig 8. City of Vancouver. (2017a). Atlantic/Malkin Transitional Edge [image], in False Creek Flats Area Plan. Retrieved from: https://vancouver.ca/files/cov/false-creek-flats-plan-2017-0517.pdf

Fig 9. City of Vancouver. (2017a). Illustrated Character of Innovation Hub [image], in False Creek Flats Area Plan. Retrieved from: https://vancouver.ca/files/cov/false-creek-flats-plan2017-05-17.pdf

Fig 10. City of Vancouver. (2017a). Map of Corridor [map], in False Creek Flats Area Plan. Retrieved from: https://vancouver.ca/files/cov/false-creek-flats-plan-2017-05-17.pdf

Fig 11. City of Vancouver. (2017a). False Creek Flats Planning Area and Rezoning Policy Areas [map], in False Creek Flats Area Plan. Retrieved from: https://vancouver.ca/files/cov/falsecreek-flats-plan-2017-05-17.pdf

Fig 12. TransLink. (2018). Millennium Line Broadway Extension [map], in TransLink 2018-2027 Investment Plan. Retrieved from: https://tenyearvision.translink.ca/Documents/10year vision phase 2 investment plan.pdf

Fig 13. KRJ Photography. (n.d.). GBL Architects - Strathcona Village - East Hastings, Vancouver BC [photo]. Retrieved from: https://kri.photos/architecture-photographer-vancouversquamish-whistler

Fig 14. GBL Architects. (2011). Cross Section of 955 East Hastings Street [image]. Retrieved from: https://rezoning.vancouver.ca/applications/955ehastings/index.htm

Fig 15. Colliers International. (2019). Floor Plan of the The WorkSpaces and Current Tenants [image]. Retrieved from: http://listingsprod.blob.core.windows.net

Fig 16. Kilroy Realty. (n.d.). Photo of 100/150 Hooper [photo]. Retrieved from: https://forgesf.com/projects/100-and-150-hooper/

Fig 17. Kilroy Realty. (2017). 100 Hooper Floor Plan (edited to indicate 150 Hooper) [image]. Retrieved from: http://listingsprod.blob.core.windows.net/ourlistings-usa/48ddbb1c-959b-4f79ad57-ce8b5377fce5/76e4efe0-e744-4b47-8e97-2ca766945d0b

Fig 18. Kilroy Realty. (2017). 100 Hooper Project Breakdown [image]. Retrieved from: http://listingsprod.blob.core.windows.net/ourlistings-usa/48ddbb1c-959b-4f79-ad57ce8b5377fce5/76e4efe0-e744-4b47-8e97-2ca766945d0b

Fig 19. Kilroy Realty. (2017). The Breezeway [image]. Retrieved from: http://listingsprod.blob.core.windows.net/ourlistings-usa/48ddbb1c-959b-4f79-ad57ce8b5377fce5/76e4efe0-e744-4b47-8e97-2ca766945d0b

Fig 20. Toronto City Planning. (2019). Toronto's Employment Areas and Employment Monitoring Areas [map], in Toronto Employment Survey 2019. Retrieved from: https://www.toronto.ca/wp-content/uploads/2020/01/9453-Toronto-Employment-Survey-2019Bulletin.pdf

Fig 21. City of Toronto. (2019b). Character Area 3.0 / Geary Davenport Park, The Green Line [map], in The Green Line: Implementation Plan Summary Report. Retrieved from: 
https://www.toronto.ca/wp-content/uploads/2019/07/89a2-Green-

Line Implementation Report 2019-07-25.pdf

Fig 22. Map Your Property. (2020). Toronto Development Tracking, 2014-2020 [map]. Retrieved from: https://app.mapyourproperty.com/\#/dev-app-

toronto?address $=22 \% 20$ Geary\%20Ave $\% 20$ Toronto\&lat $=43.67129791794248 \& \operatorname{lng}=-$ $\underline{79.43104061104509}$

Fig 23. RAW Design. (2018). Rendering of 22 Geary [image]. Retrieved from:

http://app.toronto.ca/DevelopmentApplications/associatedApplicationsList.do?action=init\&folder $\underline{\mathrm{Rsn}=4300387 \& \text { is CofASearch=false }}$

Fig 25. TAS LLP \& Suulin Architects Inc. (2019). Aerial View of 888 Dupont Street Looking Northeast [image]. Retrieved from:

http://app.toronto.ca/DevelopmentApplications/associatedApplicationsList.do?action=init\&folder $\underline{\mathrm{Rsn}=4674467 \& \text { is CofASearch=false }}$

Fig 26. TAS LLP \& Suulin Architects Inc. (2019). Illustrated Mix of Uses for 888 Dupont Street. http://app.toronto.ca/DevelopmentApplications/associatedApplicationsList.do?action=init\&folder $\underline{\mathrm{Rsn}=4674467 \& \text { is CofASearch=false }}$

Fig 28. Google Maps. (2020). Kensington Market Parking Lot with retail at-grade [photo].

Retrieved from: https://www.google.com/maps/@43.6549085,-

79.400283,3a, 75y, 104.09h,89.63t/data=!3m6!1e1!3m4!1sTYPvb30CPzbGefhEoMcpiA!2e0!7i13 $\underline{312 ! 8 i 6656}$ 